\title{
Nanostructured electrode materials for lithium-ion and sodium-ion batteries via electrospinning
}

\author{
Weihan $\mathrm{Li}^{1}$, Linchao Zeng ${ }^{1}$, Ying $\mathrm{Wu}^{1}$ and $\mathrm{Yan} \mathrm{Yu}^{1,2,3^{*}}$
}

\begin{abstract}
Electrospinning has attracted tremendous attention in the design and preparation of $1 \mathrm{D}$ nanostructured electrode materials for lithium-ion batteries (LIBs) and sodium-ion batteries (NIBs), due to the versatility and facility. In this review, we present a comprehensive summary of the development of electrospun electrode nanomaterials for LIBs and NIBs, and a brief introduction about electrode materials beyond LIBs and NIBs. By summarizing various electrochemical active materials, this review focuses on the evolution in structures and the constitution of electrospun electrode materials. In detail, a variety of electrospun anode and cathode materials of LIBs and NIBs have been properly discussed, respectively. Finally, the current progress in the electrospun electrode materials is well reviewed and the development direction is also pointed out. We believe that in the nearly future, electrospun electrode materials would be applied in commercial LIBs and promote the advance in NIBs. And we hope that this review could be helpful in the design and fabrication of electrospun hierarchical materials for other advanced energy-storage devices.
\end{abstract}

Keywords: electrospinning, one-dimensional nanostructures, lithium-ion batteries, sodium-ion batteries, electrochemical activity.

\section{INTRODUCTION}

Global energy crisis and environmental pollution are two of the toughest problems that the human beings are currently facing. In the last decades, scientists and engineers have made great efforts to study and address these two severe issues via developing new energy-related technologies, such as wind power and solar power. Among them, energy conversion and storage are crucial factors to realize the highly efficient and environment-friendly utilization of renewable energy. To achieve the goal, rechargeable batteries have been chosen to reversibly store chemical energy and release electric energy through electrochemical processes [1]. Due to the high energy density and power density, and long cycle life, lithium-ion batteries (LIBs) show great promise in the large scale applications, which have been already widely applied in portable electronic devices, electric vehicles and hybrid electric vehicles [2-4]. On the other hand, sodium-ion batteries (NIBs) have attracted intensive attention as one promising alternative to current LIBs [5]. As applications of rechargeable batteries have been extended to the large scale grid energy storage, the primary concern would be the cost and the availability of resources. Since sodium is the $4^{\text {th }}$ most abundant element in the Earth crust, NIBs show low cost and the promising potential to meet the requirements of the large scale applications [6-12].

To meet the global ever-increasing demands of advanced energy storage systems, it is urgent to develop batteries with low cost, and high energy and power density [13]. The valuable performance characteristics to evaluate batteries, such as specific capacity and operation current densities, are determined by the electrochemical performances of the electrode materials in batteries $[14,15]$. Therefore, developing reasonable electrode materials for LIBs and NIBs is of great importance to realize the aim. Rechargeable batteries function via Faradaic reactions, accompanied by mass and charge transfer within electrodes and electrolytes [16]. Nanostructured electrode materials have been confirmed to be able to enhance the electrochemical activity of electrode materials, due to the decreased particle size and increased specific surface area, leading to the reduced mass and charge diffusion length, and enhanced intercalation kinetics [17-19]. Among these as-prepared

\footnotetext{
${ }^{1}$ Key Laboratory of Materials for Energy Conversion, Chinese Academy of Sciences, Department of Materials Science and Engineering, University of Science and Technology of China, Hefei 230026, China

${ }^{2}$ Key Laboratory of Advanced Energy Materials Chemistry (Ministry of Education), Nankai University, Tianjin 300071, China

${ }^{3}$ State Key Laboratory of Fire Science, University of Science and Technology of China, Hefei 230026, China

${ }^{*}$ Corresponding author (email: yanyumse@ustc.edu.cn)
} 
nanostructures, one-dimensional (1D) nanomaterials are one promising choice applied in energy related areas to improve the lithium/sodium storage performance, which present high specific surface areas, short transport paths for ions and fast electron transfers along longitudinal direction [20-29]. Various methods have been studied to prepare 1D nanostructured electrode materials, such as: self-assembly [30], chemical vapor deposition (CVD) [31-33], solution-growth [34,35], solvothermal or hydrothermal methods [36-39], and electrospinning [40-43]. Compared with other strategies, electrospinning is a simple, effective and versatile strategy to prepare $1 \mathrm{D}$ nanofibers with tunable features, including long length, uniform diameter and designable morphology [44-46]. In this paper, we briefly review the application of electrospinning technology in LIBs and NIBs, focusing on the recent development of electrospun $1 \mathrm{D}$ electrode materials.

\section{PRINCIPLE OF ELECTROSPINNING}

Electrospinning is a fast, simple and facile strategy to prepare 1D nanofibers. As shown in Fig. 1, a typical electrospinning setup consists of one syringe with one metallic needle as a spinneret, one high voltage power supply, and one collector [44]. During a typical electrospinning process, a polymer solution is loaded in the syringe and moves into the spinneret via a syringe pump, forming a pendant droplet functioned by the surface tension. As a high voltage is applied between the spinneret and the collector, the electrostatic repulsive force at the surface of pendant droplet would drive it to elongate and form a conical structure, Taylor cone [47]. When the applied voltage increases to one critical value, the surface repulsive force would overcome the surface tension and thus a liquid jet ejects from the tip of spinneret. As the surface is filled with like charges, the liquid jet is continuously elongated by the electrostatic repulsive force from the needle to the collector during the process, leading to reduced diameter of liquid jet to hundreds or tens of nanometers $[45,48]$. During the typical process, the solvent in the liquid jet would be evaporated and the solidified polymer fibers would form one randomly oriented, non-woven mat. The diameter $(R)$ of the electrospun nanofibers is determined by the preparation parameters (i.e., flow rate $(Q)$, electric field intensity $(E)$, electric current $(I)$, distance between the spinneret and collector $(D)$, density of the precursor solution $(\rho))$. Spivak et al. $[49,50]$ presented a model analysis of diameter of collected electrospun nanofibers as $R=\left(\rho Q^{3}\right)^{1 / 4} \cdot\left(2 I E D \pi^{2}\right)^{-1 / 4}$. Therefore, the diameter of the electrospun nanofibers is controllable through tuning the related parameters [51].

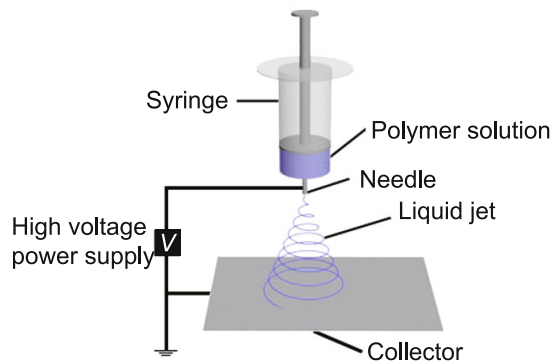

Figure 1 Schematic illustration of a fundamental electrospinning setup.

In 1914, Zeleny [52] first studied the electrospinning technology, which was initially patented by Anton in 1934 [53], focusing on the preparation of polymer filaments. Up until 1990s, only a few works studied the application of electrospinning in thin fibers [54,55]. Afterwards, along with great advance of nanomaterials in various fields, electrospinning has reobtained intensive attention and been used to produce a large number of 1D nanomaterials $[44,56,57]$. Due to the simplicity and efficiency of electrospinning, various kinds of precursor solutions have been electrospun to nanofibers, such as poly(vinyl alcohol) (PVA) [58], polyacrylonitrile (PAN) [59], poly(vinyl pyrrolidone) (PVP) [60], poly(ethylene oxide) (PEO) [61]. By further designing the solution compositions, the setup, especially the needle and collector, and subsequent treatments, scientists have prepared various $1 \mathrm{D}$ nanofibers with modified structures. Kim et al. [62] prepared porous carbon nanofibers (PCNFs) via applying PAN and poly(methyl methacrylate) PMMA polymer-blend solution as the electrospinning precursor. Due to the phase separation, in the electrospun polymer nanofiber, PMMA solution would be dispersed in the PAN solution like particles in fibers. After the carbonization process, PMMA phase decomposed and PAN phase was converted to carbon, finally obtaining PCNFs with hollow cores. Different to the work of the polymer blend by Kim et al., Yu et al. [63] used mixed solvents of dimethylformamide (DMF) and $\mathrm{H}_{2} \mathrm{O}$ to dissolve PAN as the precursor solution and obtained electrospun porous PAN fibers based on one induced phase separation from solution. Designing the new needles with two coaxial tubes and multi-tubes, Jiang and co-workers $[64,65]$ prepared novel nanofibers with hollow and multichannel structures via electrospinning. Moreover, the walled number and inner morphology of channels in the electrospun nanofibers are both controllable by tuning the structure of needles. In addition, McCann et al. [66] prepared special nanofibers with high porosity by gradually reducing solvent evaporation 
rate during electrospinning process and created the phase separation effect between residual solvent and polymer in nanofibers by immersing the collectors into one liquid nitrogen bath with a low temperature of about $-196^{\circ} \mathrm{C}$. Uniform polypyrrole (PPy) nanotubes have been prepared by Xie et al. [67] via using electrospun $\operatorname{poly}(\varepsilon$-caprolactone) (PCL) and poly(L-lactide) (PLLA) nanofibers as templates.

In addition, a variety of electrospun ceramic nanofibers have also been prepared by several groups. One efficient strategy is direct electrospinning of proper viscous inorganic sols. Larsen et al. [68] combined sol-gel methods and electrospinning and successfully fabricated ceramic nanofibers, including $\mathrm{TiO}_{2} / \mathrm{SiO}_{2}$ and $\mathrm{Al}_{2} \mathrm{O}_{3}$ nanofibers. Later, Choi and co-workers [69] realized fabrication of silica nanofibers by direct electrospinning of silica sol, which was prepared from tetraethyl orthosilicate (TEOS), $\mathrm{H}_{2} \mathrm{O}$, ethanol and $\mathrm{HCl}$. However, the diameter of electrospun nanofibers produced from the strategy was usually hundred nanometers. To further reduce the diameter of electrospun ceramic nanofibers, Li et al. [70] used polymer, such as PVP to adjust the viscosity of the solution and control the viscoelastic behavior. After electrospinning and subsequent thermal treatment, $\mathrm{TiO}_{2}$ nanofibers with uniform diameter of less than $200 \mathrm{~nm}$ have been fabricated. Later, a variety of electrospun ceramic nanofibers, such as $\mathrm{SiO}_{2}$ [71], $\mathrm{ZrO}_{2}$ [72], $\mathrm{CuO}$ [73], and $\mathrm{N}_{2} \mathrm{O}_{5}$ [74] nanofibers, have been fabricated by this strategy with different polymers (e.g., PVA and PEO).

Electrospinning is one facile and cost-effective strategy to design and prepare novel nanostructures. Owing to the versatility of electrospinning, the research on electrospun electrode materials for LIBs and NIBs focuses on modifications of materials to realize improvements of electrochemical activity. With wide applications of electrospinning for preparing nanomaterials with controllable structure and composition, electrospinning shows great potential in designing electrode materials for LIBs and NIBs.

\section{ELECTROSPUN ELECTRODE MATERIALS IN LITHIUM-ION BATTERIES}

\section{Anode materials}

In the LIBs, graphite is currently used as the commercial anode materials, due to its low working potential, low cost and good cyclability. However, low specific capacity of graphite $\left(372 \mathrm{~mA} \mathrm{~h} \mathrm{~g}^{-1}\right)$ and low diffusion rate of lithium into graphite limit the energy and power density $[75,76]$.
Therefore, it is required to develop advanced anode materials with higher capacity and fast Li-ion diffusion rate. In this review, we focus on the 1D carbonaceous materials, alloys, metal oxides, and metal sulfides/nitrides prepared by electrospinning.

\section{Carbonaceous materials}

Various types of carbon nanofibers (CNFs) have been prepared using different sources in last decades, such as PAN [77], PVP [78], PVA [79], polyimides (PIs) [80], poly(vinylidene fluoride) (PVDF) [81] and pitch [82]. Among them, PAN and pitch are the usually used precursor polymers to fabricate CNFs after proper carbonization processes $[83,84]$, which are prepared for numerous applications, for example, supercapacitors [85], electric conductors [86], and catalysts [87]. For the electrochemical applications, electrospinning-derived CNFs prepared from PAN were firstly applied as anode materials for LIBs by Kim and co-workers [88]. They studied the influence of carbonization temperature on the structural characteristics and electrochemical performances of CNFs, demonstrating the CNFs carbonized at $1000^{\circ} \mathrm{C}$ showed the highest initial capacity of $450 \mathrm{~mA} \mathrm{~h} \mathrm{~g}^{-1}$ at a current rate of $30 \mathrm{~mA}$ $\mathrm{g}^{-1}$ but without long-cycle performance. Afterwards, Wu et al. [89] realized the long-term cycling of PAN-electrospinning derived CNFs, reaching $400 \mathrm{~mA} \mathrm{~h} \mathrm{~g}^{-1}$ after 500 cycles at $0.27 \mathrm{C}$, and provided reasonable experimental explanation of the gradually increased capacity during long cycle life of CNFs, possible continuous exfoliation of graphene layer in CNFs during Li-ion intercalation/de-intercalation. And Ramakrishna et al. [90] successfully prepared free-standing PAN-electrospun CNFs by modifying the carbonization process. However, the capacity of CNFs in these three works is still limited.

To improve the capacity of CNFs, several groups combined electrospinning with other methods to obtain CNFs with designed structure and improved capacity. Chemical doping is one general strategy to improve electrochemical performance of carbonaceous materials due to the enhancement of electric conductivity and capacity ascribed to the atom doping in carbon layers. Nan et al. [91] prepared nitrogen-enriched PCNFs (NPCNFs) via using PAN and melamine with high nitrogen content as precursors and $\mathrm{NH}_{3}$ treatment during carbonization. With a high nitrogen content (7.9\%), NPCNFs displayed a high reversible capacity of $1323 \mathrm{~mA} \mathrm{~h} \mathrm{~g}^{-1}$ at $50 \mathrm{~mA} \mathrm{~g}^{-1}$ and improved rate performance.

Another strategy to increase the electrochemical performance of carbonaceous materials is to prepare porous 
structures with a large number of lithium storage sites. Template-based methods and activating agents (e.g., $\mathrm{KOH}$ ) are widely applied strategies to realize the porous structure, templates here as sacrificial sections. Hard templates, such as silica nanoparticles and soft templates, such as PLLA, have been used in electrospinning to prepare PCNFs as anode materials for LIBs [92-94]. Different from the traditional template-based methods and $\mathrm{KOH}$-activation methods used in other carbonaceous materials, Li et al. [95] firstly reported a simple, low cost and environment-friendly strategy to prepare highly porous carbon nanofibers (HPCNFs) as flexible anode materials for LIBs, activation with air. As shown in Fig. 2, by introducing a certain amount of air into the Ar flow during carbonization, the controllable combustion of CNFs would form numerous pores to form HPCNFs, displaying a high capacity of $\sim 1780 \mathrm{~mA} \mathrm{~h} \mathrm{~g}^{-1}$ at $50 \mathrm{~mA} \mathrm{~g}^{-1}$ and a ultra-long cycle life $\left(\sim 1500 \mathrm{~mA} \mathrm{~h} \mathrm{~g}^{-1}\right.$ after 600 cycles at $\left.500 \mathrm{~mA} \mathrm{~g}^{-1}\right)$. Moreover, for the flexible carbonaceous materials, the flexibility of the obtained CNF film can be tuned via subsequent carbonization processes and fabricating composite CNFs. Arshad and co-workers [96] have studied the parameters (i.e., heat temperature, diameter of electrospun CNFs) affecting the tensile strength and elastic modulus. While the tensile strength showed a maximum at $1400^{\circ} \mathrm{C}$, the elastic modulus increased along with increasing temperature until $1700^{\circ} \mathrm{C}$. Moreover, the CNFs with smaller diameter showed higher tensile strength and elastic modulus. Another strategy to enhance flexibility of CNFs is to fabricate composite CNFs, such as CNFs-carbon nanotubes (CNTs)-hybrid material [97]. On the other hand, hierarchical porous structures are also helpful to improve the electrochemical activity of carbonaceous materials. Dong and co-workers [98] prepared electrospun CNFs-Co nanoparticles composite nanofibers to improve the electrochemical performance of CNFs through the formation of Co nanoparticles in CNFs, which would enhance the specific surface area and electronic conductivity of CNFs. Due to the synergistic effect of Co nanoparticles, the composite nanofibers presented improve cycle performance and rate capacity. In addition, Chen et al. [99] reported a series of PCNFs with hierarchical porous structures by introducing $\mathrm{Ni}$ nanoparticles as sacrificial catalysts. As shown in Figs 3a and b, Chen et al. [99] reported the in situ formation of hollow graphitic carbon nanospheres (HGCNs) in amorphous CNFs (ACNFs/HGCNs) with catalytic effects of $\mathrm{Ni}$ nanoparticles in the CNFs. With increased defects in HGCNs as extra lithium storage sites,
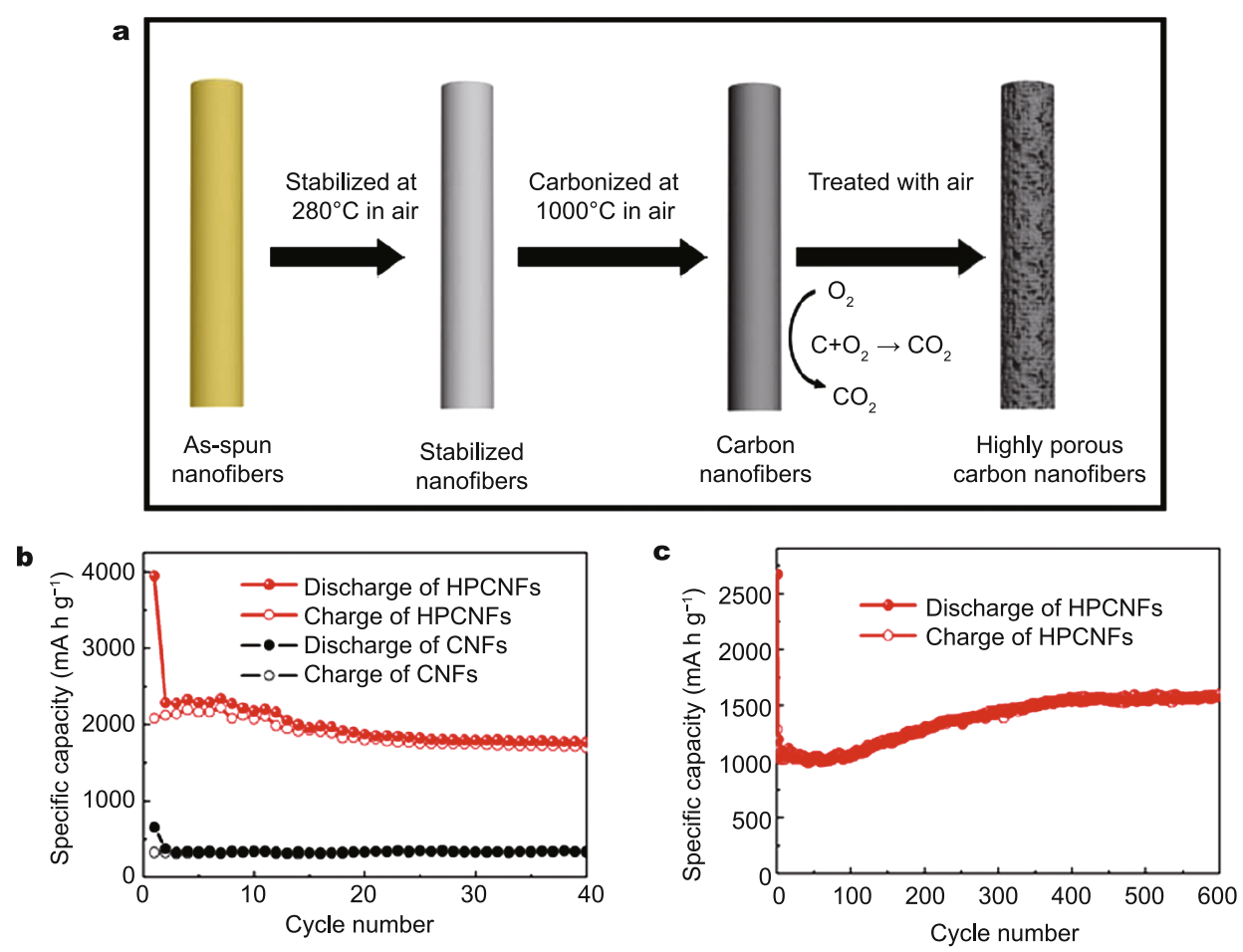

Figure 2 (a) Schematic illustration of the preparation strategy for the HPCNFs electrode. (b and c) Capacity retention of the electrodes at a cycling rate

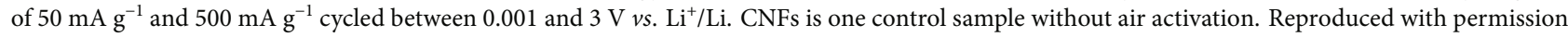
from Ref. [95], Copyright 2015, Elsevier. 


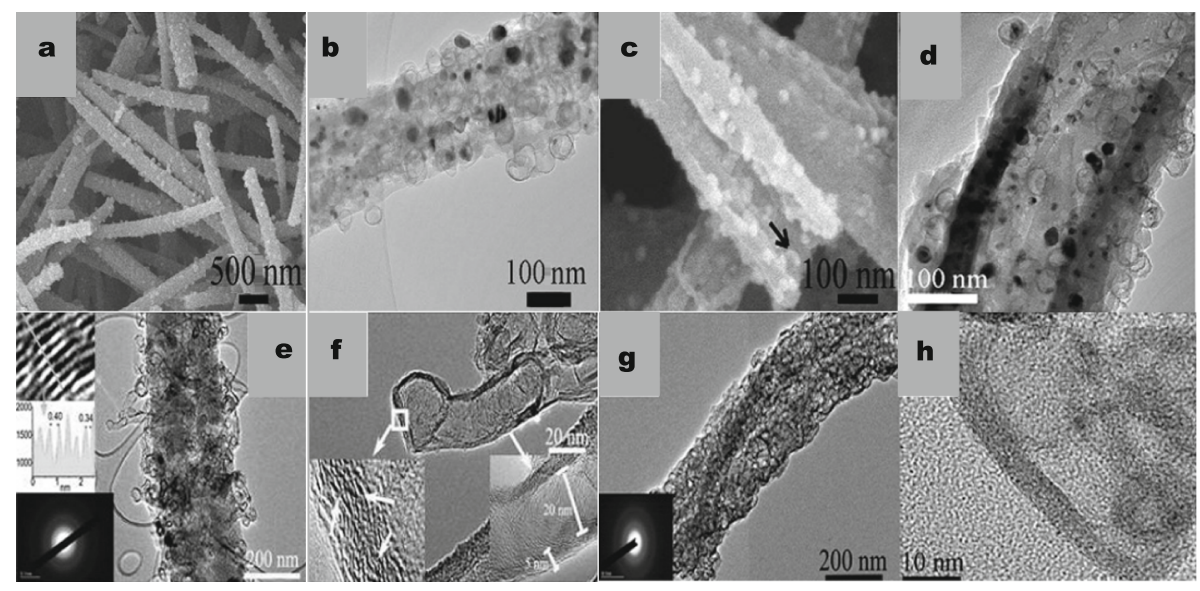

Figure 3 SEM and TEM images of (a and b) ACNFs/HGCNs (Reproduced with permission from Ref. [99], Copyright 2012, the Royal Society of Chemistry), (c and d) ACNHGCNs (Reproduced with permission from Ref. [101], Copyright 2012, the Royal Society of Chemistry), (e and f) N-doped CNTs-CNFs hybrid material (Reproduced with permission from Ref. [102], Copyright 2013, American Chemical Society), and (g and h) ANHTGCNs (Reproduced with permission from Ref. [103] Copyright 2014, Royal Society of Chemistry).

the hybrid material displayed a high reversible capacity of $\sim 750 \mathrm{~mA} \mathrm{~h} \mathrm{~g}^{-1}$ at a current density of $50 \mathrm{~mA} \mathrm{~g}^{-1}$. Similar to $\mathrm{Ni}$ nanoparticles as sacrificial catalysts, Fe nanoparticles were also used to prepare functionalized porous graphitic CNFs (FPG-CNFs), delivering a remarkable capacity of $983 \mathrm{~mA} \mathrm{~h} \mathrm{~g}^{-1}$ at $100 \mathrm{~mA} \mathrm{~g}^{-1}$ [100]. Through introducing triple-coaxial electrospinning, as shown in Figs $3 \mathrm{c}$ and d, HGCNs were decorated in amorphous CNTs (ACNHGCNs) prepared by Chen and co-workers [101]. Compared with the ANCFs in Ref. [99], amorphous CNTs in this work showed better access to electrolyte and facilitated the Li-ion diffusion, presenting a higher capacity of $\sim 969 \mathrm{~mA} \mathrm{~h} \mathrm{~g}^{-1}$ at a current density of $50 \mathrm{~mA} \mathrm{~g}^{-1}$. As shown in Figs $3 e$ and $f$, Chen et al. [102] then introduced PMMA into the precursor solution to prepare one CNFs-CNTs hybrid material. During the carbonization process at the atmosphere of $\mathrm{N}_{2} / \mathrm{H}_{2}, \mathrm{C}_{2} \mathrm{H}_{2}$, along with the thermal decomposition of PMMA, served as a carbon source to form CNTs under the catalytic effect of Ni nanoparticles embedded in the CNFs, forming the N-doped CNFs-CNTs hybrid materials. Through one subsequent $\mathrm{KOH}$ activation process and removing of $\mathrm{Ni}$ nanoparticles by $\mathrm{HNO}_{3}$, activated $\mathrm{N}$-doped CNFs-CNTs hybrid materials were finally obtained, showing an enhanced capacity of $\sim 1150 \mathrm{~mA} \mathrm{~h}$ $\mathrm{g}^{-1}$ at 0.27 C. Moreover, by controlling the atmospheric pressure during the carbonization process, as shown in Figs $3 \mathrm{~g}$ and $\mathrm{h}, \mathrm{Ni}$ in CNFs can diffuse out of the nanoparticles to create inner hollow-tunnel structure, forming $\mathrm{N}$-doped hollow-tunneled graphitic CNFs (ANHTGCNs) via subsequent chemical activation and acid treatment [103]. The prepared material showed a very high capacity of $\sim 1560 \mathrm{~mA} \mathrm{~h} \mathrm{~g}^{-1}$ at a current density of $0.1 \mathrm{~A} \mathrm{~g}^{-1}$.

Alloys

Alloy anode materials show promising potentials as anode materials for commercial LIBs, owing to high theoretical capacities, such as silicon ( $\mathrm{Si})$, germanium $(\mathrm{Ge})$, tin $(\mathrm{Sn})$, and phosphorus $(\mathrm{P})$, which can be electrochemically alloyed with Li. However, practical applications of these alloy anode materials are hindered by huge volume change during lithiation and delithiation, leading to cracking and pulverization of electrode materials, disconnection from current collectors, and unstable solid-electrolyte-interface (SEI) [104]. These would result in fast fade of capacity and low Coulombic efficiency (CE). To solve these problems, significant efforts have been made to reduce the stress from volume change and crack of SEI, such as downsizing alloy particles, preparing porous structures, and introducing protective matrixes.

Among the as-prepared Si nanostructures, 1D Si nanostructures have shown great promise for improvement of electrochemical performance of $\mathrm{Si}$ anode materials due to the enhanced electrochemical activity. Lee et al. [105] prepared mesoporous Si nanofibers (m-SiNFs) via combining electrospinning and magnesiothermic reduction. As shown in Fig. 4a, electrospun polyarylic acid (PAA)/ $\mathrm{SiO}_{2}$ nanofibers were firstly calcined at $500^{\circ} \mathrm{C}$ in air to remove the PAA and mesoporous $\mathrm{SiO}_{2}$ nanofibers were obtained. The $\mathrm{m}$-SiNFs would be prepared after the magnesiothermic reduction of mesoporous $\mathrm{SiO}_{2}$ nanofibers and etching with $\mathrm{HCl}$ to remove unreacted $\mathrm{Mg}$, as shown in Fig. 4b, displaying mesoporous structures formed by contacted Si 

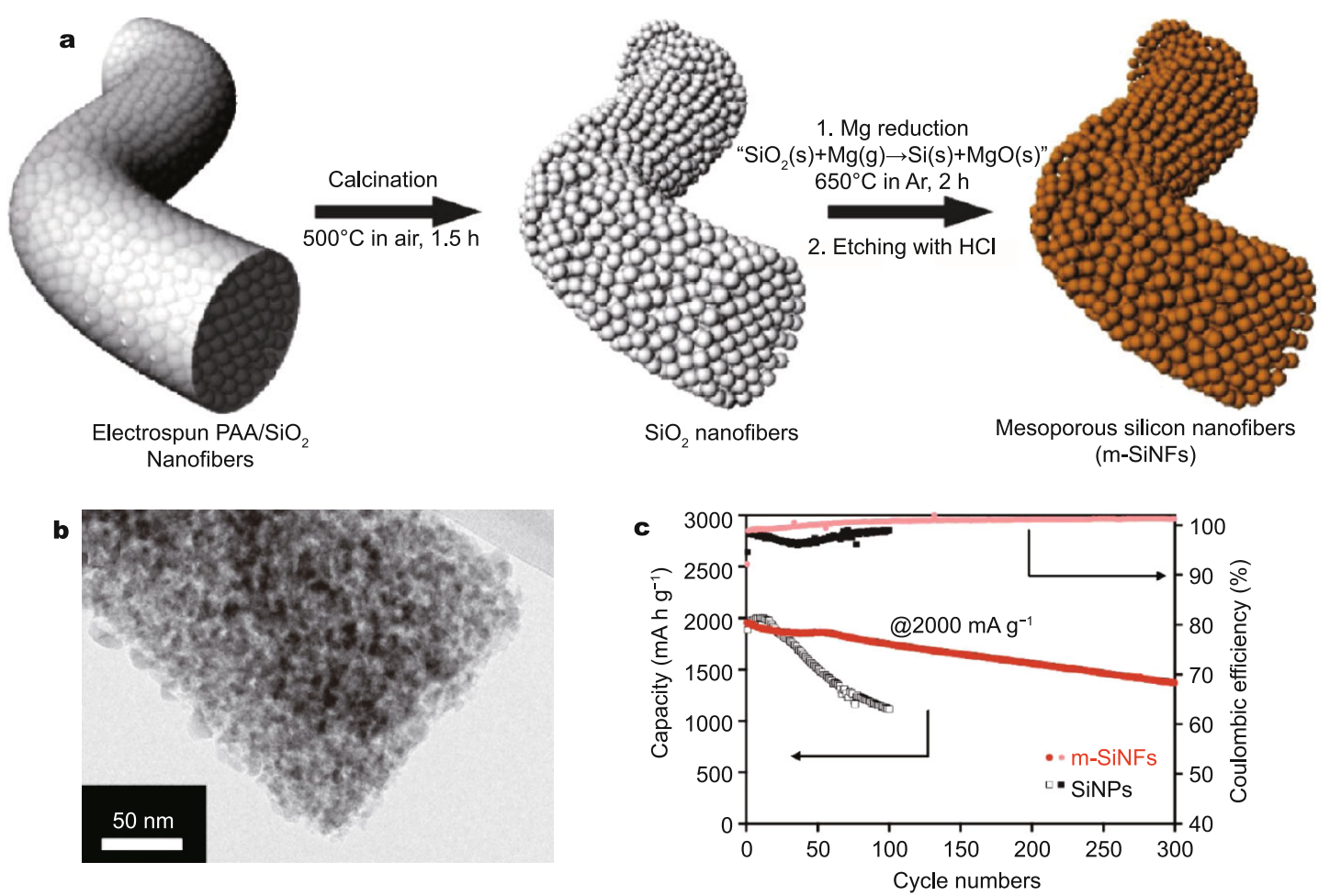

Figure 4 (a) Schematic illustration of the synthesis process and (b) TEM image of mesoporous silicon nanofibers (m-SiNFs); (c) cycle performances and Coulombic efficiencies of the unit cell fabricated using SiNPs and m-SiNFs at $2 \mathrm{~A} \mathrm{~g}^{-1}$. Reproduced with permission from Ref. [105] , Copyright 2013, American Chemical Society.

nanoparticles. Benefiting from the fast electron and Li-ion diffusion along with nanosized Si particles and accommodation effect of mesoporous structure for volume change during cycling, the $\mathrm{m}$-SiNFs delivered a high reversible capacity of $\sim 1364 \mathrm{~mA} \mathrm{~h} \mathrm{~g}^{-1}$ after 300 cycles at $2 \mathrm{~A} \mathrm{~g}^{-1}$ (Fig. 4c). On the other hand, great efforts have been devoted to develop silicon-carbon composites, regarded as promising candidates for advanced LIBs. In this regard, Wang et al. [106] prepared CNFs-Si composites by electrospinning, displaying agglomerated nanosized $\mathrm{Si}$ dispersed in the CNF matrix, showing higher capacity than that of nanosized Si/activated carbon mixture composites. However, due to the non-uniform dispersion of nanosized Si particles, the cycle life is still limited. $\mathrm{Xu}$ et al. [107] then realized the uniform distribution of Si/C clusters in three-dimensional (3D) CNF matrix by simultaneously electrospinning PAN fibers and electrospraying nano-Si-PAN clusters. After carbonization, PAN fibers became 3D CNFs and nano-Si-PAN clusters formed Si/C clusters, forming a flexible $3 \mathrm{D} \mathrm{Si} / \mathrm{C}$ fiber paper electrode as shown in Figs 5a and b. Attributed to the enhanced ionic and electronic conductivity and volume accommodation in the porous structure, the flexible 3D Si/C fiber paper displayed an enhanced overall capacity of $\sim 1600 \mathrm{~mA} \mathrm{~h} \mathrm{~g}^{-1}$ after 600 cycles (Fig. 5c).

On the other hand, Si nanoparticles (0D) encapsulated in CNFs (1D) is one promising strategy to accommodate the volume change of Si [108-111]. Zhou et al. [112] prepared one Si@PCNF hybrid material with Si nanoparticles encapsulated in PCNFs via a single-nozzle electrospinning technique as shown in Fig. 6a. Si nanoparticles were first coated with $\mathrm{SiO}_{x}$ with a thickness of 10-12 nm by calcination. Then the PAN/DMF solution with $\mathrm{Si@SiO}$ nanoparticles was electrospun to nanofibers. After carbonization and etching with hydrogen fluoride to remove $\mathrm{SiO}_{x}$, the Si@PCNF was obtained. As shown in Fig. 6b, the Si@PCNF presented that Si nanoparticles were encapsulated in the PCNFs with void space, which would accommodate the volume change of Si nanoparticles during cycling and finally improve the cyclability with enhanced capacity retention of $69.1 \%$ as shown in Fig. 6c. Other prospective encapsulation design, core $(\mathrm{Si})$-shell (carbon) fibers, is expected to be able to resolve the poor cycle performance of silicon [113-116]. Hwang and co-workers [116] prepared hybrid fibers with core full of Si nanoparticles wrapped by carbon shell (SiNP@C) by dual-nozzle electrospinning (Fig. 7a), 
a

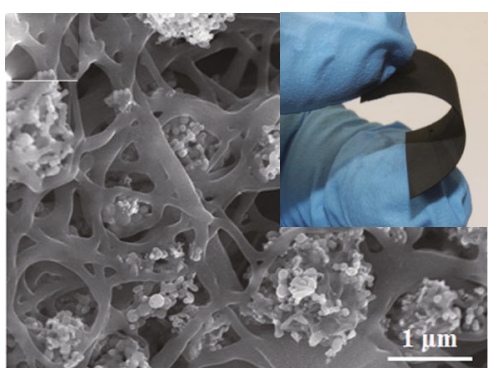

b

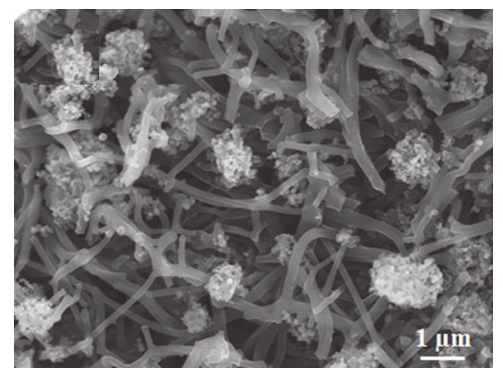

c

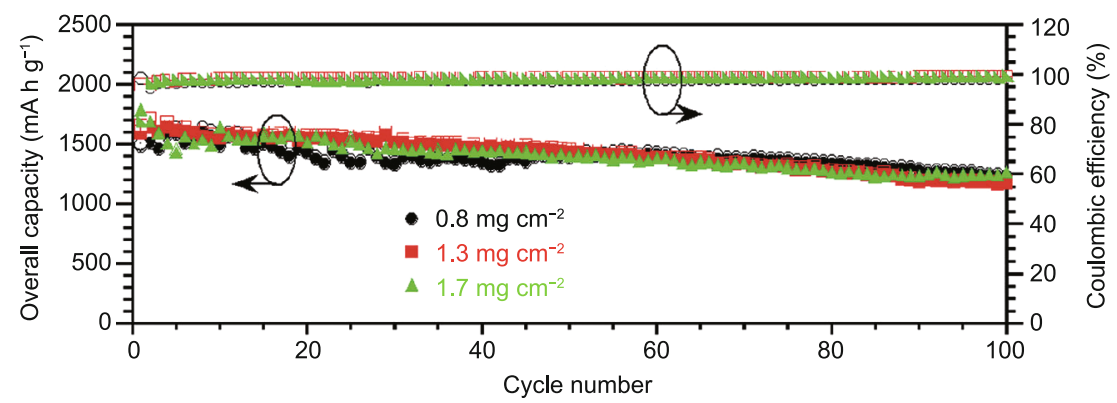

Figure 5 SEM images of the 3D Si/C fiber paper electrode, (a) top view, and (b) cross section, the insert in (a) shows one digital photo of the flexible 3D Si/C fiber paper electrode; (c) cycle performance of the 3D Si/C fiber paper electrode. Reproduced with permission from Ref. [107], Copyright 2015, Wiley.
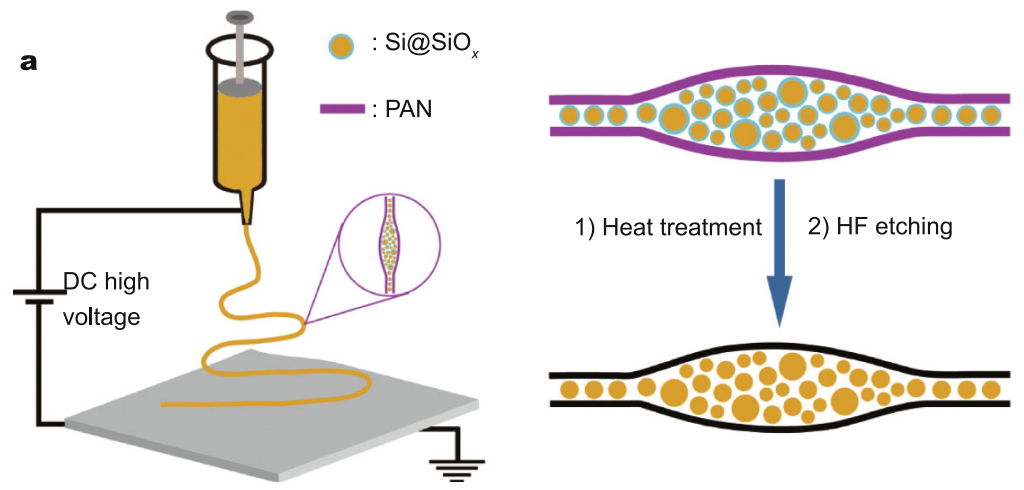

b

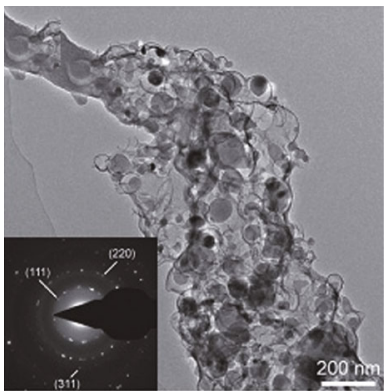

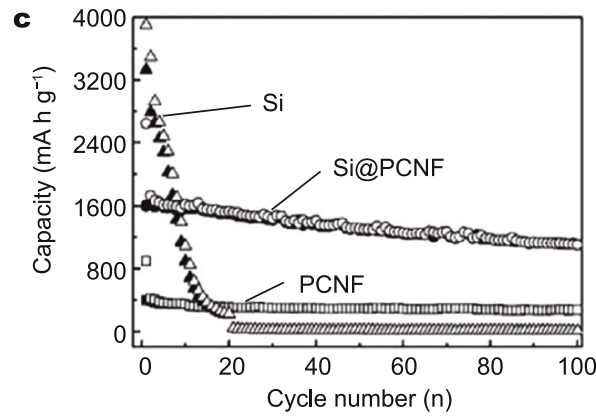

Figure 6 (a) Schematic illustration of the synthesis process of the Si@PCNF hybrid structure. (b) TEM image of the Si@PCNF hybrid structure. (c) Cycle performance of Si@PCNF, PCNF, and nano-Si at $0.2 \mathrm{~A} \mathrm{~g}^{-1}$. Reproduced with permission from Ref. [112], Copyright 2013, Wiley.

SiNP with PMMA dissolved in a mixed solvent of DMF and acetone as the core solution and PAN dissolved in DMF as the shell solution. After electrospinning, as shown in Fig. 7b, the obtained core (SiNP-PMMA)-shell (PAN) nanofibers were heated to form core (SiNP)-shell (carbon) nanofibers (Fig. 7c) resulted from the decomposition of 


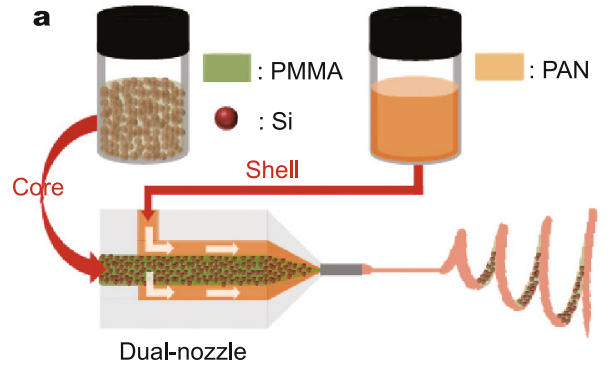

c

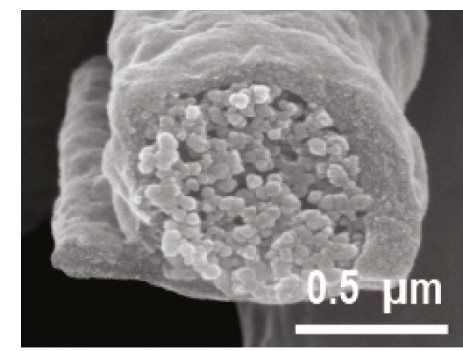

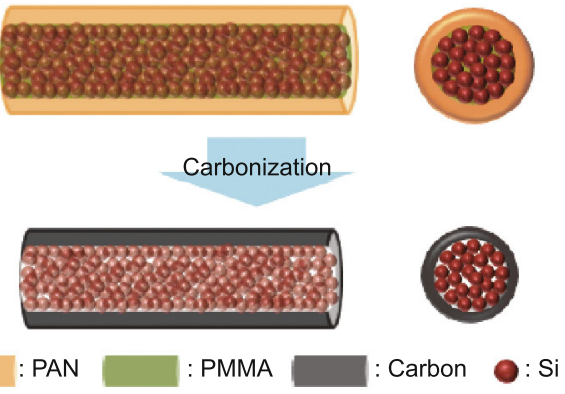

d

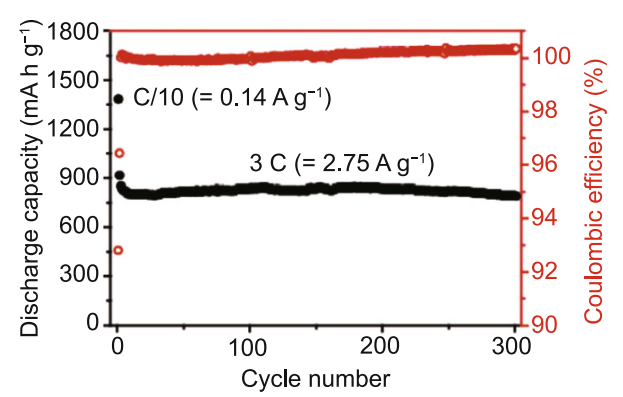

Figure 7 ( $a$ and b) Schematic illustration of the synthesis process of the SiNP@C nanofibers. (c) Cross-sectional SEM image of the SiNP@C nanofibers. (d) Cycle performance of SiNP@C nanofibers at $2.75 \mathrm{~A} \mathrm{~g}^{-1}$ (3 C). Reproduced with permission from Ref. [116], Copyright 2012, American Chemical Society.

PMMA and carbonization of PAN. The robust carbon shell in the structure can accommodate the huge volume change and severe pulverization of Si during cycling, forming stable SEI layers, and facilitate the electron diffusion along the carbon shells, finally maintaining excellent cyclability at 3 $\mathrm{C}$ as shown in Fig. $7 d$.

Tin, as another promising alloy anode material, has been widely studied, due to its theoretical capacity of $990 \mathrm{~mA} \mathrm{~h} \mathrm{~g}$. Nevertheless, the cyclability of $\mathrm{Sn}$ anode materials suffers from large volume change and easy aggregation of Sn nanoparticles during cycling. To address these problems, Yu et al. [117,118] designed two kinds of porous structures to buffer the large volume variation and prevent Sn NPs from aggregation via electrospinning. As shown in Fig. 8a [118], through a single-nozzle electrospinning of one solution of tin octoate-PMMA-PAN dissolved in DMF, the as-spun nanofibers display one core (tin octoate-PMMA)-shell (PAN) structure, due to the easier stretch of a PAN solution than a PMMA/DMF fluid. The as-spun nanofibers were first stabilized in air at $250^{\circ} \mathrm{C}$, forming $\mathrm{SnO}_{2}$ NPs embedded in porous hollow fibers as the PAN and tin octoate decomposed (Fig. 8b). Then Sn nanoparticles $(\sim 200 \mathrm{~nm})$ encapsulated in the porous hollow carbon fibers (diameter $\sim 2 \mu \mathrm{m}$ ) (SPMCTs) were obtained after carbonization in one mixed atmosphere of $\mathrm{Ar}$ and $\mathrm{H}_{2}$ (Fig. 8c). Compared with commercial Sn nanoparticles, the SPMCTs presented a high reversible capacity of $648 \mathrm{~mA} \mathrm{~h} \mathrm{~g}^{-1}$ at $0.5 \mathrm{C}$ after 140 cycles (Fig. 8d), ascribed to the sufficient void space to alleviate the huge volume change of Sn NPs and high surface area accessible to electrolyte. Then another novel Sn@carbon NPs encapsulated in bamboo-like hollow CNF hybrid material was prepared by $\mathrm{Yu}$ and co-workers [117] via a typical coaxially electrospinning strategy. A mixed solution of tributyltin (TBT) and mineral oil and a solution of PAN dissolved in DMF were applied as the inner solution and outer solution, respectively. As shown in Fig. 9a, with soaking with $n$-octane to remove the mineral oil, the as-spun nanofibers were converted to one hollow structure. After heat treatment under an $\mathrm{Ar} / \mathrm{H}_{2}$ mixed atmosphere, the Sn@carbon nanoparticles encapsulated in hollow CNFs were obtained as shown in Figs 9b and c. The carbon shell of hollow CNFs would relief the strain resulted from the volume change of Sn NPs. Moreover, the carbon coating layer on the Sn NPs would prevent pulverization Sn. Finally,the hybrid structure maintained the excellent cycle performance of $737 \mathrm{~mA} \mathrm{~h} \mathrm{~g}^{-1}$ after 200 cycles at $0.5 \mathrm{C}$ (Fig. 9d). In addition, the electrochemical activity of Sn NPs is related to the size of Sn NPs as well as the electrospun CNF matrix. Zhang et al. [119] have prepared Sn quantum dots (QDs) $(\sim 5 \mathrm{~nm})$ embedded in N-doped CNFs (Sn QDs@CNFs) by electrospinning followed annealing in $\mathrm{N}_{2}$. With the reduced mass diffusion length along Sn QDs and enhanced electronic conductivity of N-doped CNFs, the Sn QDs@CNFs dis- 


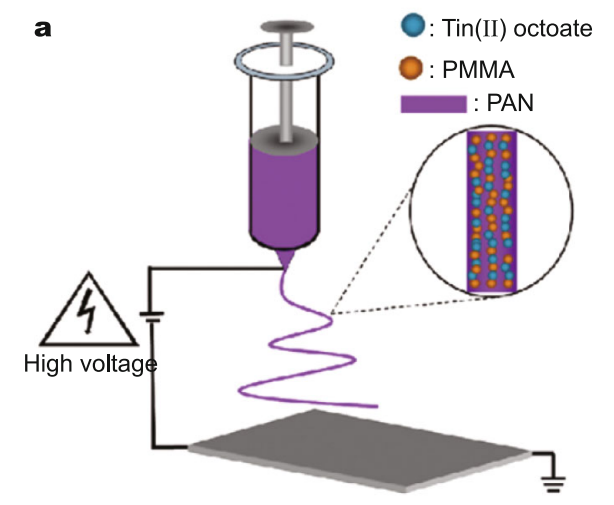

b
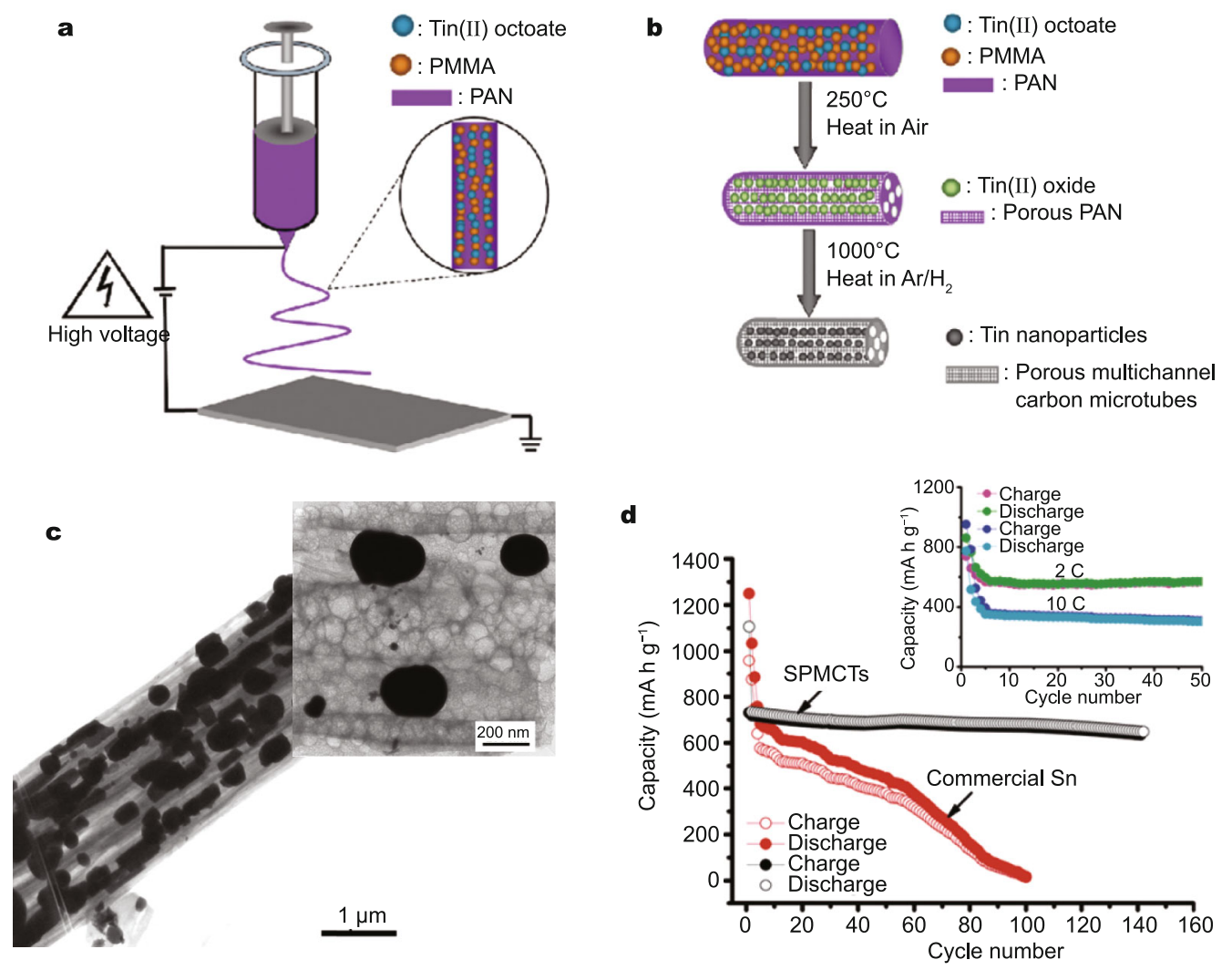

Figure 8 ( $a$ and $b$ ) Schematic illustration of the synthesis process of the SPMCTs nanofibers. (c) TEM image of the SnNP@C nanofibers, the insert shows the TEM image with higher resolution. (d) Cycle performance of SnNP@C nanofibers at 0.25, 2 and 10 C. Reproduced with permission from Ref. [118] , Copyright 2009, American Chemical Society.

a

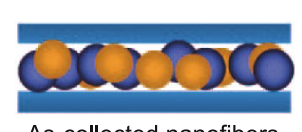

As-collected nanofibers

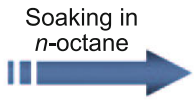

II
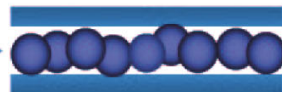

After soaking

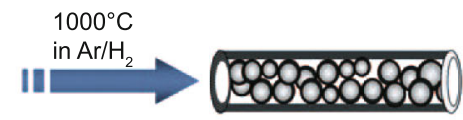

Sn@C encapsulated in hollow carbon nanofibers

: Mineral oil $\bigcirc$ : тBT : $\quad$ :PAN $\bigcirc$ :Sn@C nanoparticles : Hollow carbon nanofibers
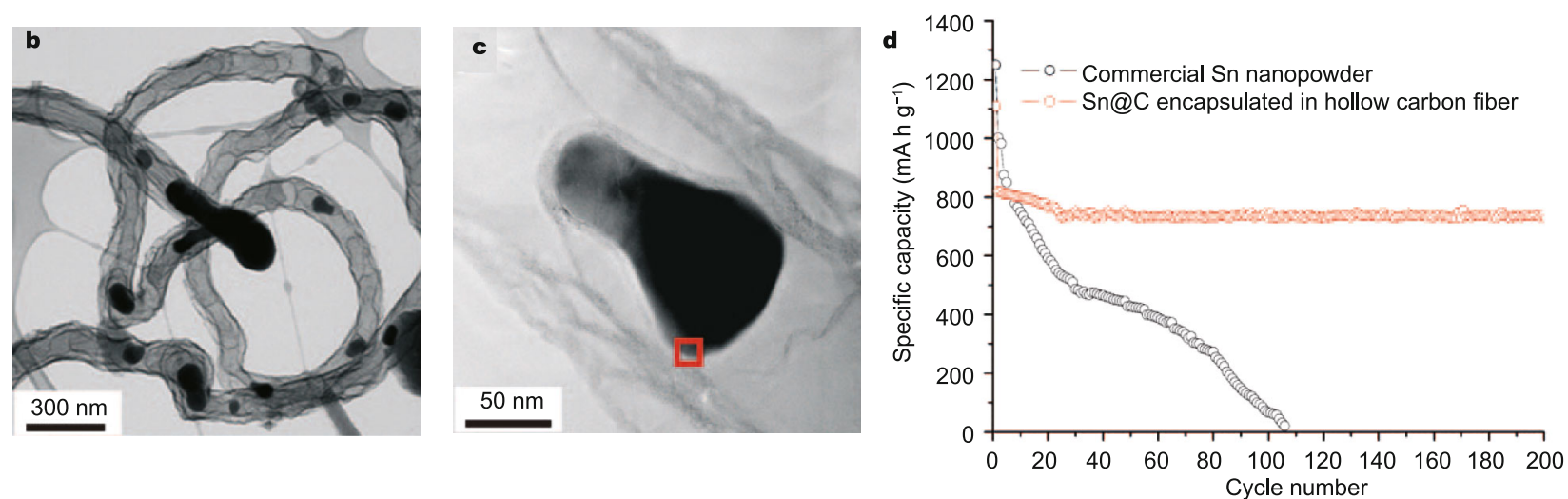

Figure 9 (a) Schematic illustration of the preparation process, (b and c) TEM images and (d) cycle performance at 0.5 C of the Sn@carbon nanoparticles encapsulated in hollow CNFs. Reproduced with permission from Ref. [117], Copyright 2009, Wiley. 
played long cyclability of $887 \mathrm{~mA} \mathrm{~h} \mathrm{~g}^{-1}$ after 200 cycles at a cycling rate of $0.1 \mathrm{~A} \mathrm{~g}^{-1}$.

Germanium $(\mathrm{Ge})$ is another promising anode material with a high theoretical capacity $\left(1624 \mathrm{~mA} \mathrm{~h} \mathrm{~g}^{-1}\right.$ for $\mathrm{GeLi}_{4.4}$ ), higher Li-ion diffusion coefficient and electrical conductivity than $\mathrm{Si}$ [120]. Ge is applied to prepare electrospun anode materials for LIBs to overcome strain from volume change after lithiation. A flexible electrode consisting of Ge nanoparticles embedded in CNFs (Ge-CNFs) has been prepared by Li et al. [121] via electrospinning. The precursor solution containing tetramethoxygermane (TMOG) and PAN dissolved in DMF was firstly electrospun to nanofibers, followed by stabilization at $280^{\circ} \mathrm{C}$ in air and carbonization at $650^{\circ} \mathrm{C}$ in $\mathrm{Ar} / \mathrm{H}_{2}$. The Ge-CNFs were finally obtained and exhibited excellent electrochemical performance of $1420 \mathrm{~mA} \mathrm{~h} \mathrm{~g}^{-1}$ at $0.15 \mathrm{C}$ after 100 cycles based on the synergistic effects of OD Ge NPs, 1D CNFs and 3D interconnected CNF matrix. To further stabilize Ge in CNFs, Wang and co-workers [122] prepared amorphous germanium encapsulated in $\mathrm{N}$-doped CNFs (Ge/N-CNFs) forming Ge-N chemical bonds via electrospinning a homogeneous solution of ethanediamine-germanium-PVP (EDA-Ge-PVP) dissolved in water. The Ge-N chemical bonds benefited the cyclability of Ge during cycling. To further enhance the structural stability of Ge during cycling, Wang et al. [123] applied additional $\mathrm{TiO}_{2}$ layer on the surface of Ge-CNFs and finally obtained improved cycle performance. In addition, to study the electrochemical activity of different dimensional Ge anode materials, Li and co-workers [124] designed and prepared carbon-coated single crystal Ge nanowires grown on the surface of CNFs (c-GeNWs-CNFs hybrid materials) as flexible and self-supported anode materials for LIBs. A precursor solution of PAN/nickel acetate/TMOG (PAN/Ni(Ac) 2 /TMOG) dissolved in DMF was electrospun to nanofibers. During the process, DMF evaporated and TMOG reacted with $\mathrm{H}_{2} \mathrm{O}$ in the air to form $\mathrm{GeO}_{2}$, forming $\mathrm{PAN} / \mathrm{Ni}(\mathrm{Ac})_{2} / \mathrm{GeO}_{2}$ composite nanofibers. After stabilization in air, the nanofibers were carbonized at $550^{\circ} \mathrm{C}$ in $\mathrm{Ar} / \mathrm{H}_{2}$ atmosphere. As shown in Fig. 10a, during the pyrolysis process, $\mathrm{NiO}$ nanoparticles produced from $\mathrm{Ni}(\mathrm{Ac})_{2}$ and $\mathrm{GeO}_{2}$ would converted to be Ni nanoparticles (Ni NPs) and $\mathrm{Ge}$, respectively, under the reduction of $\mathrm{H}_{2}$. Under the catalytic effect of Ni NPs, small organic molecule gas (i.e., $\mathrm{C}_{2} \mathrm{H}_{2}$ and $\mathrm{CH}_{4}$ ), produced from partial decomposition of $\mathrm{PAN}$, and $\mathrm{GeO}$ gas, generated from reaction between $\mathrm{Ge}$ and unreduced $\mathrm{GeO}_{2}$ served as the source of carbon layer and Ge NWs, respectively. Finally, Ge NWs (diameter $\sim 10 \mathrm{~nm})$ coated by carbon layers $(\sim 2 \mathrm{~nm})$ were grown on CNFs, forming a flexible film with a hybrid structure as shown in Figs 10b and c. Resulted from increased specific surface area accessible to electrolyte and good electronic conductivity along the Ge NWs, carbon layers and 3D interconnected CNF network, the c-GeNWs-CNFs hybrid
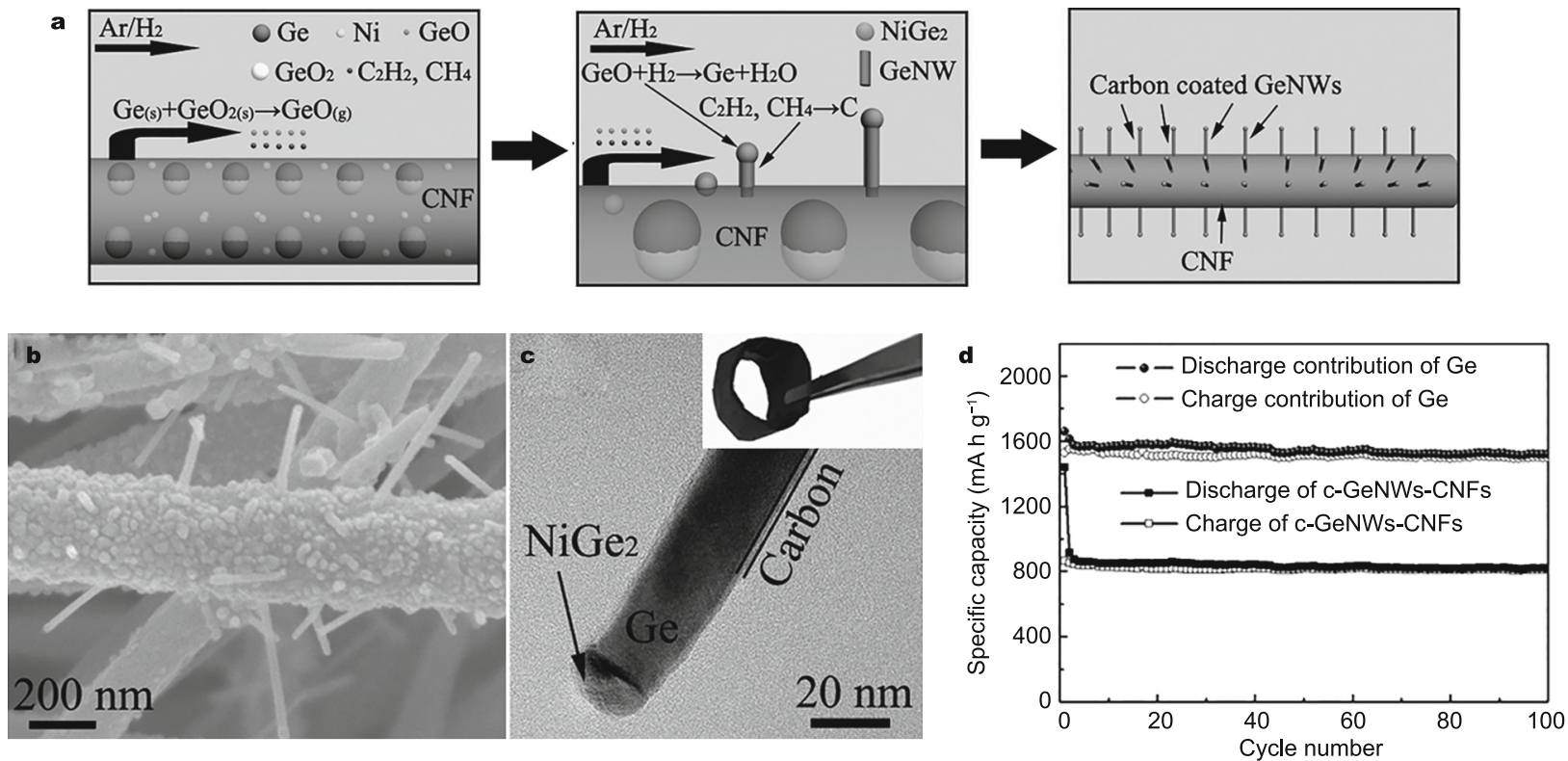

Figure 10 (a) Schematic illustration of the preparation process, (b) SEM, (c) TEM images and (d) cycle performance at $0.1 \mathrm{C}$ of the c-GeNWs-CNFs hybrid materials. The insert in (c) shows one digital photograph of the flexible c-GeNWs-CNFs hybrid film. Reproduced with permission from Ref. [124], Copyright 2015, Wiley. 
materials presented an outstanding cycle performance of $1520 \mathrm{~mA} \mathrm{~h} \mathrm{~g}^{-1}$ at $0.1 \mathrm{C}$ after 100 cycles (Fig. 10d).

Phosphorus is another alloy anode material with a very high theoretical capacity of $2595 \mathrm{~mA} \mathrm{~h} \mathrm{~g}^{-1}$, but suffers from huge volume change ( $300 \%)$ during cycling and low electronic conductivity. Li and co-workers [125] used electrospun PCNFs as matrix to load red P, forming a flexible film electrode. PAN and PMMA were co-electrospun to nanofibers in a solvent of DMF, which formed PCNFs after pyrolysis at $1000^{\circ} \mathrm{C}$ in $\mathrm{Ar}$ based on the decomposition of PMMA and carbonization of PAN. Benefiting from the nanosized red $\mathrm{P}$ nanoparticles confined in PCNFs and enhanced electron transfer along 3D interconnected PCNFs, the flexible electrode delivered an excellent cyclability ( $2030 \mathrm{~mA} \mathrm{~h} \mathrm{~g}^{-1}$ at $0.1 \mathrm{C}$ after 100 cycles).

\section{Metal oxides}

Tremendous efforts have been devoted to study metal oxide anode materials for LIBs, including numerous oxides, such as $\mathrm{Li}_{4} \mathrm{Ti}_{5} \mathrm{O}_{12}, \mathrm{TiO}_{2}, \mathrm{Fe}_{3} \mathrm{O}_{4}, \mathrm{CoO}$, and $\mathrm{SnO}_{2}$. This review intends to summarize recent development of metal oxides prepared via electrospinning as anode materials for LIBs, including intercalation/de-intercalation materials and conversion materials based on the types of electrochemical reaction with lithium.

The research of metal oxide anode materials based on the intercalation/de-intercalation mechanism mainly focuses on $\mathrm{Li}_{4} \mathrm{Ti}_{5} \mathrm{O}_{12}, \mathrm{TiO}_{2}$, and $\mathrm{TiNb}_{2} \mathrm{O}_{7}$. As one promising alternative to commercial carbonaceous anode materials for LIBs, $\mathrm{Li}_{4} \mathrm{Ti}_{5} \mathrm{O}_{12}$ (LTO) has been widely investigated, due to zero-strain during lithium intercalation/de-intercalation and avoidable formation of decomposition of electrolyte and formation of SEI layers. However, the low Li-ion diffusion coefficient and poor electronic conductivity hinder the practical applications of LTO. To solve these issues, nanosized LTO fibers have been applied. Wang et al. [126] synthesized porous LTO nanofibers consisting of interconnected LTO nanoparticles via pyrolysis of electrospun nanofibers (tetrabuyl titanate, lithium acetate and PVP). Ascribed to increased electrode-electrolyte interface of porous nanofibers and reduced Li-ion diffusion length of the LTO nanoparticles, the LTO nanofibers showed improved rate performance $\left(90.4 \mathrm{~mA} \mathrm{~h} \mathrm{~g}^{-1}\right.$ at 60 C). To further improve the electronic conductivity of LTO nanofibers, Park and co-workers [127] prepared electrospun LTO nanofibers coated with conductive TiN/TiO $\mathrm{N}_{y}$ layers via nitridation. The obtained LTO nanofibers after electrospinning and thermal treatment in air were heated in an atmosphere of $\mathrm{NH}_{3}$ gas to complete the nitridation process and amorphous $\mathrm{TiN} / \mathrm{TiO}_{x} \mathrm{~N}_{y}$ layers formed on the surface of the LTO nanofibers. Compared with the pristine LTO nanofibers, the nitridated LTO nanofibers with the outer conductive layers showed better rate performance. On the other hand, CNF matrixes have been widely employed as conductive matrix to improve the electronic conductivity of electrode materials in LIBs. Choi et al. [128] and Zhu et al. [129] synthesized LTO/CNF composites showing enhanced rate performance. To further increase the electrolyte/electrode interface area and shorten the Li-ion transfer length, Xu et al. [130,131] designed and prepared highly porous carbon-coated LTO fibers by combining electrospinning with treatment in air. As shown in Fig. 11a, the as-spun nanofibers containing lithium acetylacetonate (LAA), titanium isopropoxide (TTIP) and PVP were firstly carbonized at $800^{\circ} \mathrm{C}$ in $\mathrm{Ar} / \mathrm{H}_{2}$ $(v / v=95: 5)$ to form LTO/C nanofibers. Then the composite nanofibers were treated in air at $350^{\circ} \mathrm{C}$ to partially burn off the carbon matrix, obtaining highly porous LTO/C nanofibers with a large number of pores in the composite nanofibers as shown in Figs 11b-d. With facilitated infiltration of electrolyte within the highly porous structure and improved electron transfer along the carbon matrix, the PLTO/C delivered excellent rate performance of 161, 154,150 , and $143 \mathrm{~mA} \mathrm{~h} \mathrm{~g}^{-1}$ cycled at $0.5,2,10$ and $30 \mathrm{C}$, respectively (Fig. 11e).

$\mathrm{TiO}_{2}$ is another low-cost and environment-friendly anode material with high lithium insertion voltage, presenting similar advantages of LTO but higher capacity than LTO. Unfortunately, the cyclability and rate performance of $\mathrm{TiO}_{2}$ are also hindered by the inferior electron and Li-ion conductivity. Electrospinning provides a promising solution to prepare $1 \mathrm{D} \mathrm{TiO}_{2}$ nanomaterials to conquer these issues [132]. To increase penetration of the electrolyte, Yuan et al. [133] and Zhang et al. [134] prepared $\mathrm{TiO}_{2}$ hollow nanofibers through the coaxial electrospinning strategy by using $\mathrm{TiO}_{2}$-precursor solutions and mineral oil or polymer solutions as the materials for the core and shell, respectively. $\mathrm{TiO}_{2}$ hollow nanofibers were obtained after pyrolysis in air. Afterwards, Tang and co-workers [135] synthesized multichannel hollow $\mathrm{TiO}_{2}$ nanofibers through a simple single-nozzle electrospinning process. As shown in Fig. 12a, the precursor solution of PAN/PVP/tetrabutyl titanate (TBOT) in DMF would undergo phase separation during the evaporation of DMF, forming the multichannel hollow nanofibers. After pyrolysis in air, as shown in Figs $12 \mathrm{~b}$ and c, $\mathrm{TiO}_{2}$ nanofibers (diameter of $\sim 200 \mathrm{~nm}$ ) with multi-channels (diameter of tens of nanometers) were prepared and displayed enhanced rate performances of $218,200,170$, 
a

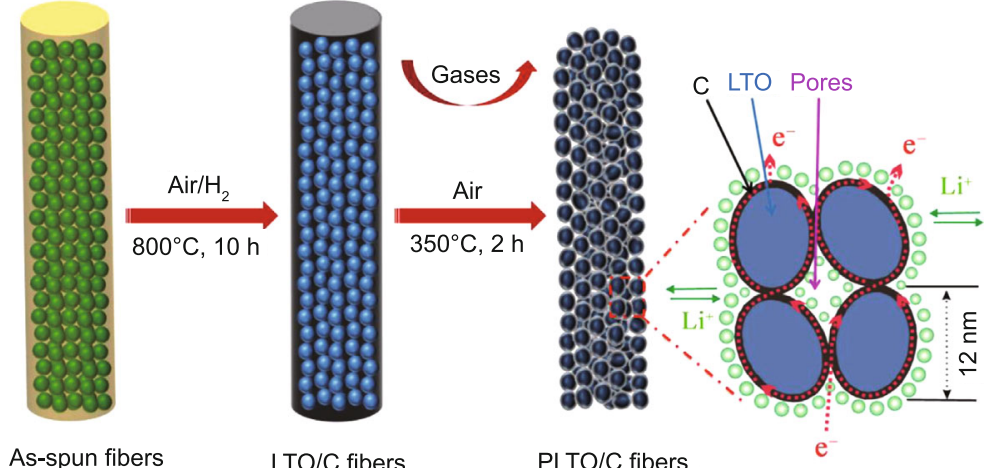

b

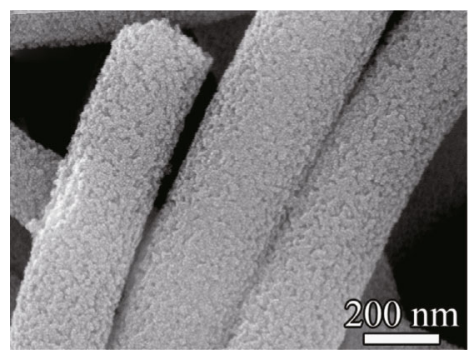

PVP LTO precursor LTO $\square$ O LTO/C

c

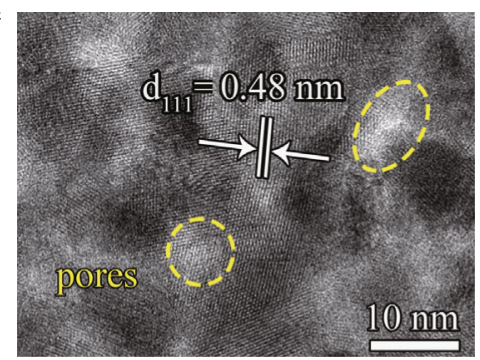

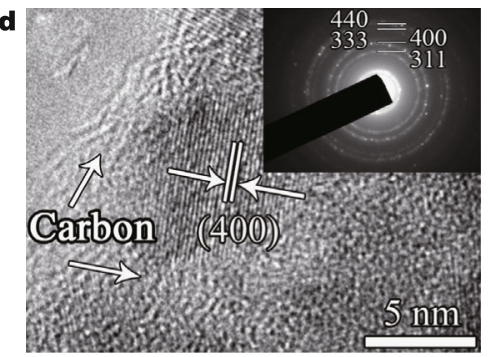

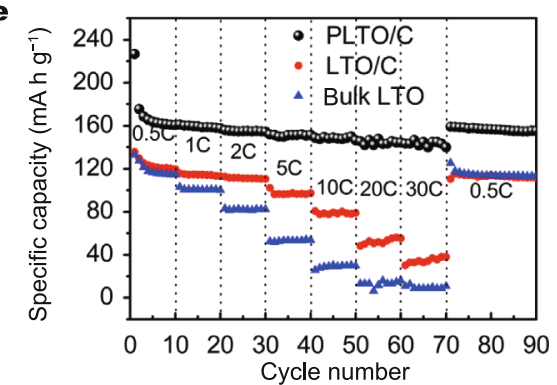

Figure 11 (a) Schematic illustration of the formation of the PLTO/C nanofibers, (b) SEM, (c and d) HRTEM images and (e) rate performance of the PLTO/C nanofibers. Reproduced with permission from Ref. [131], Copyright 2014, Elsevier.

144, 110, and $72 \mathrm{~mA} \mathrm{~h} \mathrm{~g}^{-1}$ at $1,2,5,10,20$ and $50 \mathrm{C}$, respectively (Fig. 12d). The electronic conductivity is another key factor determining the electrochemical activity of $\mathrm{TiO}_{2}$. As shown in Fig. 13, nitridation [136,137], metal nanoparticles [138,139], and carbon matrix [140-143] were usually applied to enhance the electronic conductivity of $\mathrm{TiO}_{2}$ nanofibers. Han et al. [137] produced N-doped $\mathrm{TiO}_{2}$ hollow nanofibers via one typical electrospinning process and subsequent nitridation process in the $\mathrm{NH}_{3}$ atmosphere. With the increased electrolyte/electrode interface, the $\mathrm{TiO}_{2}$ hollow nanofibers were also sheathed with highly conductive $\mathrm{TiN} / \mathrm{TiO}_{x} \mathrm{~N}_{y}$ layers. Owing to simultaneously enhanced electronic conductivity and shortened Li-ion diffusion distance, the N-doped $\mathrm{TiO}_{2}$ hollow nanofibers showed higher rate capability than pristine $\mathrm{TiO}_{2}$ nanofibers.

With higher theoretical capacity of $387.6 \mathrm{~mA} \mathrm{~h} \mathrm{~g}$, $\mathrm{TiNb}_{2} \mathrm{O}_{7}$ is regarded as one promising candidate anode material to LTO, with reversible insertion of $\mathrm{Li}$-ion and lithium occupation in the interstitial sites. Similar to LTO, low electronic and ionic conductivity of $\mathrm{TiNb}_{2} \mathrm{O}_{7}$ limit the electrochemical performance. To solve these problems, Tang and co-workers [144] firstly prepared "nano-pearl-string" $1 \mathrm{D} \mathrm{TiNb}_{2} \mathrm{O}_{7}$ nanofibers with attached $\mathrm{TiNb}_{2} \mathrm{O}_{7}$ nanoparticles by the electrospinning method. A solution of PVP, niobium ethoxide $\left(\mathrm{Nb}\left(\mathrm{OC}_{2} \mathrm{H}_{5}\right)_{5}\right)$ and tetrabutyl orthotitanate $\left(\mathrm{Ti}\left(\mathrm{OC}_{4} \mathrm{H}_{9}\right)_{4}\right)$ dissolved in a mixed solvent of ethanol and acetic acid was firstly electrospun to nanofibers. The as-spun nanofibers were calcined at $1000^{\circ} \mathrm{C}$ in air to produce $\mathrm{TiNb}_{2} \mathrm{O}_{7}$ nanofibers. As shown in Figs $14 \mathrm{a}$ and $\mathrm{b}$, the nanofibers displayed a uniform diameter of $\sim 500 \mathrm{~nm}$ and consisted of interconnected nanoparticles (50-200 nm). Benefiting from the favorable kinetics based on nanofibers, the material showed excellent cyclability (a high capacity of $250 \mathrm{~mA} \mathrm{~h} \mathrm{~g}^{-1}$ after 50 cycles at $1 \mathrm{C})$ and rate performance $\left(198,137\right.$ and $63 \mathrm{~mA} \mathrm{~h} \mathrm{~g}^{-1}$ at current densities of 2, 5 and $20 \mathrm{C}$, respectively) (Figs 14c and d). Moreover, Aravidan et al. [145] reported the applications of electrospun $\mathrm{TiNb}_{2} \mathrm{O}_{7}$ nanofibers as insertion-type anode material in Li-ion hybrid electrochemical capacitors with high energy and power density.

In addition, iron oxides, cobalt oxides, manganese oxides and nickel oxides are typical transition metal oxide anode materials with the conversion reaction mechanism in LIBs. During the conversion reaction, the transition metal oxides react with $\mathrm{Li}$ to form metal and $\mathrm{Li}_{2} \mathrm{O}$ and generate large 

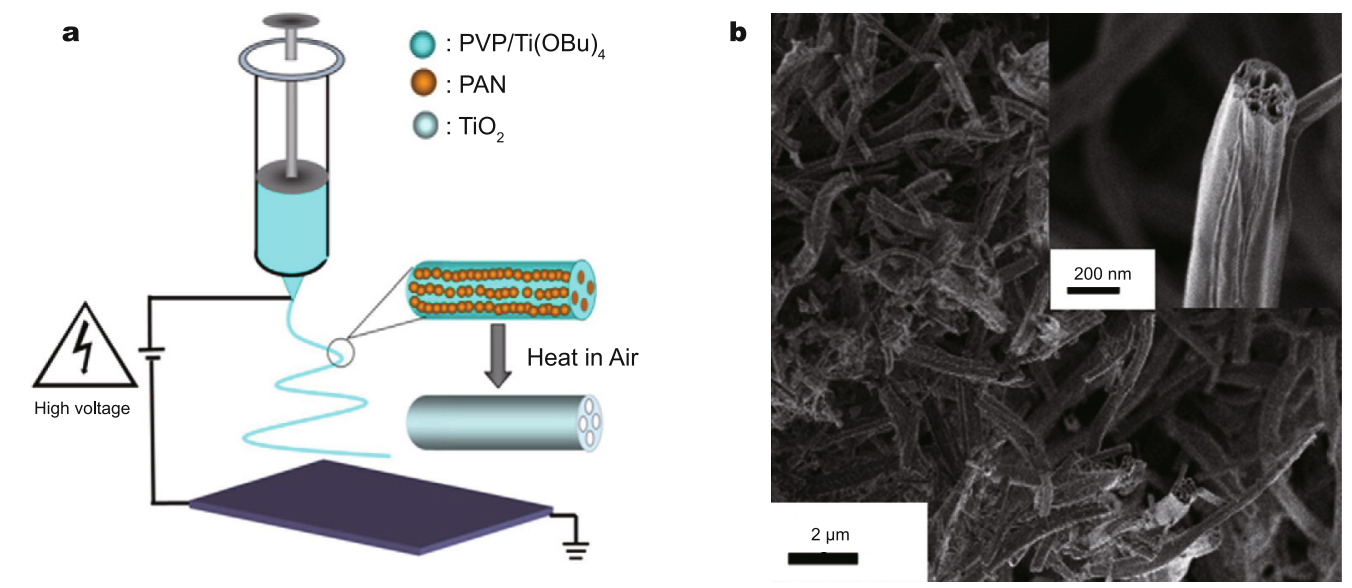

c

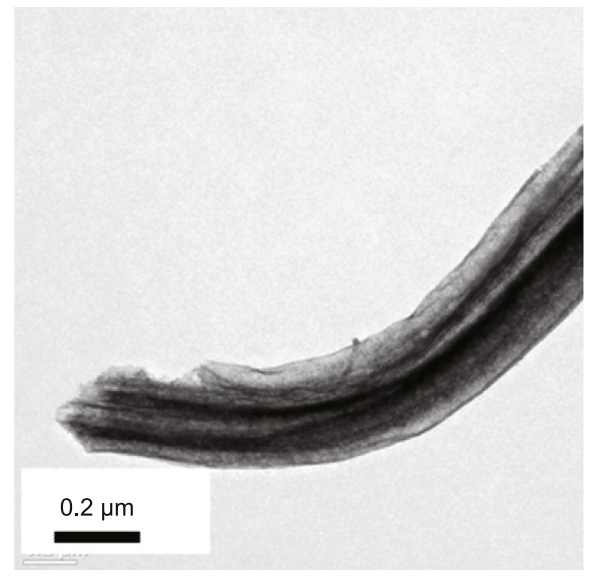

d

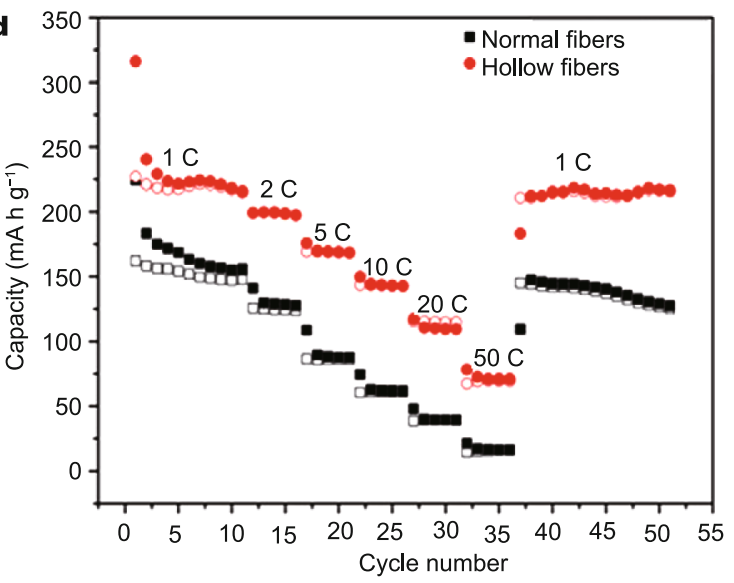

Figure 12 (a) Schematic illustration of the electrospinning process of the multichannel hollow TiO 2 nanofibers; (b) SEM, (c) TEM images and (d) rate performance of multichannel hollow $\mathrm{TiO}_{2}$ nanofibers. Reproduced with permission from [135], Copyright 2012, Elsevier.

volume change of electrode materials, which would limit the cyclability of electrode materials along with the electronic insulating nature [146]. To improve the electrochemical performance of this type anode materials, electrospun CNFs and porous structures have been applied to buffer the volume change and enhance the electron transfer [133]. $\quad \mathrm{Fe}_{2} \mathrm{O}_{3}$ and $\mathrm{Fe}_{3} \mathrm{O}_{4}$ are abundant, low-cost and eco-friendly anode materials with high theoretical capacities. To strengthen the kinetics of iron oxides in conversion reaction with lithium, Ji et al. [147], Zhang et al. [148], Wang et al. [149], and Gu et al. [150] synthesized electrospun $\mathrm{Fe}_{2} \mathrm{O}_{3} /$ carbon or $\mathrm{Fe}_{3} \mathrm{O}_{4} / \mathrm{CNF}$ with iron oxides nanoparticles embedded in conductive CNFs to improve the electrochemical activity of iron oxides. In addition, $1 \mathrm{D}$ hollow nanofiber was another promising structure to increase access of iron oxides to electrolyte and enhance Li-ion diffusion [151-153]. By combining conductive carbon matrix and hollow structures, Cho and co-workers [154] prepared bubble-nanorod-structured $\mathrm{Fe}_{2} \mathrm{O}_{3}-\mathrm{C}$ composite nanofibers with hollow $\mathrm{Fe}_{2} \mathrm{O}_{3}$ nanospheres encapsulated in amorphous carbon matrix. As shown in Fig. $15 \mathrm{a}$, the as-spun nanofibers consisting of iron acetylacetonate $\left(\mathrm{Fe}(\mathrm{acac})_{3}\right)$ and PAN were first carbonized at $500^{\circ} \mathrm{C}$ in $\mathrm{Ar} / \mathrm{H}_{2}$ to form $\mathrm{FeO}_{x}$-CNFs. Then based on the Kirkendall effect in the subsequent thermal treatment, hollow $\mathrm{Fe}_{2} \mathrm{O}_{3}$ nanospheres were prepared, accommodating the volume change during cycling (Fig. 15b). The unique nanosized $\mathrm{Fe}_{2} \mathrm{O}_{3}$ spheres- $\mathrm{C}$ nanofibers realized long-term cycling of $812 \mathrm{~mA} \mathrm{~h} \mathrm{~g}^{-1}$ at $1 \mathrm{~A} \mathrm{~g}^{-1}$ after 300 cycles (Fig. 15c).

Similarly, electrospinning was also applied to enhance electronic and ionic conductivity of cobalt oxides (e.g., $\mathrm{CoO}$ and $\mathrm{Co}_{3} \mathrm{O}_{4}$ ) [155-157], manganese oxides (e.g., $\mathrm{MnO}$ ) [158,159] and nickel oxides (e.g., NiO) [160,161], preparing porous oxides nanofibers with connected oxide nanoparticles, and oxide nanoparticles encapsulated in CNFs [155-159]. The synthesized 1D metal oxide nanomaterials showed improved electrochemical performance.

$\mathrm{SnO}_{2}$-based materials have gained intensive attention as 
a
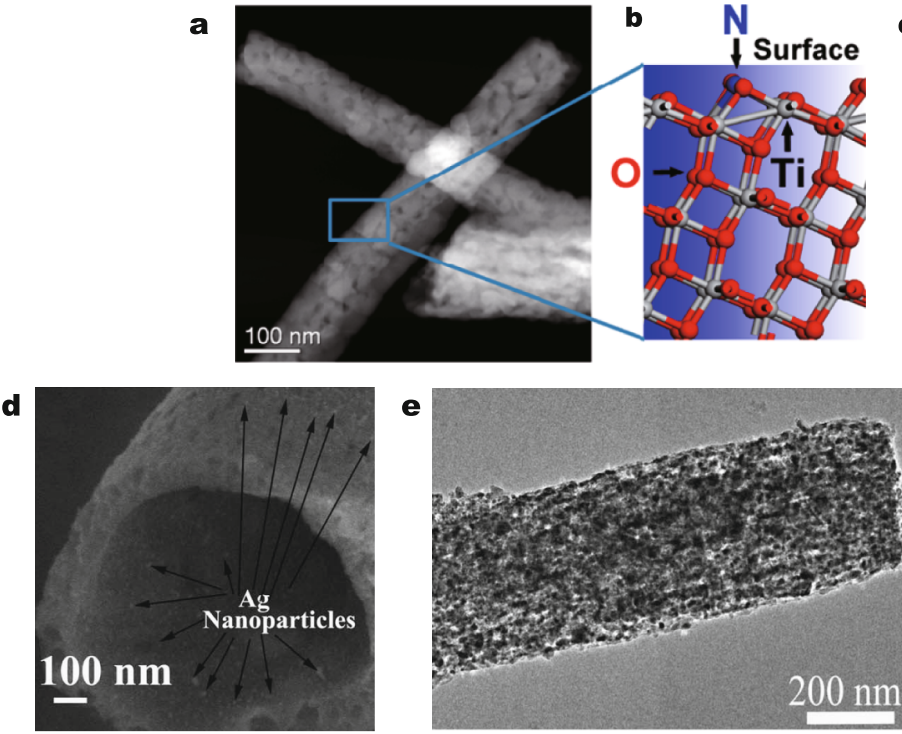

c
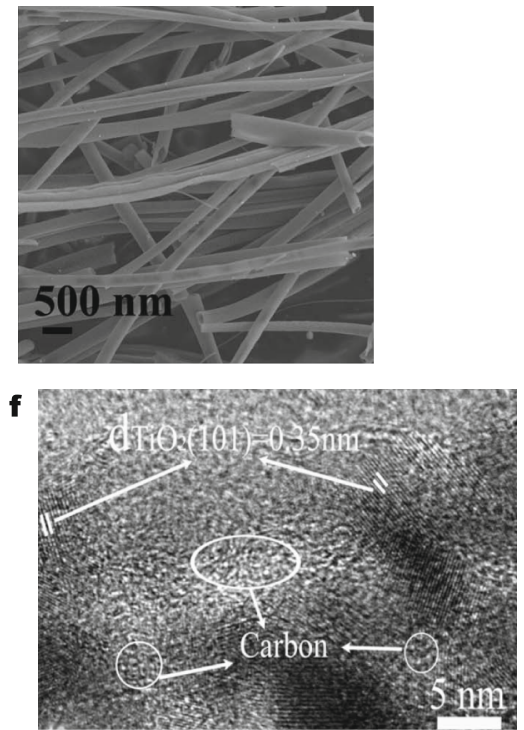

Figure 13 (a) TEM image and (b) schematic illustration of crystal structure of $\mathrm{N}$-doped $\mathrm{TiO}_{2}$ (Reproduced with permission from Ref. [136], Copyright 2013, American Chemical Society); (c and d) SEM images of Ag nanoparticles decorated $\mathrm{TiO}_{2}$ hollow nanofibers (Reproduced with permission from Ref. [139], Copyright 2013, Royal Society of Chemistry); (e) TEM and (f) HRTEM images of porous TiO ${ }_{2}$-CNFs (Reproduced with permission from Ref. [143], Copyright 2014, Royal Society of Chemistry).

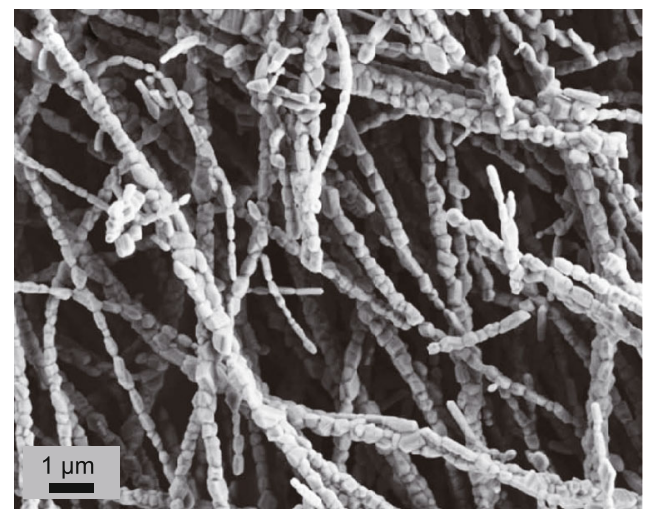

c

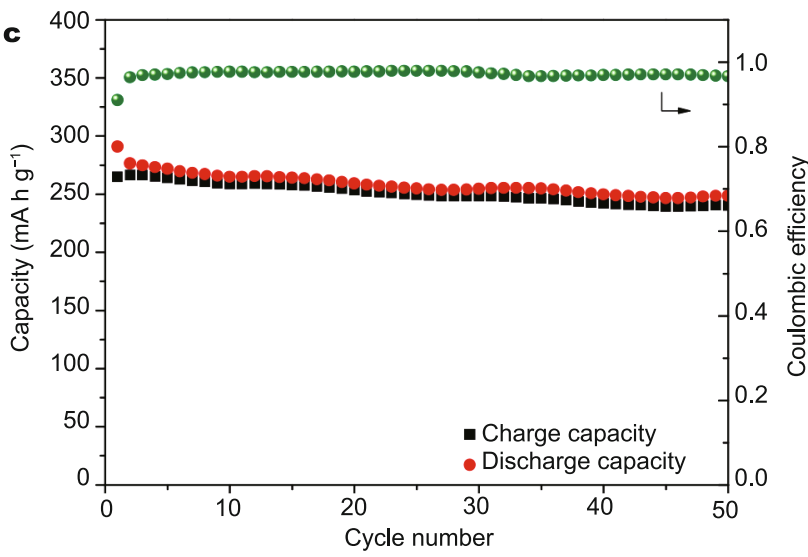

b
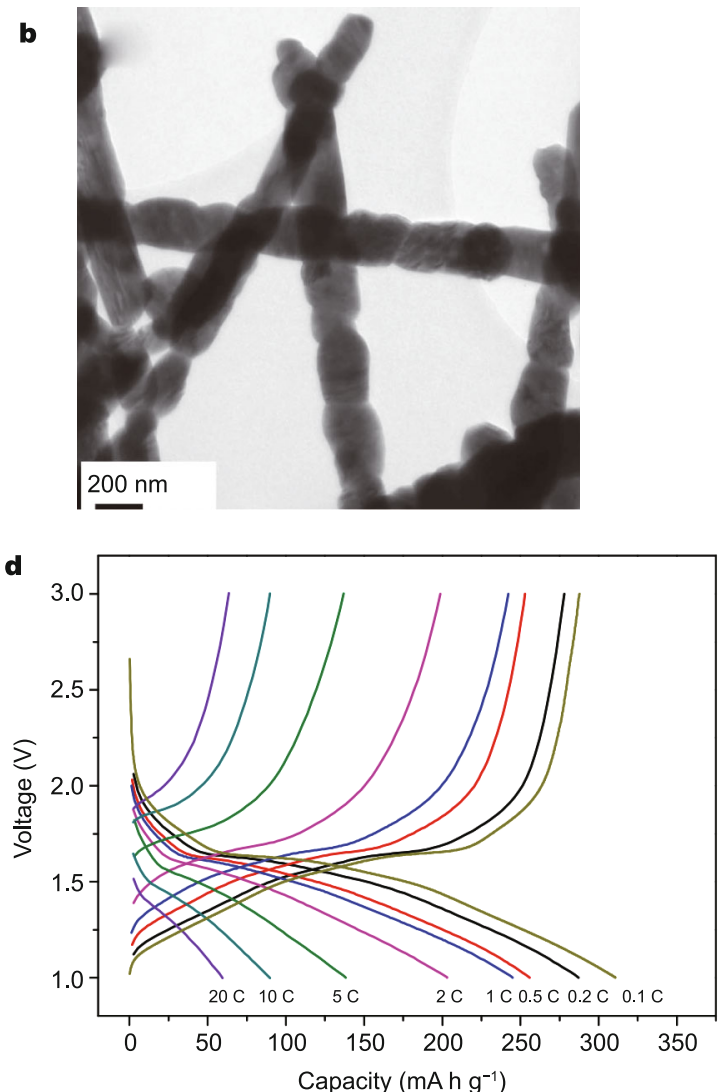

Figure 14 (a) SEM and (b) TEM images of "nano-pearl-string" $\mathrm{TiNb}_{2} \mathrm{O}_{7}$ nanofibers; (c) cycle performance of $\mathrm{TiNb}_{2} \mathrm{O}_{7}$ nanofibers at $1 \mathrm{C}$; (d) rate performance of $\mathrm{TiNb}_{2} \mathrm{O}_{7}$ nanofibers at various rates. Reproduced with permission from Ref. [144], Copyright 2013, Wiley. 


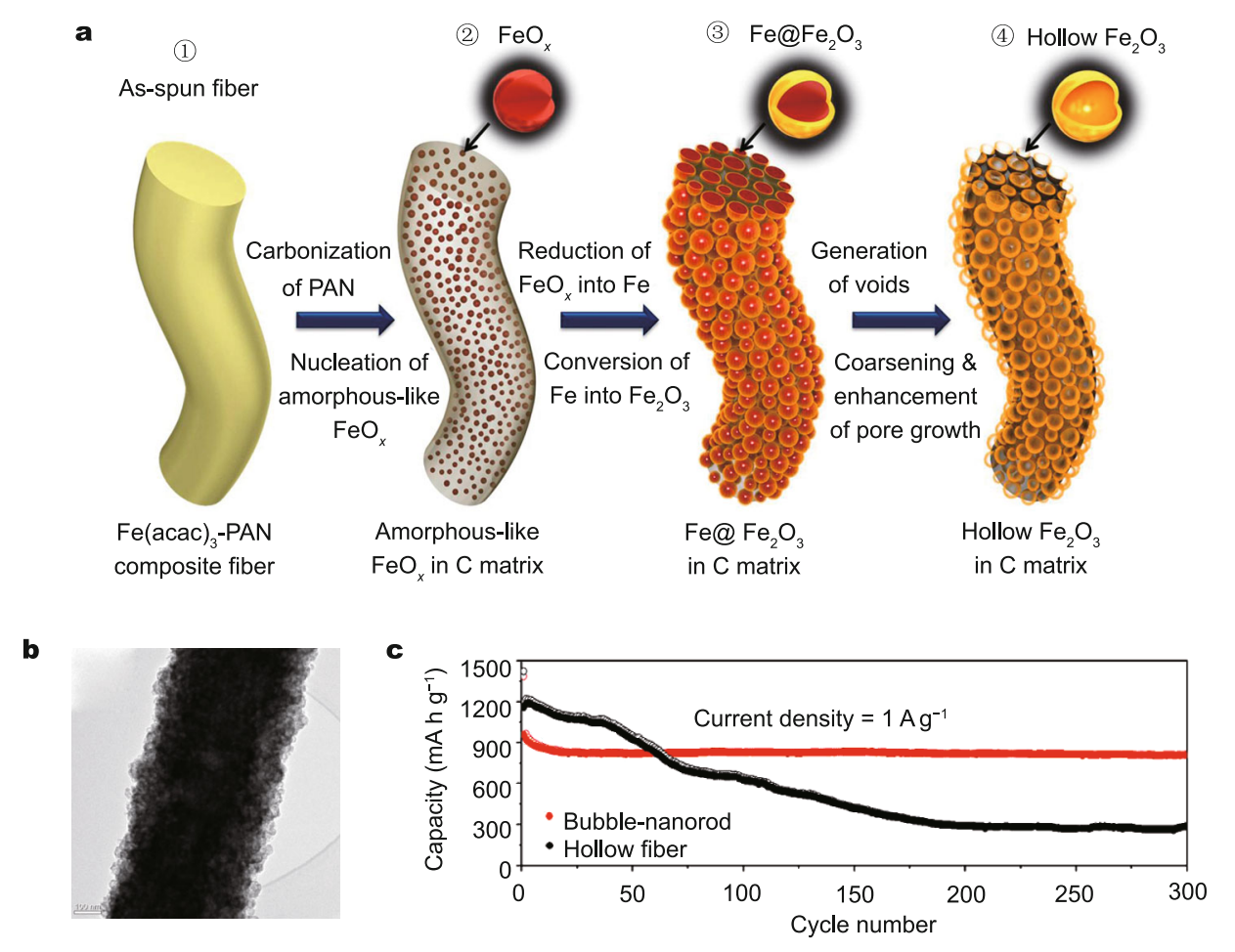

Figure 15 (a) Schematic illustration of the formation of bubble-nanorod-structured $\mathrm{Fe}_{2} \mathrm{O}_{3}$-C composite nanofibers; (b) TEM image and (c) cycle performance of $\mathrm{Fe}_{2} \mathrm{O}_{3}-\mathrm{C}$ composite nanofibers at $1 \mathrm{~A} \mathrm{~g} \mathrm{~g}^{-1}$. Reproduced with permission from Ref. [154], Copyright 2015, American Chemical Society.

one inexpensive and environmentally benign anode with high theoretical capacity. The electrochemical reaction of $\mathrm{SnO}_{2}$ with lithium is based on the conversion mechanism of $\mathrm{SnO}_{2}$ reduced to $\mathrm{Sn}$ and $\mathrm{Li}_{2} \mathrm{O}$, followed by alloying mechanism of Sn with Li. While the first step of conversion reaction is irreversible with a theoretical capacity of $\sim 780 \mathrm{~mA} \mathrm{~h} \mathrm{~g}^{-1}$ in some previous reports [162,163], several groups confirmed the reversibility of conversion reaction of $\mathrm{SnO}_{2}$ with higher theoretical capacity of $\sim 1493 \mathrm{~mA}$ $\mathrm{h} \mathrm{g}^{-1}[164,165]$. The irreversible capacity resulted from irreversible formation of $\mathrm{Li}_{2} \mathrm{O}$ and huge volume change during cycling would induce limited cycle performance of $\mathrm{SnO}_{2}$. One effective approach to modify the issues is to synthesize $1 \mathrm{D}$ porous nanomaterials to accommodate the volume variation. Hwang et al. [166] and Yang et al. [167] produced porous $\mathrm{SnO}_{2}$ nanofibers and presented enhanced cycle performance via electrospinning followed by subsequent thermal treatment. In these two works, Hwang et al. [166] reported a comprehensive study of fibrous porous $\mathrm{SnO}_{2}$ nanofibers, which were obtained by calcining the as-spun PVP- $\mathrm{SnCl}_{2} \cdot 2 \mathrm{H}_{2} \mathrm{O}$ nanofibers at $750^{\circ} \mathrm{C}$ in air. As shown in Figs $16 \mathrm{a}-\mathrm{c}$, the fabricated porous $\mathrm{SnO}_{2}$ nanofibers are composed of uniform $\mathrm{SnO}_{2}$ nanoparticles $(10-50 \mathrm{~nm})$ with numerous void spaces between the nanoparticles. Compared with the electrodes of commercial $\mathrm{SnO}_{2}$ nanoparticles, the porous $\mathrm{SnO}_{2}$ nanofibers displayed better cycle performance after 300 cycles, due to the porous structure to buffer the volume change during cycling (Fig. 16d). To further control the volume change of $\mathrm{SnO}_{2}$ during cycling, Zhao et al. [168] fabricated $\mathrm{SnO}_{2}-\mathrm{ZnO}$ composite nanofibers via electrospinning. Benefiting from the buffering effect of $\mathrm{ZnO}$ nanoparticles, the electrospun composite nanofibers showed improved cyclability and rate capacity. Moreover, graphene sheets $[169,170]$, carbon matrix [171-174] and metal nanoparticles [175] were also introduced by several groups to further stabilize the structure during cycling and improve electronic conductivity. Zhou and co-workers [176] presented hybrid nanofibers with uniformly embedded $\mathrm{SnO}_{x}$ in $\mathrm{CNFs}$ (U-SnO ${ }_{x} / \mathrm{C}$ nanofibers) as anode materials through electrospinning. $\mathrm{SnO}_{2}$ nanoparticles were dispersed in PAN/DMF solution, which was electrospun to nanofibers. As shown in Fig. 17a, the fabricated $\mathrm{U}-\mathrm{SnO}_{x} / \mathrm{C}$ nanofibers after pyrolysis showed uniform diameter of $\sim 250 \mathrm{~nm}$ with no obvious $\mathrm{SnO}_{x}$ particles. However, the $\mathrm{SnO}_{x}$ is found to be dispersed uniformly in the CNFs as shown in the STEM and corresponding elemental mapping images in Fig. 17b. Due to the novel dispersion structure, the $\mathrm{U}-\mathrm{SnO}_{x} / \mathrm{C}$ 

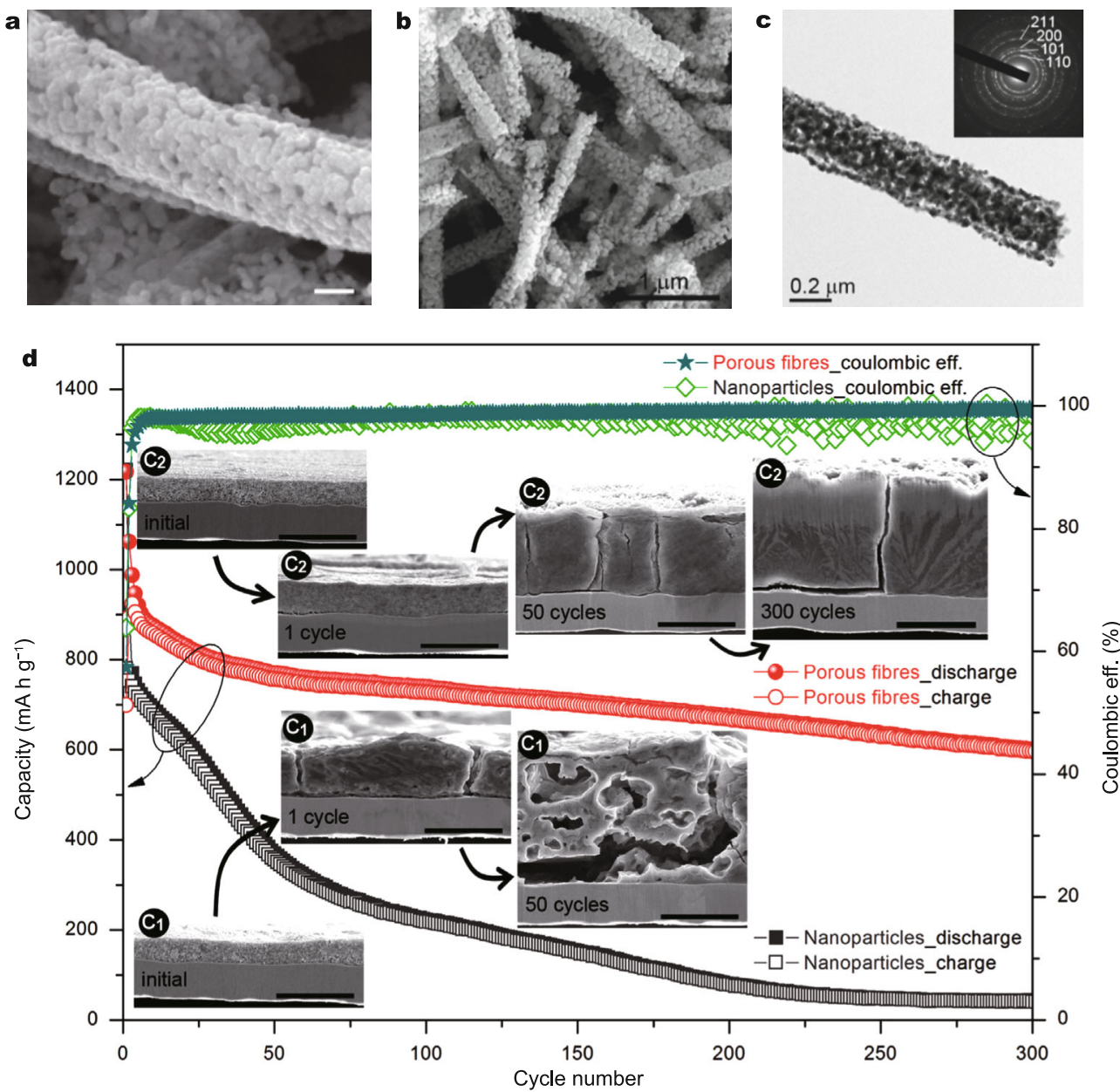

Figure 16 (a, b) SEM and (c) TEM images of porous $\mathrm{SnO}_{2}$ nanofibers; (d) cycle performance of porous $\mathrm{SnO}_{2}$ nanofibers and commercial $\mathrm{SnO} \mathrm{H}_{2}$ nanoparticles. The insert shows the cross-sectional SEM images of porous $\mathrm{SnO}_{2}$ nanofibers and commercial $\mathrm{SnO}_{2}$ nanoparticles anode before and after 1 , 50, and 300 cycles. All the scale bars indicate $20 \mu \mathrm{m}$. Reproduced with permission from Ref. [166] , Copyright 2014, Elsevier.

nanofibers displays excellent electrochemical cyclability of $608 \mathrm{~mA} \mathrm{~h} \mathrm{~g}^{-1}$ after 200 cycles at $0.5 \mathrm{~A} \mathrm{~g}^{-1}$ and rate performance of 663,518 and $365 \mathrm{~mA} \mathrm{~h} \mathrm{~g}^{-1}$ at $0.5,1$, and $2 \mathrm{~A} \mathrm{~g}^{-1}$, respectively (Figs 17c and d).

\section{Metal sulfides}

On the other hand, metal sulfides (e.g., NiS, SnS, $\mathrm{WS}_{2}$, and $\mathrm{MoS}_{2}$ ) have been extensively explored in a variety of areas, such as sensors, solar cells and LIBs. When employed as anode materials for LIBs, metal sulfides display high theoretical capacity but low conductivity and poor structural stability during cycling. To overcome these drawbacks, constructing carbon-metal sulfides hybrid materials is one general solution.

Fei et al. [177] presented a series of electrospun metal sulfide embedded in CNFs as free-standing anodes for LIBs, including $\mathrm{Cu}_{1.96} \mathrm{~S}, \mathrm{Co}_{9} \mathrm{~S}_{8}, \mathrm{MnS}, \mathrm{NiS}$ and SnS. Among them, NiS and SnS encapsulated in CNFs showed uniform nanoparticles while the others displayed aggregation tendency in CNFs. In addition, Zhao et al. [178] and Yu et al. [179] prepared electrospun $\mathrm{MoS}_{2}$ nanoflakes and $\mathrm{WS}_{2}$ nanoplates dispersed in CNFs, respectively. To further improve the structural stability and electronic conductivity, Zhi's group presented preparation of $\mathrm{SnS}_{2} @$ graphene nanocables [180] and $\mathrm{MoS}_{2} @$ graphene nanocables [181] as anode materials for LIBs. In the typical fabrication process, a PVP solution containing metal source (i.e., Sn and Mo) and tetraethylorthosilicate (TEOS) was first electrospun to form composite nanofibers. The composite nanofibers were then calcined at high temperature in methane $\left(\mathrm{CH}_{4}\right)$ to get graphene coating layers, followed by treatment with $\mathrm{H}_{2} \mathrm{~S}$ to get metal sulfides and subsequent $\mathrm{HF}$ to remove $\mathrm{SiO}_{2}$. $\mathrm{SnS}_{2}$ or $\mathrm{MoS}_{2} @$ graphene was finally obtained and delivered excellent capacity retention of over $93.5 \%$ for 

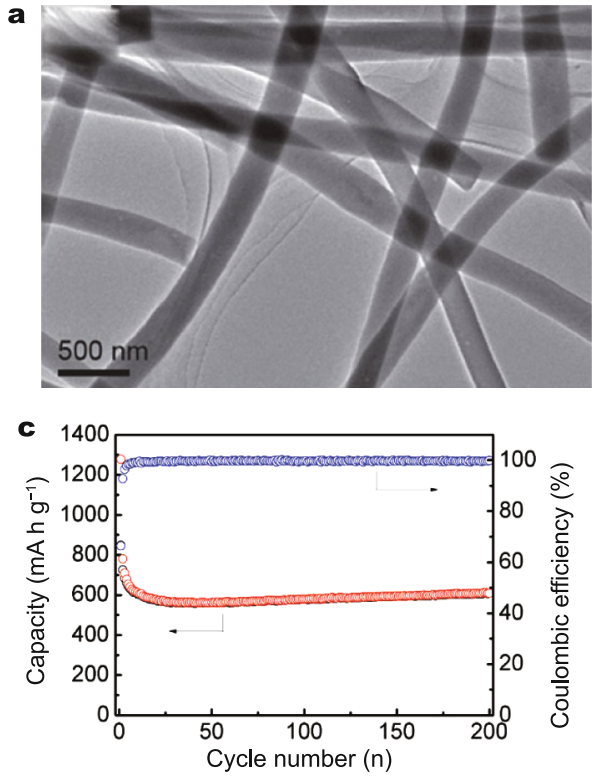

b
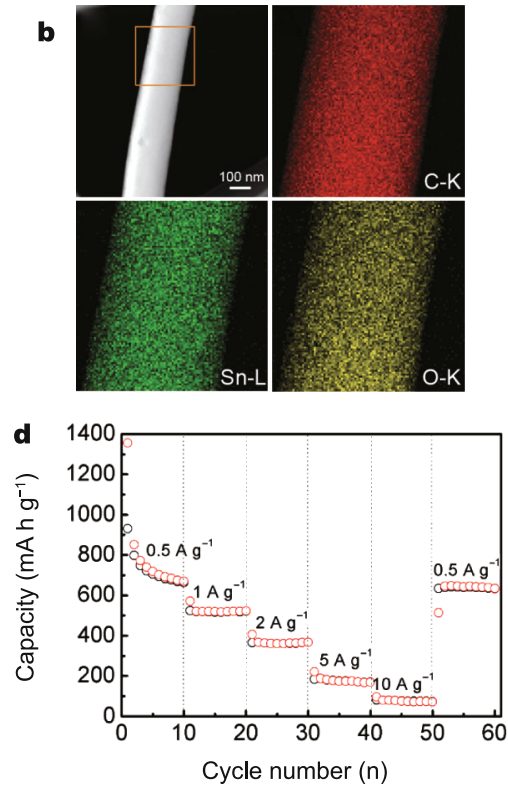

Figure 17 (a) TEM and (b) STEM \& elemental mapping images of $\mathrm{U}_{-} \mathrm{SnO}_{x} / \mathrm{C}$ nanofibers. (c) Cycle performance at $0.5 \mathrm{~A} \mathrm{~g}^{-1}$ and (d) rate performance of $\mathrm{U}-\mathrm{SnO}_{x} / \mathrm{C}$ nanofibers. Reproduced with permission from Ref. [176], Copyright 2014, Wiley.

$\mathrm{SnS}_{2} @$ graphene nanocable composite after 350 cycles and almost 100\% for SnS @ @graphene nanocable composite after 160 cycles. Different from the structure of metal sulfides encapsulated in graphene nanocables, Liu' group presented CNFs@metal sulfides (i.e., $\mathrm{MoS}_{2}[182]$ and NiS [183]) core/shell as flexible anode materials for LIBs. Liu and co-workers first fabricated electrospun PAN-derived $\mathrm{CNFs}$ as the matrix to load metal sulfides. Then the obtained flexible CNF films were anchored with $\mathrm{MoS}_{2}$ via a one-step solvothermal reaction or with $\mathrm{NiS}$ via a facile low-temperature chemical bath deposition followed by sulfidation. Here, CNFs acted as the conductive matrix to buffer volume expansion of metal sulfides during cycling, resulting in excellent cycling stability $\left(736 \mathrm{~mA} \mathrm{~h} \mathrm{~g}^{-1}\right.$ after 50 cycles at $50 \mathrm{~mA} \mathrm{~g}^{-1}$ of CNFs-MoS 2 and $1020 \mathrm{~mA} \mathrm{~h} \mathrm{~g}^{-1}$ after 100 cycles at $100 \mathrm{~mA} \mathrm{~g}^{-1}$ of CNFs-NiS).

\section{Cathode materials}

Recent development in electrospun cathode materials in LIBs focused on lithium-based transition metal oxides, transition metal oxides, and transition metal sulfides, such as $\mathrm{LiCoO}_{2}, \mathrm{LiMn}_{2} \mathrm{O}_{4}, \mathrm{LiFPO}_{4}, \mathrm{~V}_{2} \mathrm{O}_{5}$ and $\mathrm{FeS}_{x}(x=1$ or 2). Among them, $\mathrm{LiCoO}_{2}$ is one layered cathode material used in current commercial LIBs with high specific energy density. Electrospinning has been applied to fabricate 1D $\mathrm{LiCoO}_{2}$ nanowires to improve Li-ion diffusion rate in interconnected $\mathrm{LiCoO}_{2}$ nanoparticles, leading to enhanced electrochemical activity and cyclability $[184,185]$.
Additionally, Lu et al. [186] prepared electrospun $\mathrm{LiCoO}_{2}$ nanofibers coated with a lithium phosphorous oxynitride (LiPON) layer to further improve the structural stability of $\mathrm{LiCoO}_{2}$ during cycling, where the LiPON layer was applied as a solid electrolyte layer. Compared with the Li$\mathrm{CoO}_{2}$ nanofibers without LiPON layers, the LiPON coated one showed better cycle performance and rate capacity. $\mathrm{MgO}$ layer has also been confirmed to be another promising coating layer to stabilize $\mathrm{LiCoO}_{2}$ nanofibers during cycling by $\mathrm{Gu}$ and co-workers [187]. They employed the typical coaxial electrospinning strategy to fabricate $\mathrm{LiCoO}_{2}-\mathrm{MgO} /$ core-shell nanofibers, with one $\mathrm{LiCoO}_{2}$ spinnable sol and one $\mathrm{MgO}$ spinnable sol used as the inner and outer precursor solution, respectively. As shown in Figs 18a and b, the electrospun $\mathrm{LiCoO}_{2}$ nanofibers with uniform diameter of $\sim 1 \mu \mathrm{m}$ were coated by a thin $\mathrm{MgO}$ layer of around $5 \mathrm{~nm}$, presenting enhanced cyclability (Fig. 18c).

As one environmentally benign and low cost cathode material, $\mathrm{LiFePO}_{4}$ (LFP) has received much interest with high capacity and operating voltage, widely used in current commercial LIBs. To further realize higher electrochemical activity of LFP, the electronic and ionic transfer limitation should be overcomed. Electrospun CNFs, as highly conductive matrix, have been introduced to improve the electronic conductivity [188]. Dimesso and co-workers [189] fabricated 3D electrospun CNFs deposited with LFP, displaying improved cyclability and rate performance of LFP. 
a

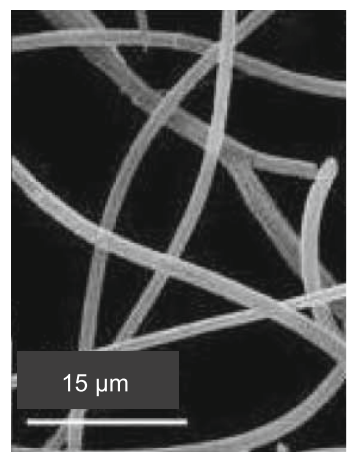

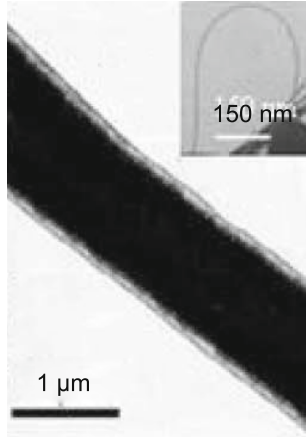

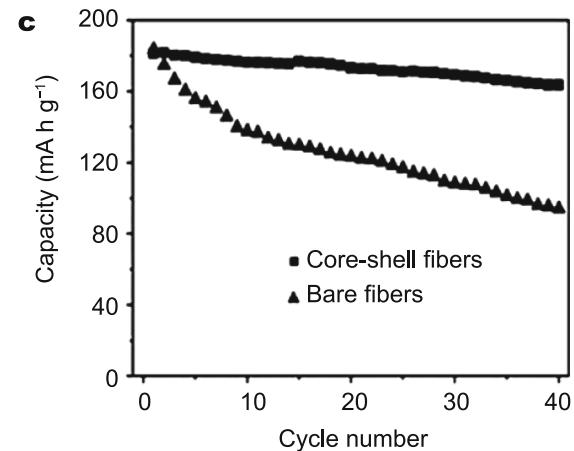

Figure 18 (a) SEM and (b) TEM images of $\mathrm{LiCoO}_{2}-\mathrm{MgO} /$ core-shell nanofibers; (c) cycle performance of bare $\mathrm{LiCoO}_{2}$ and $\mathrm{LiCoO}_{2}-\mathrm{MgO}_{\mathrm{c}}$ core-shell nanofibers. Reproduced with permission from Ref. [187], Copyright 2007, Royal Society of Chemistry.

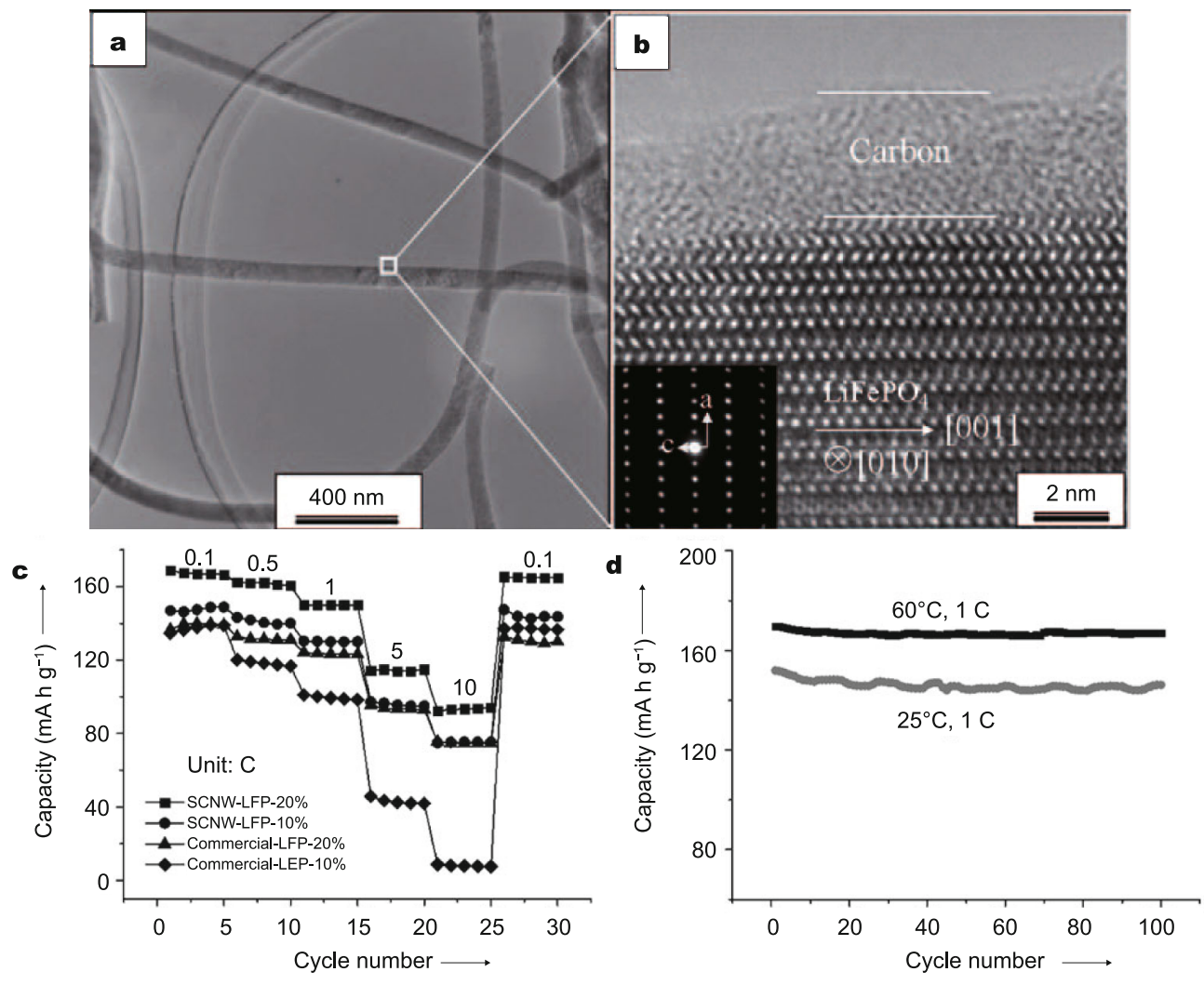

Figure 19 (a) TEM and (b) HRTEM images of carbon-coated single crystalline LFP nanowires; (c) rate performance and (d) cycle performance at 1 C of carbon-coated single crystalline LFP nanowires. Reproduced with permission from Ref. [193], Copyright 2011, Wiley.

Moreover, Toprakci et al. [190] prepared LFP nanocrystals encapsulated in CNFs via electrospinning to ensure effective electron transport paths along CNFs. To further reduce electric resistance, Toprakci et al. [191] and Hosono et al. [192] introduced CNTs into electrospun LFP/CNFs employed as one conductive additive. In addition, $\mathrm{Zhu}$ and co-workers [193] reported single-crystalline LFP nanowires (SCNW-LFP) coated by carbon layers through electrospinning. They used an aqueous $\mathrm{PEO}$ solution with $\mathrm{LiH}_{2} \mathrm{PO}_{4}$ and $\mathrm{Fe}\left(\mathrm{NO}_{3}\right)_{3}$ for electrospinning. After one pyrolysis process at $600^{\circ} \mathrm{C}$ in $\mathrm{Ar} / \mathrm{H}_{2}$, the as-spun composite nanofibers converted to carbon-coated LFP nanowires with uniform diameter of about $100 \mathrm{~nm}$. As shown in Figs 19a and b, the prepared SCNW-LFP grew along the $c$ axis, shortening the diffusion length of ions along $a$ and $b$ directions. As the ionic and electronic transfer rate along the $b$ 
direction was much faster than the $a$ and $c$ directions, fast insertion/extraction of $\mathrm{Li}$-ion was achieved in SCNW-LFP. The thin carbon layer coated on SCNW-LFP of about $~ 3$ $\mathrm{nm}$ thickness would further increase the electronic conductivity along the $3 \mathrm{D}$ interconnected structure. Owing to the benefit of the hybrid structure, the material showed excellent rate performance $(169,162,150,113$, and 93 $\mathrm{mA} \mathrm{h} \mathrm{g}^{-1}$ at $0.1,0.5,15$, and $10 \mathrm{C}$, respectively) and cycle performance at $1 \mathrm{C}$ (Figs $19 \mathrm{c}$ and $\mathrm{d}$ ).

Spinel phase $\mathrm{LiMn}_{2} \mathrm{O}_{4}$ is one promising cathode material due to high operation voltage, low cost and environmental benignity. Poor cycle life is a major issue limiting the practical applications of $\mathrm{LiMn}_{2} \mathrm{O}_{4}$. For this matter, Zhou and co-workers [194] synthesized 1D "network-like" porous $\mathrm{LiMn}_{2} \mathrm{O}_{4}$ nanowires ( $\sim 150 \mathrm{~nm}$ in diameter) via electrospinning. Compared with $\mathrm{LiMn}_{2} \mathrm{O}_{4}$ nanoparticles, the as-prepared $\mathrm{LiMn}_{2} \mathrm{O}_{4}$ nanowires presented superior cyclability and rate capability. Additionally, $\mathrm{LiMn}_{2} \mathrm{O}_{4}$ hollow nanofibers were prepared by Jayaraman et al. [195] through the electrospinning method. Owing to facile lithium diffusion along the porous hollow nanofibers, the material delivered excellent capacity retention of $87 \%$ after 1250 cycles at a current density of $1 \mathrm{C}$. Besides the aforementioned cathode materials, the electrospinning strategy has also been applied in other cathode materials to enhance the mass and charge transfer and improve cyclability and rate perfor- mance, such as $\mathrm{Li}_{3} \mathrm{~V}_{2}\left(\mathrm{PO}_{4}\right)_{3}[196,197]$ and $\mathrm{LiMnPO}_{4}$ [198].

Vanadium pentoxide $\left(\mathrm{V}_{2} \mathrm{O}_{5}\right)$ is one promising cathode material with a high theoretical capacity of $510 \mathrm{~mA} \mathrm{~h} \mathrm{~g}$ but low electron and lithium diffusion rate. 1D nanosized $\mathrm{V}_{2} \mathrm{O}_{5}$ has been proven to modify the electronic and ionic conductivity. Ban et al. [199] prepared nanostructured $\mathrm{V}_{2} \mathrm{O}_{5}$ via electrospinning and subsequent thermal treatment. With an effective protective layer on $\mathrm{V}_{2} \mathrm{O}_{5}$ formed from one electrolyte additive, lithium bis(oxalate)borate (LiBOB), the nanostructured $\mathrm{V}_{2} \mathrm{O}_{5}$ showed acceptable cyclability of $240 \mathrm{~mA} \mathrm{~h} \mathrm{~g}^{-1}$ after 25 cycles at $0.1 \mathrm{~mA} \mathrm{~cm}^{-2}$. Although the nanostructured $\mathrm{V}_{2} \mathrm{O}_{5}$ fabricated by Ban and co-workers cannot display traditional electrospun fibrous structure, their study provided potential strategies to synthesize $1 \mathrm{D}$ nanostructured $\mathrm{V}_{2} \mathrm{O}_{5}$ through electrospinning. Later, Mai et al. [200] firstly presented ultra-long hierarchical $\mathrm{V}_{2} \mathrm{O}_{5}$ nanowires synthesized by electrospinning. An aqueous solution containing PVA and $\mathrm{NH}_{4} \mathrm{VO}_{3}$ was electrospun to nanofibers, which were annealed at $480^{\circ} \mathrm{C}$ to obtain $\mathrm{V}_{2} \mathrm{O}_{5}$ nanowires. As shown in Figs 20a and b, the long $\mathrm{V}_{2} \mathrm{O}_{5}$ nanowires of diameter of 100-200 nm consist of attached nanorods (about $50 \mathrm{~nm}$ in diameter and 100 $\mathrm{nm}$ in length). Owing to high specific surface area and stable structure of the nanowires, the hierarchical $\mathrm{V}_{2} \mathrm{O}_{5}$ nanowires delivered improved capacity retention (Figs 20c and d). In addition, Wang and co-workers [201] realized
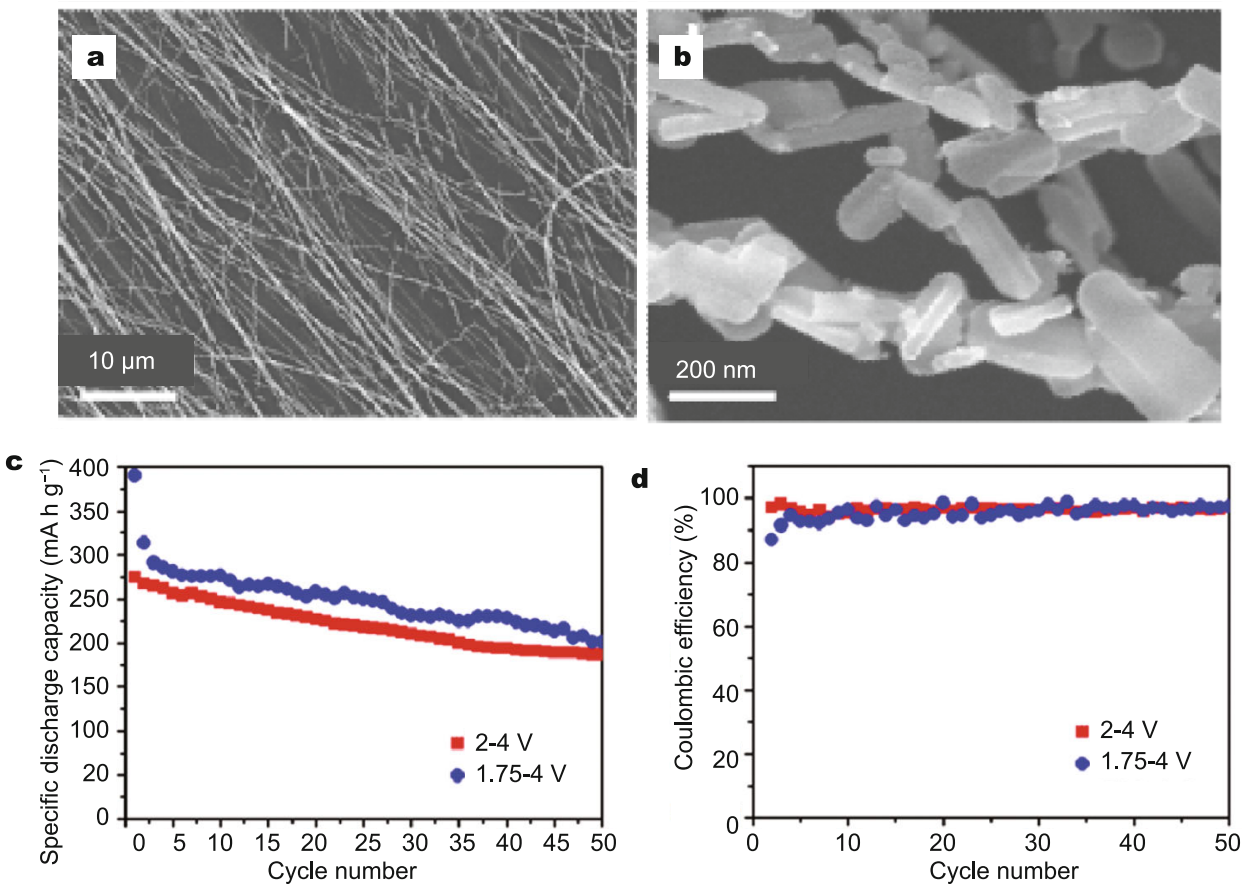

Figure 20 (a and b) SEM images of ultra-long $\mathrm{V}_{2} \mathrm{O}_{5}$ nanowires; (c) cycle performance and (d) Coulombic efficiency of $\mathrm{V}_{2} \mathrm{O}_{5}$ nanowires at a current density of $30 \mathrm{~mA} \mathrm{~g}^{-1}$. Reproduced with permission from Ref. [200], Copyright 2010, American Chemical Society. 
the morphology control of electrospun $\mathrm{V}_{2} \mathrm{O}_{5}$ nanostructures by tuning the subsequent annealing treatment. The as-spun PVP and vanadium acetylacetone composite nanofibers were firstly prepared, which were then calcined at different temperature. As shown in Fig. 21, as the annealing temperature increased, the morphology of the annealed nanofibers evolved from nanofibers to porous nanotubes, later hierarchical nanofibers, and finally into nanobelts. Employed as cathode materials for LIBs, the series of as-prepared nanostructured $\mathrm{V}_{2} \mathrm{O}_{5}$ exhibited superior cyclability, ascribed to the unique $1 \mathrm{D}$ nanostructure. Later, Cheah et al. [202] presented electrospun Al-intercalated $\mathrm{V}_{2} \mathrm{O}_{5}$ nanofibers to further stabilize the structure during cycling and Pham-Cong et al. [203] fabricated electrospun $\mathrm{V}_{2} \mathrm{O}_{5}$ nanowires and conductive graphene composites to enhance the electronic conductivity and electrochemical activity. In addition, Yan and co-workers [204] realized preparation of electrospun $\mathrm{V}_{2} \mathrm{O}_{5}$ nanofibers with superior cyclability and high rate capacity using commercial $\mathrm{V}_{2} \mathrm{O}_{5}$ through formation of $\mathrm{VOC}_{2} \mathrm{O}_{4}$ with $\mathrm{H}_{2} \mathrm{C}_{2} \mathrm{O}_{4} \cdot 2 \mathrm{H}_{2} \mathrm{O}$. Moreover, based on comprehensive electrochemical test and discussion, the authors pointed out the practical strategies to improve the electrochemical performance of $\mathrm{V}_{2} \mathrm{O}_{5}$ cathode materials for LIBs, such as increasing the electrode-electrolyte interface area, reducing the size of $\mathrm{V}_{2} \mathrm{O}_{5}$ particles and doping alien metal ions into $\mathrm{V}_{2} \mathrm{O}_{5}$ crystals to enhance the electrochemical activity.

Iron sulfides ( $\mathrm{FeS}$ and $\mathrm{FeS}_{2}$ ) have been investigated as low-cost and eco-friendly cathode materials for LIBs with high theoretical capacities (609 and $894 \mathrm{~mA} \mathrm{~h} \mathrm{~g}^{-1}$ for FeS and $\mathrm{FeS}_{2}$, respectively) [205]. However, based on the conversion mechanism, the formed $\mathrm{Li}_{2} \mathrm{~S}$ would be isolated and Fe nanoparticles would aggregate, decreasing the electrochemical activity of iron sulfides. Recently, Zhu et al. [206] fabricated FeS nanoparticles dispersed in CNF matrix as cathode for LIBs. Electrospun composite nanofibers with $\mathrm{Fe}\left(\mathrm{NO}_{3}\right)_{3}$ and PVP were firstly prepared, which were converted to $\mathrm{Fe}_{3} \mathrm{C} /$ carbon nanowires with $\mathrm{Fe}_{3} \mathrm{C}$ /graphitic carbon core-shell structure resulted from the catalytic effect of Fe. After subsequent sulfidation, FeS nanodots (5-10 nm) embedded in porous graphitic carbon nanowires $(\sim 100 \mathrm{~nm}$ in diameter) (FS-NDCPGC-NW) were finally obtained, as

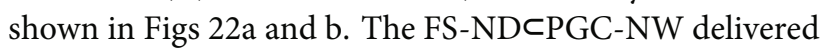
outstanding cyclability of $\sim 400 \mathrm{~mA} \mathrm{~h} \mathrm{~g}^{-1}$ after 50 cycles at $0.5 \mathrm{C}$ (Fig. 22c) and a high discharge energy density of $\sim 550$ $\mathrm{W} \mathrm{h} \mathrm{kg}$, even higher than that of $\mathrm{LiCoO}_{2}$ (Fig. 22d). Additional protective layers, for example, $\mathrm{Al}_{2} \mathrm{O}_{3}$ would further improve structural stability during cycling and finally

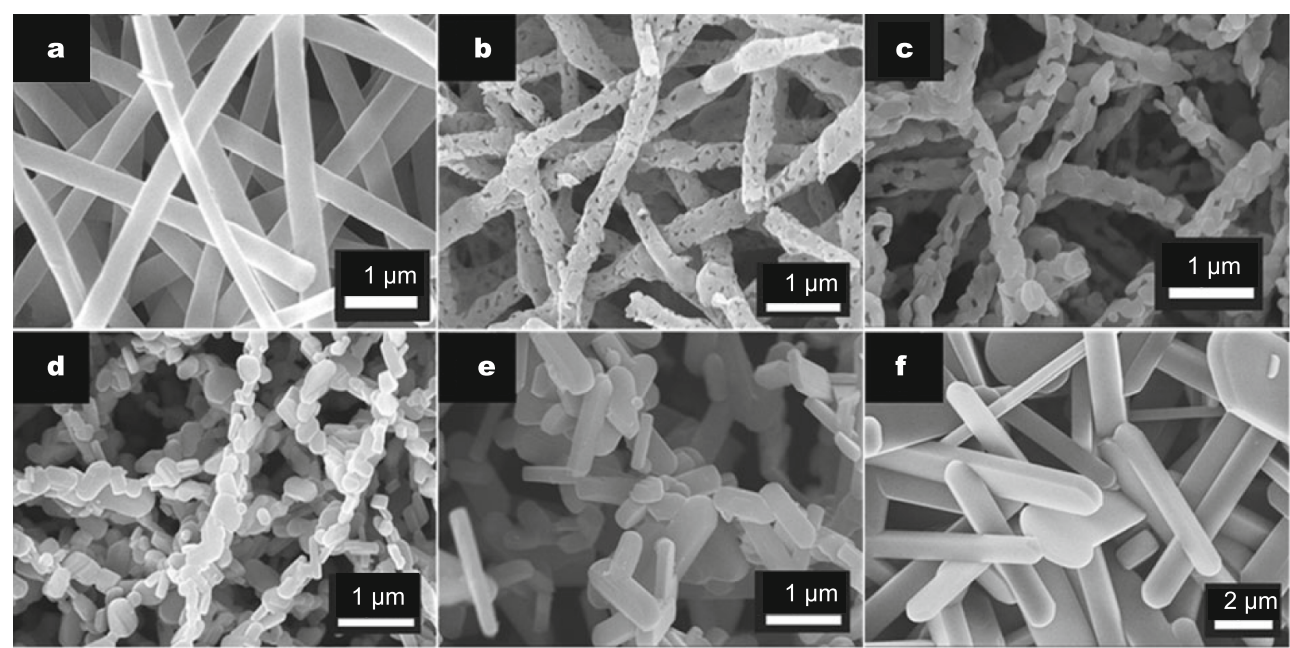

$\mathbf{9}$

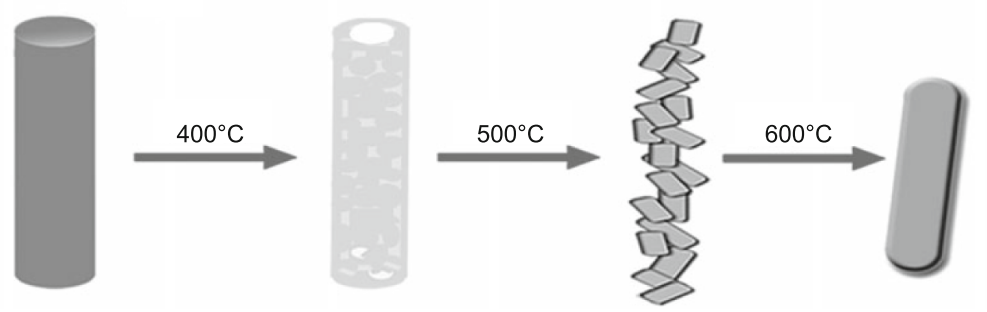

Figure 21 SEM images of nanostructured $\mathrm{V}_{2} \mathrm{O}_{5}$ annealed at (a) $350^{\circ} \mathrm{C}$, (b) $400^{\circ} \mathrm{C}$, (c) $450^{\circ} \mathrm{C}$, (d) $500^{\circ} \mathrm{C}$, (e) $550^{\circ} \mathrm{C}$ and (f) $600^{\circ} \mathrm{C}$. (g) The transformation of nanostructured $\mathrm{V}_{2} \mathrm{O}_{5}$ with the increase of annealing temperature. Reproduced with permission from Ref. [201], Copyright 2012, Wiley. 

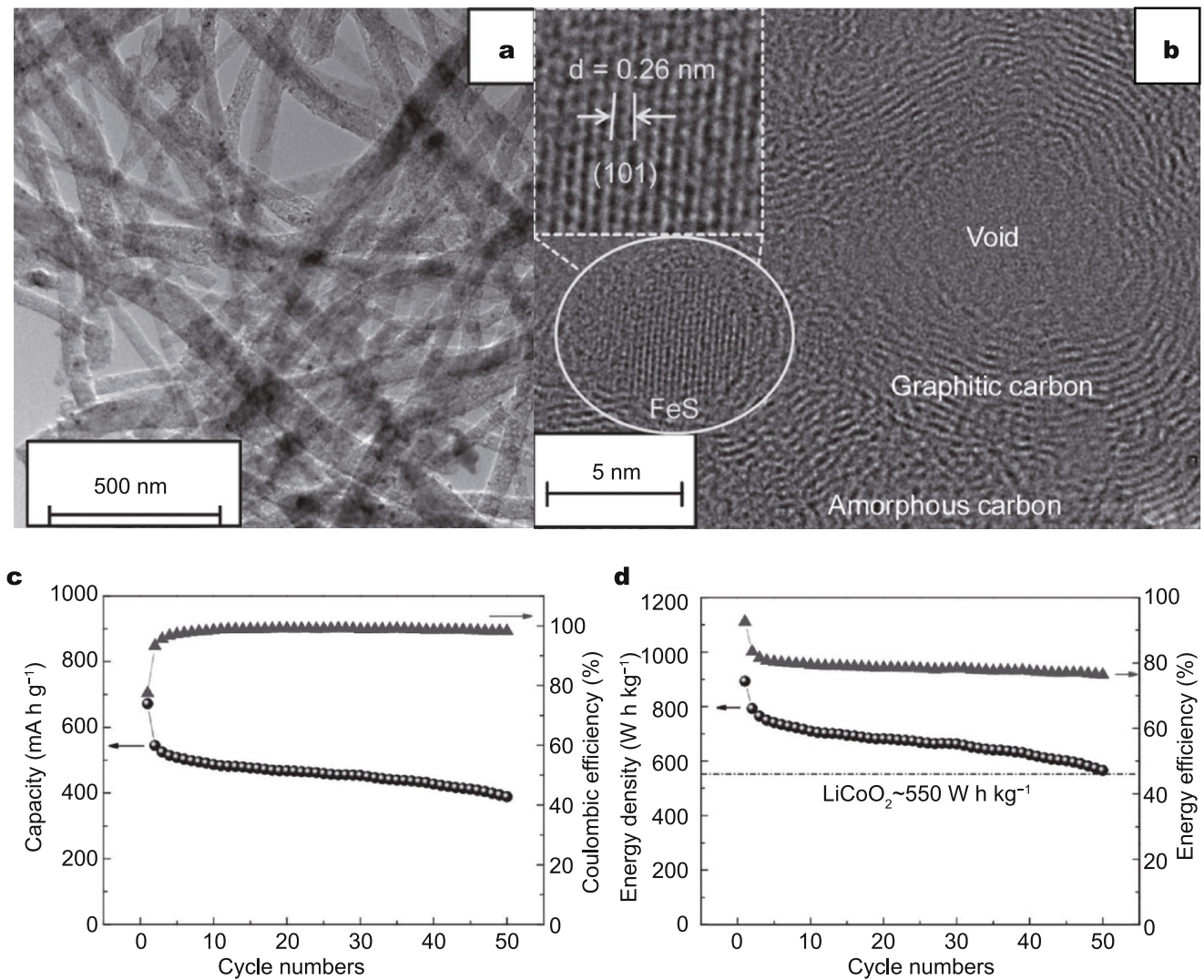

Figure 22 (a) TEM and (b) HRTEM images of FS- NDCPGC-NW; (c) cycle performance and Coulombic efficiency and (d) discharge energy density

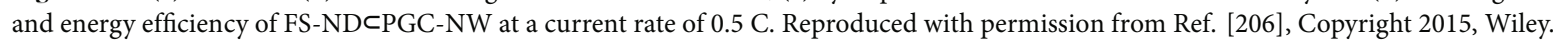

maintain electrochemical performance. Recently, Zhu et al. [207] synthesized $\mathrm{Al}_{2} \mathrm{O}_{3}$-coated $\mathrm{FeS}_{2} @ \mathrm{CNFs}$ by combining electrospinning and an atomic layer deposition (ALD). Through the ALD strategy, the as-synthesized FeS $2 @ \mathrm{CNFs}$ were uniformly coated with $\mathrm{Al}_{2} \mathrm{O}_{3}$ layers $(\sim 5 \mathrm{~nm})$. Compared with the composite nanofibers without $\mathrm{Al}_{2} \mathrm{O}_{3}$ coating layers, the $\mathrm{Al}_{2} \mathrm{O}_{3}$ coated one showed better electrochemical performance at one wide voltage range $(1.0-3.0 \mathrm{~V} v \mathrm{~s}$. $\mathrm{Li} / \mathrm{Li}^{+}$), owing to the protective effect of $\mathrm{Al}_{2} \mathrm{O}_{3}$ layers for mechanical degradation.

\section{ELECTROSPUN ELECTRODE MATERIALS IN SODIUM-ION BATTERIES}

NIBs have become one of the most promising alternative for LIBs, especially applied in large-scale electric energy storage systems, ascribed to low-cost and abundant resource. While NIBs display similar reaction mechanism compared with LIBs, the larger ionic radius of sodium leads to sluggish kinetics during cycling. Therefore, it is crucial to design and prepare electrode materials with reasonable structures to enhance the electrochemical activity of electrode materials for NIBs. Recently, electrospun 1D electrode materials have presented improved electrochemical performance in NIBs owing to the enhanced effect ascribed to $1 \mathrm{D}$ nanomaterials.

\section{Anode materials}

Graphite is one traditional carbonaceous anode materials applied in LIBs with a theoretical capacity of $372 \mathrm{~mA} \mathrm{~h} \mathrm{~g}^{-1}$ and excellent cyclability. However, the discordance of graphite layer distance $\left(d_{(002)}=0.334 \mathrm{~nm}\right)$ and the larger ionic radius of Sodiun result in poor $\mathrm{Na}$-ion storage performance of graphite. Hence, the recent research on carbonaceous anode materials for NIBs focuses on disorder porous carbon with various $\mathrm{Na}$-ion storage sites. Among them, 3D interconnected electrospun CNFs have gained great interest applied as anode materials for NIBs due to excellent cyclability and rate capability. Chen et al. [208] presented improved Na-ion storage performance of electrospun PAN-derived CNFs. Later, Jin et al. [209] studied the influence of carbonization temperature on the electrochemical performance of electrospun PAN-derived CNFs, figuring out that the different carbonization temperature 
leaded to different porous structure and sodium storage capacity. In this work, $1250^{\circ} \mathrm{C}$ was the ideal temperature to get the highest capacity. To further improve the capacity of CNFs, nitrogen-doping and porous structure were applied to increase the sodium storage sites [210-212]. Li et al. [213] fabricated flexible electrospun PAN-derived PCNFs (Fig. 23a) by utilizing one triblock copolymer F127 as one soft template to create micropores in CNFs. As shown in Fig. 23b, the as-fabricated PCNFs displayed uniform diameter of $\sim 280 \mathrm{~nm}$ and plenty of micropores. When used as anode materials for NIBs, PCNFs delivered improved capability of $266 \mathrm{~mA} \mathrm{~h} \mathrm{~g}^{-1}$ after 100 cycles at $0.2 \mathrm{C}$, excellent ultra-long cycle life of $71.5 \%$ capacity retention after 1000 cycles at $2 \mathrm{C}$ (Fig. 23c) and impressive rate capability of 90 and $40 \mathrm{~mA} \mathrm{~h} \mathrm{~g}^{-1}$ at 5 and $20 \mathrm{~A} \mathrm{~g}^{-1}$, respectively (Fig. 23d). The excellent electrochemical performance of PCNFs is ascribed to enhanced electronic conductivity from the $3 \mathrm{D}$ interconnected conductive network and increased Na-ion storage sites from a plenty of micropores.

Alloy-based anode materials include Si, Ge, Sn, Sb, which are based on alloying/de-alloying reaction with Na-ion during cycling [214-217]. As Si and Ge presented limited $\mathrm{Na}$-ion storage capacity ascribed to the sluggish kinetics of electrochemical reaction, the recent study of anode materials for NIBs mainly focus on $\mathrm{Sb}$ and $\mathrm{Sn}$. Zhu and co-workers [218] synthesized Sb nanoparticles (NPs) embedded in 3D interconnected CNFs (SbNP@C) as free-standing anode for NIBs via a facile electrospinning strategy. As shown in Figs 24a and b, $230 \mathrm{~nm}$ Sb NPs was homogeneously dispersed in the 1D CNFs (about $400 \mathrm{~nm}$ in diameter), showing highly stable cycle performance of $422 \mathrm{~mA} \mathrm{~h} \mathrm{~g}^{-1}$ after 300 cycles at $0.1 \mathrm{~A} \mathrm{~g}^{-1}$ (Fig. 24c). Moreover, the SbNP@C maintained enhanced rate capability at higher current densities (Fig. 24d). Almost at the same time, Wu et al. [219] presented similar result of Sb-C nanofibers as anode for NIBs. Similar to the encapsulation structure in $\mathrm{Sb}-\mathrm{C}$ nanofibers, the improved sodium-storage performance was realized in electrospun Sn NPs embedded in PCNF composites fabricated by Xu et al. [220] and electrospun SnSb NPs embedded in CNF
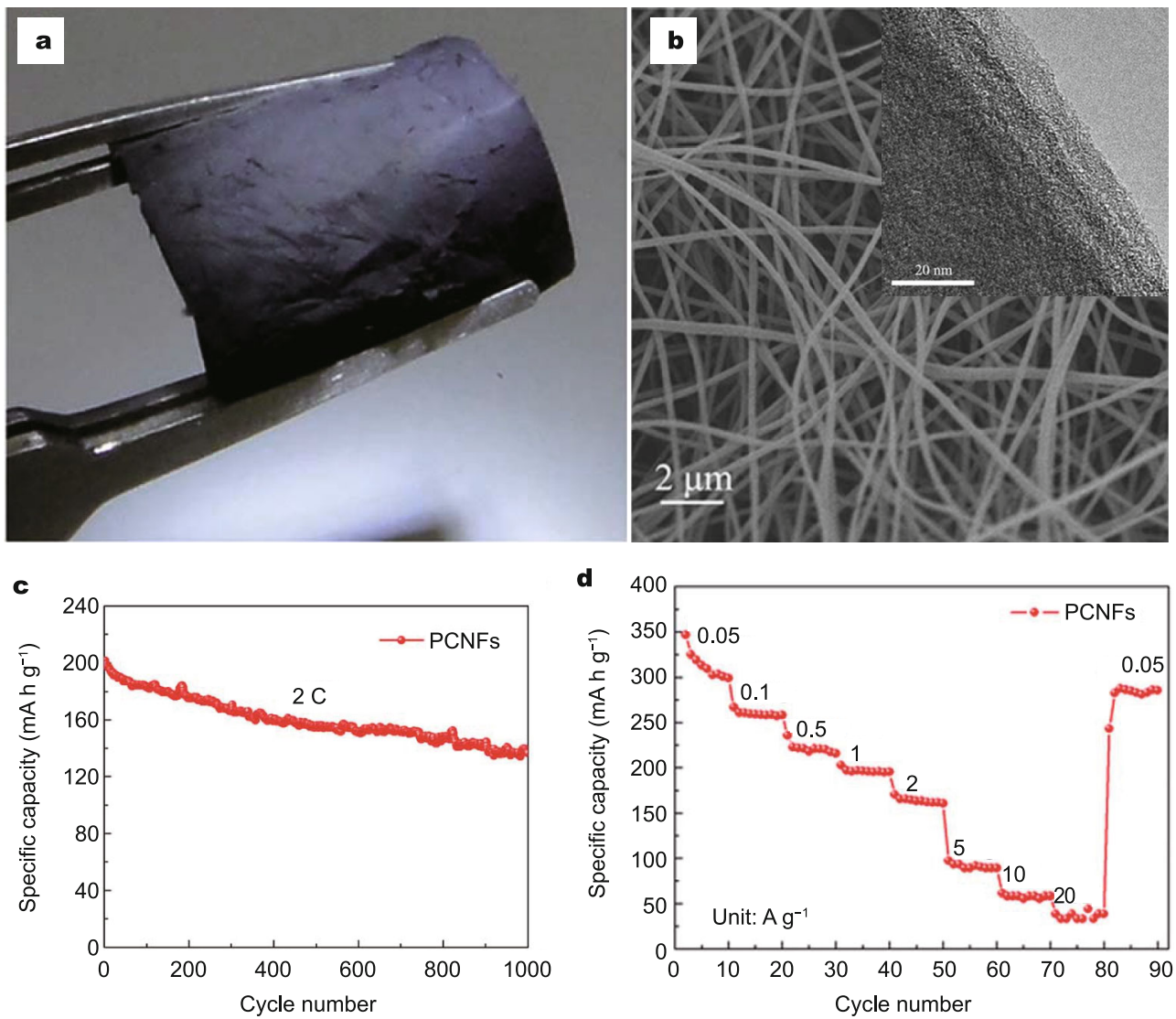

Figure 23 (a) Digital photograph and (b) SEM image of free-standing and flexible PCNF film, the insert in (b) is the HRTEM image of PCNFs. (c) Cycle performance at $2 \mathrm{C}\left(500 \mathrm{~mA} \mathrm{~g}^{-1}\right)$ and (d) rate performance of PCNFs. Reproduced with permission from Ref. [213], Copyright 2014, Royal Society of Chemistry. 
a

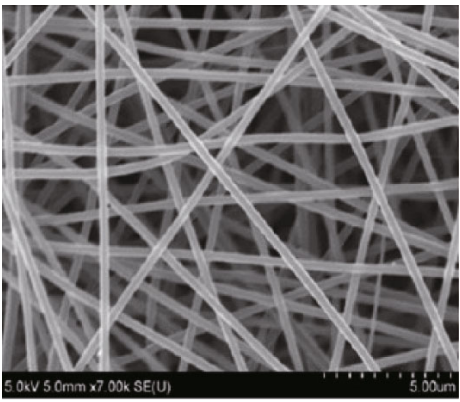

c

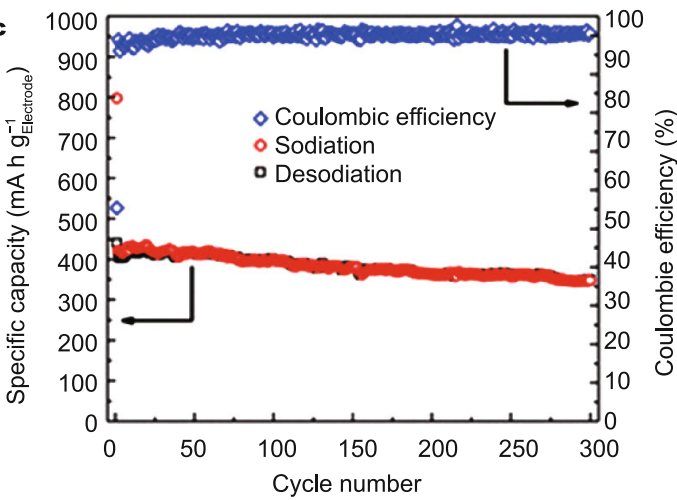

b

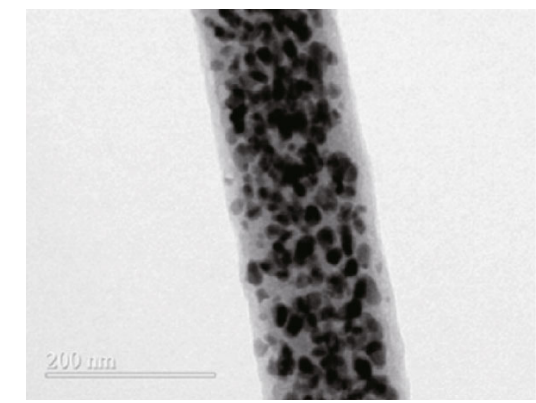

d

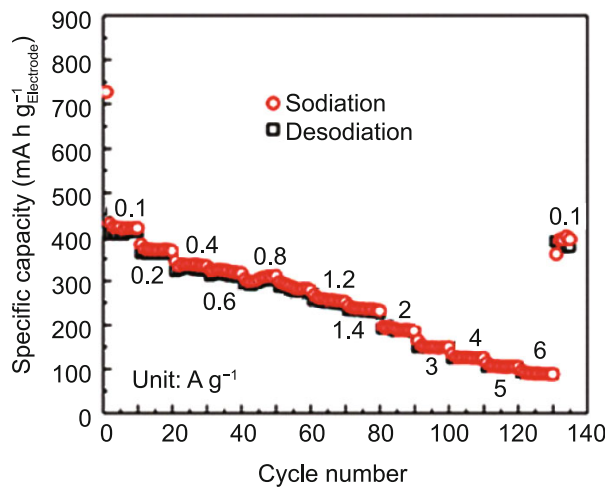

Figure 24 (a) SEM and (b) TEM images of electrospun SbNP@C nanofibers; (c) cycle performance at 0.1 A g $\mathrm{g}^{-1}$ and (d) rate performance of SbNP@C. Reproduced with permission from Ref. [218], Copyright 2013, American Chemical Society.

composites by Shiva et al. [221] and Ji et al. [222].

As for electrospun metal oxide electrode materials in NIBs, only several reports presented electrochemical performance about $\mathrm{Li}_{4} \mathrm{Ti}_{5} \mathrm{O}_{12}, \mathrm{TiO}_{2}$, and $\mathrm{SnO}_{2}$. $\mathrm{Liu}$ et al. [223] presented tiny $\mathrm{Li}_{4} \mathrm{Ti}_{5} \mathrm{O}_{12}$ nanoparticles encapsulated in CNFs $\left(\mathrm{Li}_{4} \mathrm{Ti}_{5} \mathrm{O}_{12} @ \mathrm{C}\right)$ as anode materials for NIBs. As shown in Figs 25a and b, tiny and dense $\mathrm{Li}_{4} \mathrm{Ti}_{5} \mathrm{O}_{12}$ nanoparticles were embedded in the conductive 1D CNFs, contributing to improved cyclability and rate capability. $\mathrm{Li}_{4} \mathrm{Ti}_{5} \mathrm{O}_{12} @ \mathrm{C}$ delivered a high initial capacity of $183 \mathrm{~mA} \mathrm{~h} \mathrm{~g}^{-1}$ with a high capacity retention of $82 \%$ after 100 cycles at a current density of $0.2 \mathrm{C}$ (Fig. 25c). When cycled at higher current densities, $\mathrm{Li}_{4} \mathrm{Ti}_{5} \mathrm{O}_{12} @ \mathrm{C}$ presented a reversible capacity as high as $72 \mathrm{~mA} \mathrm{~h} \mathrm{~g}^{-1}$ at $2 \mathrm{C}$ (Fig. 25d). Afterwards, Wang and co-workers [224] fabricated CNT-enhanced $\mathrm{Li}_{4} \mathrm{Ti}_{5} \mathrm{O}_{12} @ \mathrm{CNF}$ as free-standing anode for NIBs with promoted electronic conductivity and rate performance. Similarly, Zhang's group [225] fabricated electrospun nanocrystalline $\mathrm{TiO}_{2} @ \mathrm{CNF}$ with good electrochemical activity. Various metal oxides widely applied in LIBs have not been extensively reported in NIBs, for example, $\mathrm{SnO}_{2}$, possibly due to the severer volume change and depressed kinetics in NIBs. Recently, Dirican and co-workers [226] fabricated hierarchical carbon-confined $\mathrm{SnO}_{2}$ electrodeposited PCNFs (PCNF@SnO $\left.{ }_{2} @ \mathrm{C}\right)$. Owing to the interconnecting conductive PCNFs as matrix and CVD carbon layer on the surface of $\mathrm{SnO}_{2}$ to accommodate the volume change, impressive cyclability was obtained for the PCNF@SnO ${ }_{2} @ \mathrm{C}$ composite.

On the other hand, metal sulfides have got tremendous attention as anode materials for NIBs due to high capacity, such as $\mathrm{SnS}_{2}$ [227], SnS [228], $\mathrm{Sb}_{2} \mathrm{~S}_{3}$ [229] and $\mathrm{MoS}_{2}$ [230]. Recently, Zhu et al. [231] fabricated single-layered $\mathrm{MoS}_{2}$ nanoplates embedded in $\mathrm{CNF}$ s via electrospinning. Interestingly, the as-prepared CNFs were very thin, around 50 $\mathrm{nm}$ in diameter (Figs 26a and b) with uniformly dispersed single-layered $\mathrm{MoS}_{2}$ nanoplates $(0.4 \mathrm{~nm}$ in thickness, 4.0 $\mathrm{nm}$ in lateral dimension) (Figs 26c and d). As shown in Fig. 26e, the ultra-small single layered $\mathrm{MoS}_{2}$ nanoplates and conductive CNF matrix would not only alleviate the mechanical stress resulted from the volume change during cycling but also promote electronic and ionic transfer. When tested as anode for NIBs, the composite nanofibers delivered excellent rate capability of $854,700,623,436$, and $331 \mathrm{~mA} \mathrm{~h} \mathrm{~g}^{-1}$ at high current densities of $0.1,0.5,1,5$ and $10 \mathrm{~A} \mathrm{~g}^{-1}$, respectively (Fig. 26f) and impressive cyclability of $484 \mathrm{~mA} \mathrm{~h} \mathrm{~g}^{-1}$ after 100 cycles at $1 \mathrm{~A} \mathrm{~g}^{-1}$ (Fig. 26g). Moreover, considering the structural stability of electrodes during cycling, Ryu and co-workers [232] used ALD method to coat $\mathrm{TiO}_{2}$ layers on the electrospun $\mathrm{MoS}_{2}$ nanofiber elec- 
a
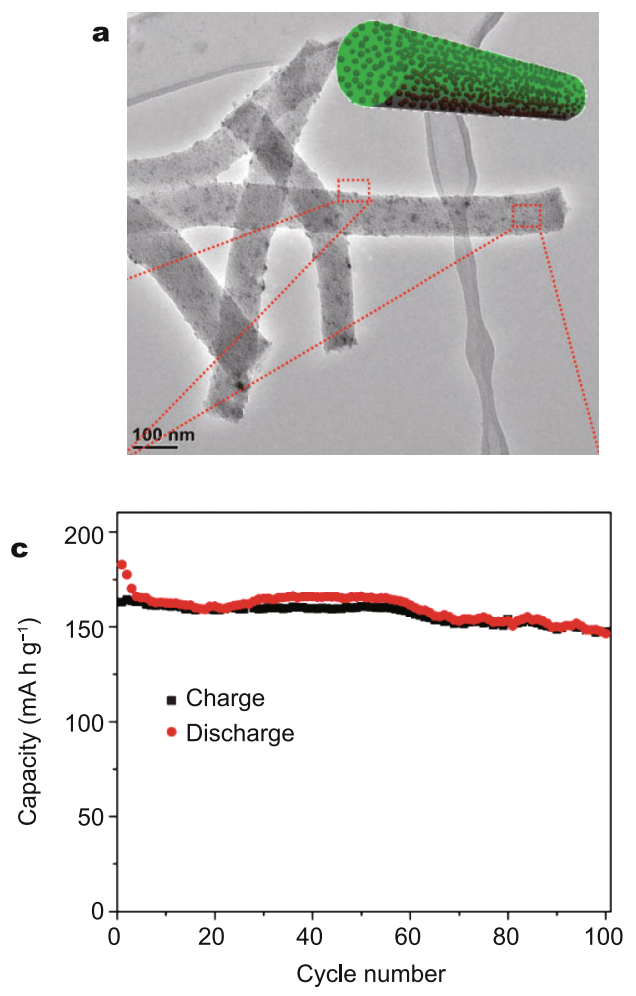

b
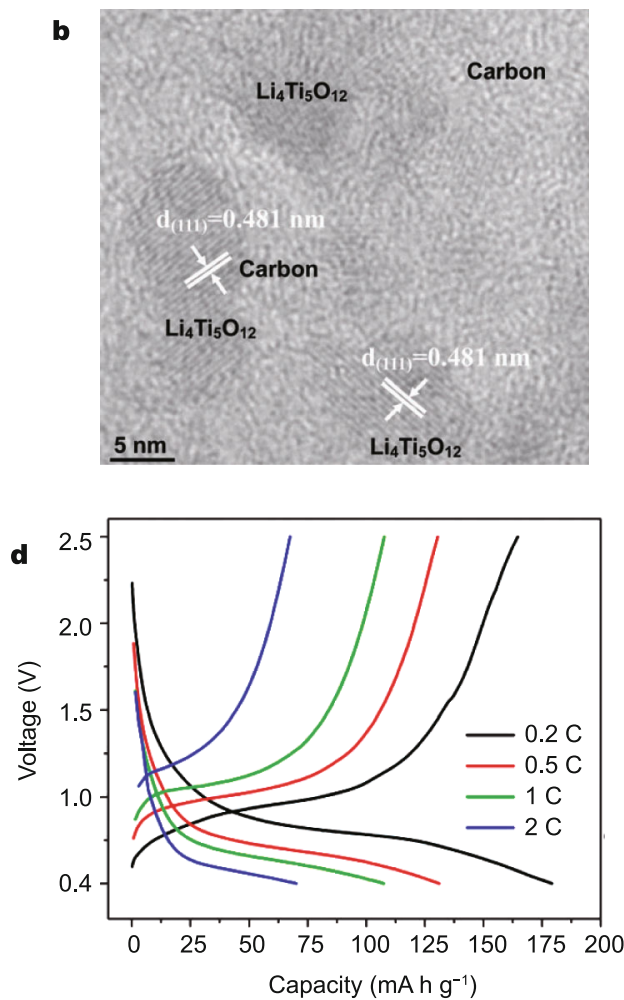

Figure 25 (a) TEM and (b) HRTEM images of electrospun $\mathrm{Li}_{4} \mathrm{Ti}_{5} \mathrm{O}_{12} @ \mathrm{C}$ nanofibers; (c) cycle performance at $0.2 \mathrm{C}$ and (d) rate performance of $\mathrm{Li}_{4} \mathrm{Ti}_{5} \mathrm{O}_{12} @ \mathrm{C}$. Reproduced with permission from Ref. [223], Copyright 2013, Royal Society of Chemistry.
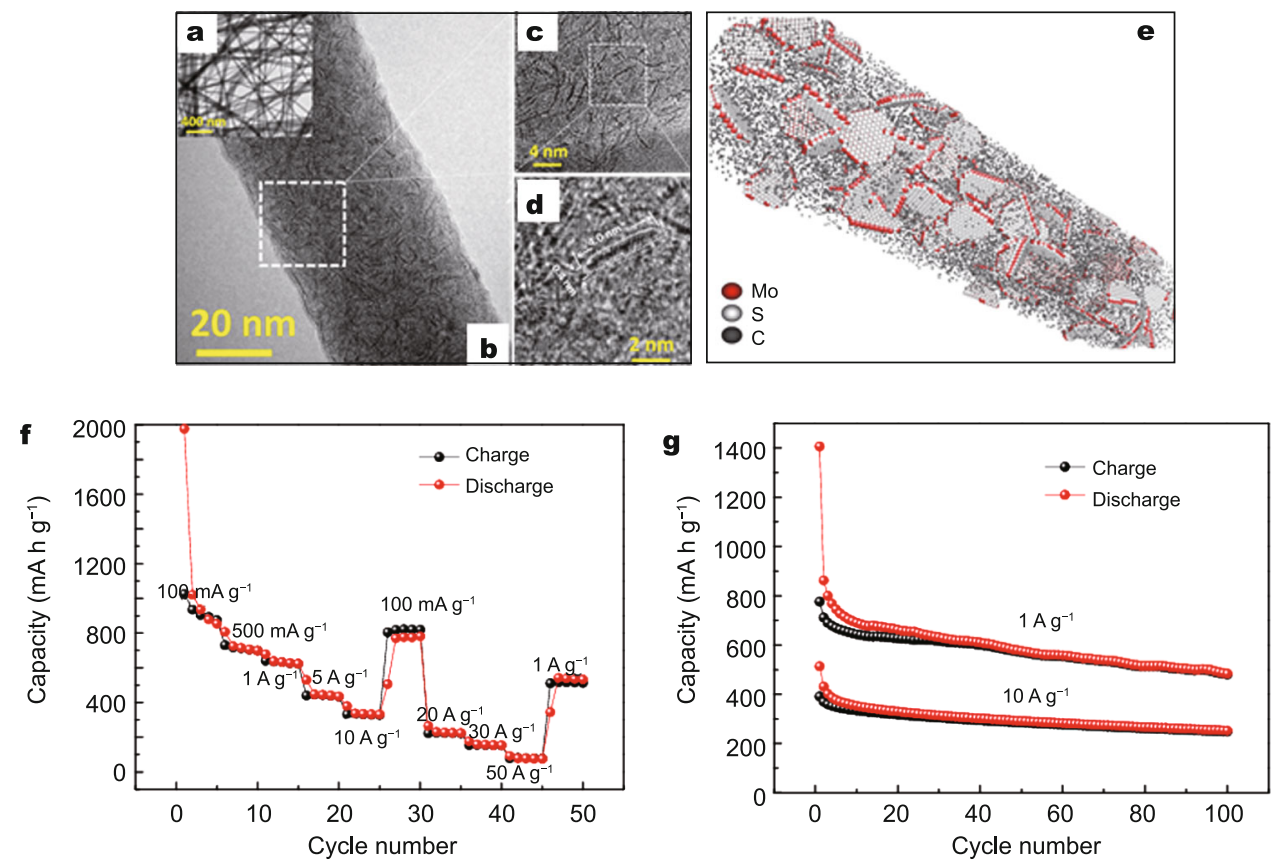

Figure 26 (a-c) TEM and (d) HRTEM images of single-layered $\mathrm{MoS}_{2}$ nanoplates embedded in CNFs. (e) Schematic representation based on TEM modeling studies to demonstrate the unique morphology of the composite nanofibers. (f) Rate performance and ( $\mathrm{g}$ ) cycle performance of single-layered $\mathrm{MoS}_{2}$ nanoplates embedded in CNFs at 1 and $10 \mathrm{~A} \mathrm{~g}^{-1}$. Reproduced with permission from Ref. [231], Copyright 2014, Wiley. 
trodes to enhance the cycling stability. Compared with the $\mathrm{MoS}_{2}$ nanofibers electrodes without coating layers, the one with $\mathrm{TiO}_{2}$ layers presented a promoted cyclability.

\section{Cathode materials}

Sodium super ionic conductor (NASICON)-type materials have been investigated as promising cathode materials for NIBs, due to native excellent $\mathrm{Na}$-ion conductivity, for example, $\mathrm{Na}_{3} \mathrm{~V}_{2}\left(\mathrm{PO}_{4}\right)_{3}$. However, the high electrical resistance prevents $\mathrm{Na}_{3} \mathrm{~V}_{2}\left(\mathrm{PO}_{4}\right)_{3}$ from presenting ideal electrochemical performance. Decreasing the size of $\mathrm{Na}_{3} \mathrm{~V}_{2}\left(\mathrm{PO}_{4}\right)_{3}$ and fabricating $\mathrm{Na}_{3} \mathrm{~V}_{2}\left(\mathrm{PO}_{4}\right)_{3}$-carbon composites would improve the electronic transfer in $\mathrm{Na}_{3} \mathrm{~V}_{2}\left(\mathrm{PO}_{4}\right)_{3}$ and finally maintain excellent cyclability. Liu and co-workers [233] prepared a electrospun $\mathrm{Na}_{3} \mathrm{~V}_{2}\left(\mathrm{PO}_{4}\right)_{3} / \mathrm{C}$ composite as cathode for NIBs with enhanced cycle performance and rate capability. As shown in Figs $27 \mathrm{a}$ and $\mathrm{b}, \mathrm{Na}_{3} \mathrm{~V}_{2}\left(\mathrm{PO}_{4}\right)_{3}$ nanoparticles (diameter ca. $20-30 \mathrm{~nm}$ ) were embedded in interconnecting conductive CNFs (diameter ca. $\sim 250 \mathrm{~nm}$ ). As a result, the as-fabricated $\mathrm{Na}_{3} \mathrm{~V}_{2}\left(\mathrm{PO}_{4}\right)_{3} / \mathrm{C}$ showed a high reversible capacity of $117 \mathrm{~mA} \mathrm{~h} \mathrm{~g}^{-1}$ at a current density of $0.1 \mathrm{C}$ and retained improved rate capacities at higher current densities (Figs 27c and d). Similar electrospun $\mathrm{Na}_{3} \mathrm{~V}_{2}\left(\mathrm{PO}_{4}\right)_{3} / \mathrm{C}$ composites have also been presented by other groups but with worse cyclability and rate perfor- mance [234,235].

In addition, other lithium-metal-oxides or sodiummetal-oxides have been studied as cathode for NIBs. Dou's group presented electrospun $\mathrm{Li}_{1+x}\left(\mathrm{Mn}_{1 / 3} \mathrm{Ni}_{1 / 3} \mathrm{Fe}_{1 / 3}\right) \mathrm{O}_{2}$ [236] and P2-type $\mathrm{Na}_{2 / 3}\left(\mathrm{Fe}_{1 / 2} \mathrm{Mn}_{1 / 2}\right) \mathrm{O}_{2}$ [237] hierarchical nanofibers as cathode materials for NIBs. Compared with nanoparticles, these nanofibers showed improved cyclability due to enhanced charge transfer along the nanofibers and higher specific surface area of nanofibers. Moreover, Niu and co-workers [238] presented one facile strategy to fabricate mesoporous nanotubes via a gradient electrospinning and controlled pyrolysis process and enhanced the $\mathrm{Na}$-ion storage performance of $\mathrm{Na}_{0.7} \mathrm{Fe}_{0.7} \mathrm{Mn}_{0.3} \mathrm{O}_{2}$ mesoporous nanotubes. The formation of mesoporous nanotubes is based on the gradient of distribution of low-/middle-/high-molecular-weight PVA during electrospinning. As shown in Fig. 28a, the precursor solution containing the mixed gradient PVA and precursor inorganic materials for $\mathrm{Na}_{0.7} \mathrm{Fe}_{0.7} \mathrm{Mn}_{0.3} \mathrm{O}_{2}$ was firstly electrospun to nanofibers. During the process, the higher-molecular-weight PVA and the smaller-molecular-weight PVA would be distributed in the outer and inner layer due to the different viscosity. Afterwards, based on different carbonization mechanism, the PVA of smaller-molecular-weight in the inner layer would be firstly pyrolyzed and move to the PVA of higher-
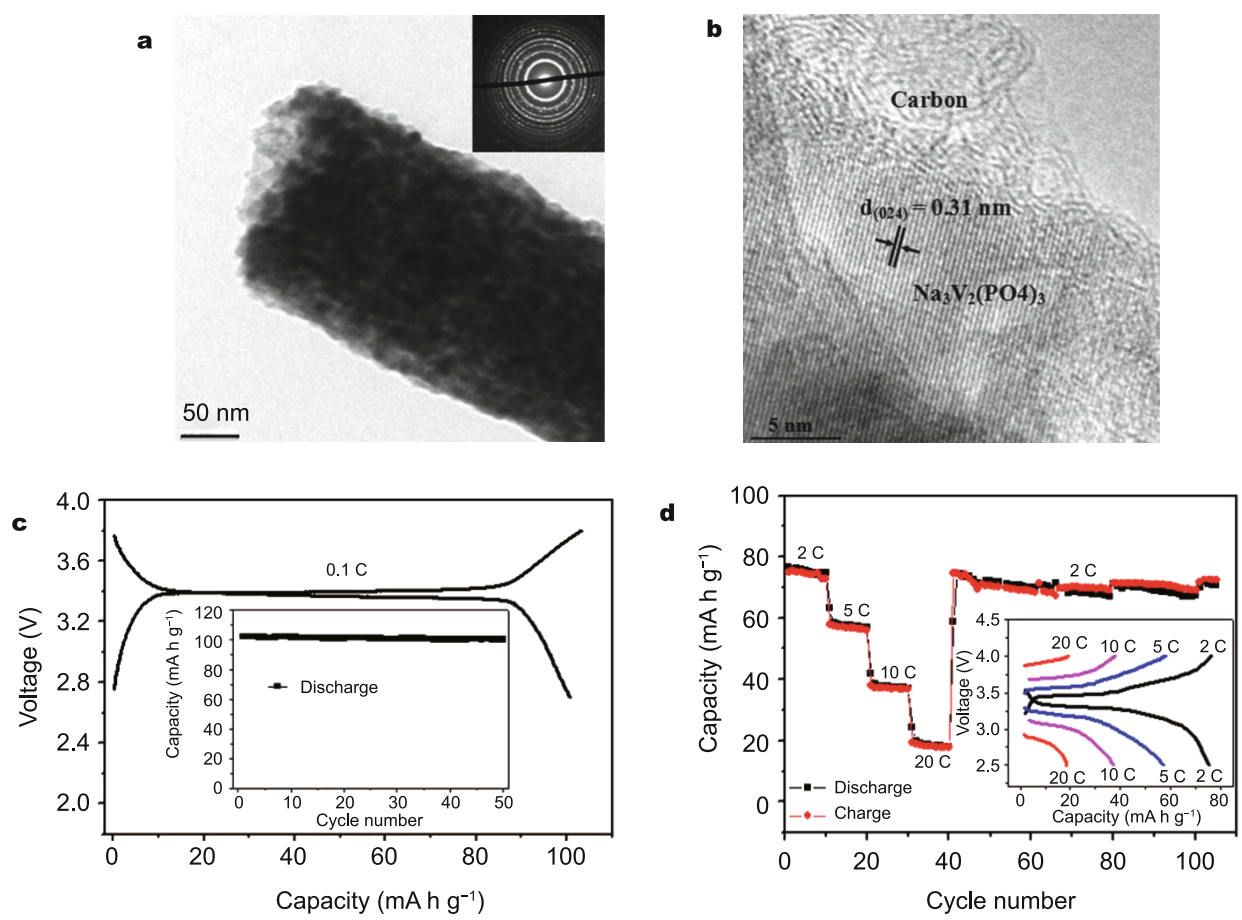

Figure 27 (a) TEM and (b) HRTEM images of the hierarchical $\mathrm{Na}_{3} \mathrm{~V}_{2}\left(\mathrm{PO}_{4}\right)_{3} / \mathrm{C}$ composite. (c) Cycle performance at $0.1 \mathrm{C}$ and (d) rate performance of $\mathrm{Na}_{3} \mathrm{~V}_{2}\left(\mathrm{PO}_{4}\right)_{3} / \mathrm{C}$. Reproduced with permission from Ref. [233] , Copyright 2014, Royal Society of Chemistry. 


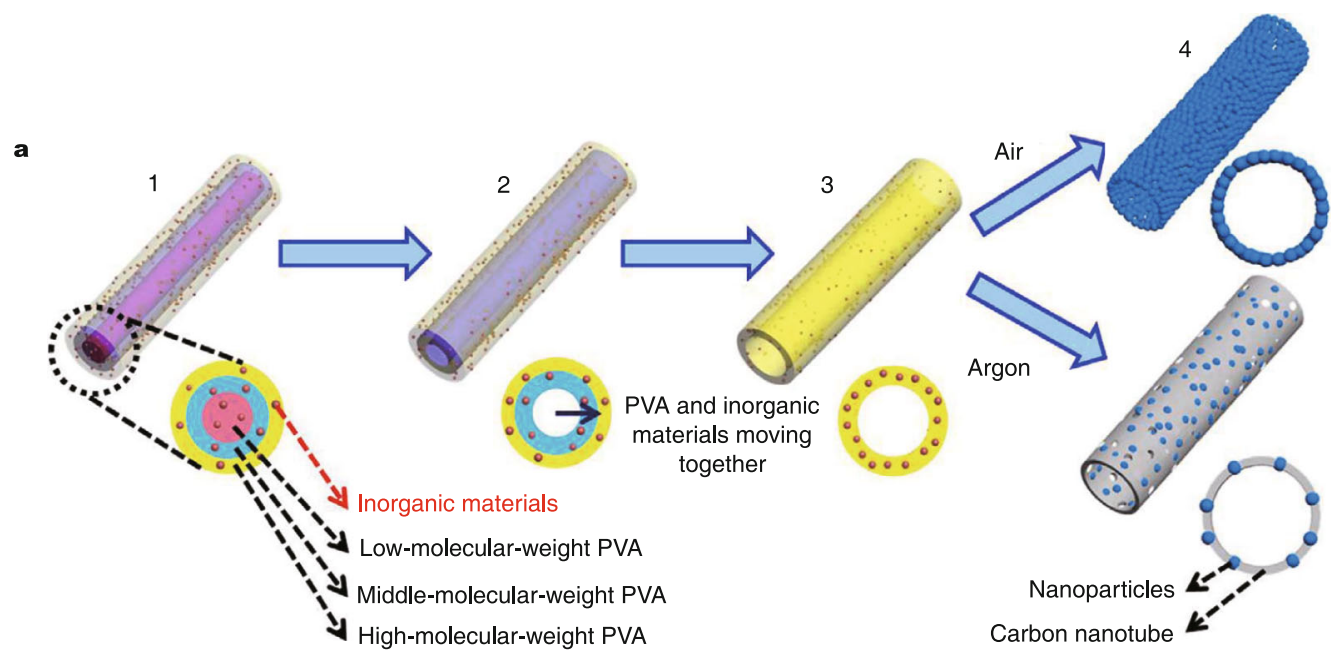

b

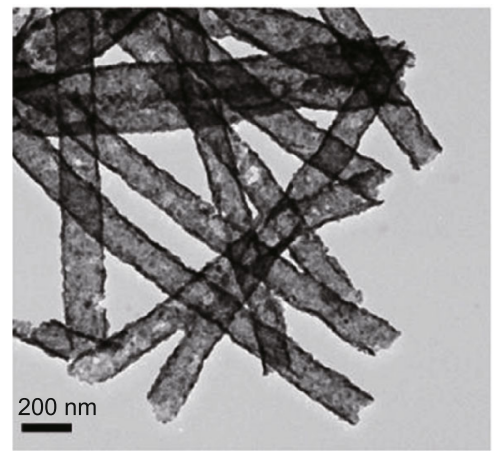

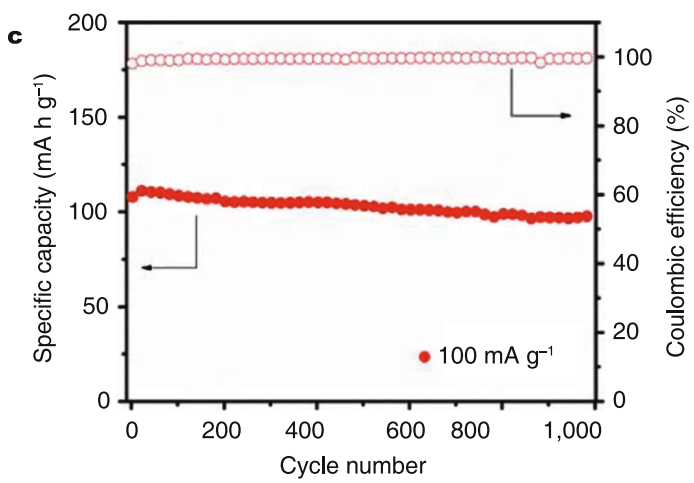

d

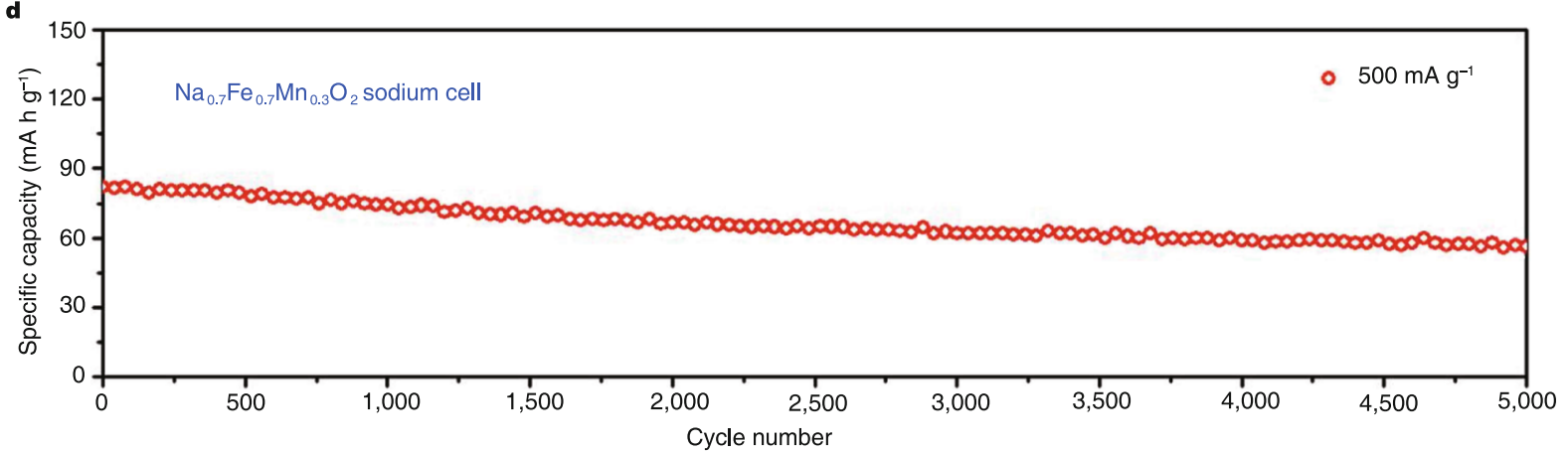

Figure 28 (a) Schematics of the controlled pyrolysis method to prepare mesoporous nanotubes; (b) $\mathrm{TEM}$ image of the $\mathrm{Na}_{0.7} \mathrm{Fe}_{0.7} \mathrm{Mn}_{0.3} \mathrm{O}_{2} \mathrm{mesoporous}$ nanotubes; (c and d) cycle performances of the $\mathrm{Na}_{0.7} \mathrm{Fe}_{0.7} \mathrm{Mn}_{0.3} \mathrm{O}_{2}$ mesoporous nanotubes at $100 \mathrm{~mA} \mathrm{~g}$ (c) and $500 \mathrm{~mA} \mathrm{~g}$ (d). Reproduced with permission from Ref. [238], Copyright 2015, Nature Publishing Group.

molecular-weight, finally forming nanotubes. As shown in Fig. 28b, the as-fabricated $\mathrm{Na}_{0.7} \mathrm{Fe}_{0.7} \mathrm{Mn}_{0.3} \mathrm{O}_{2}$ nanotubes displays $\mathrm{Na}_{0.7} \mathrm{Fe}_{0.7} \mathrm{Mn}_{0.3} \mathrm{O}_{2}$ nanoparticles $(\sim 10 \mathrm{~nm})$ encapsulated in ultrathin CNTs (diameter ca. $200 \mathrm{~nm}$ ). Owing to the unique structure, excellent cyclability was obtained when cycled at $100 \mathrm{~mA} \mathrm{~g}^{-1}$ (90\% retention of the initial capacity after 1000 cycles) and $500 \mathrm{~mA} \mathrm{~g}^{-1}$ (80\% retention of the initial capacity after 5000 cycles) (Figs $28 \mathrm{c}$ and d).

\section{ELECTROSPUN ELECTRODE NANOMATERIALS BEYOND LITHIUM-ION/SODIUM-ION BATTERIES}

Besides LIBs and NIBs, lithium-sulfur (Li-S) batteries have been considered as next-generation energy storage systems, due to high theoretical volumetric energy density of $2200 \mathrm{~W} \mathrm{~h} \mathrm{~L}^{-1}$ [239]. However, the practical applications of $S$ cathode are hindered by the native electrical insulation 
of $\mathrm{S}$, the volume change during cycling and the dissolution issue of high-order lithium polysulfides. Up to date, various electrospun nanofibers-S composite cathodes have been prepared to address these matters. Numerous PCNFs [240-245] have been reported to be effective matrixes to load sulfur to enhance the electronic conductivity, and confine the volume change and dissolution of lithium polysulfides. Li and co-workers [246] fabricated a pie-like freestanding sulfur cathode by combining interconnected ethylenediamine-functionalized reduced graphene oxide (EFG) layer with sulfur loaded electrospun multichannel CNFs. Due to the nano-confinement and enhanced electron/ion transfer of multichannel CNFs on sulfur and accommodating effect of EFG layer on migrating polysulfide intermediates, the electrode showed remarkable improvement on electrochemical performance and energy density. In addition, Yao et al. [247] prepared tin-doped indium oxide nanoparticles (ITO) decorated by CNFs to realize spatially controlled deposition of polysulfides on the surface to enhance the cyclability of sulfur. The fabricated conductive ITO nanoparticles on the surface of CNFs would adsorb polysulfides owing to a strong bonding intercalation between ITO with $\mathrm{Li}_{x} \mathrm{~S}$. Benefiting from the adsorption effect for polysulfides, the S-ITO-CNFs delivered a high capacity of above $1000 \mathrm{~mA} \mathrm{~h} \mathrm{~g}$ after
300 cycles at 0.2 C. Similar to the bonding intercalation between ITO with $\mathrm{Li}_{x} \mathrm{~S}$, Zeng and co-workers [248] fabricated copper-stabilized sulfur-CNFs as flexible cathode for Li-S batteries. The $\mathrm{Cu}$ embedded in the CNFs would form a strong bond with $S$, leading to suppression of the shuttle phenomena of polysulfides and excellent cycle performance of $680 \mathrm{~mA} \mathrm{~h} \mathrm{~g}$ after 100 cycles at a current density of $50 \mathrm{~mA} \mathrm{~g}^{-1}$. Moreover, Ma et al. [249] prepared electrospun $\mathrm{TiO}_{2}$ nanofibers/S composite and obtained enhanced cycle performance, owing to the adsorption of $\mathrm{Li}_{x} \mathrm{~S}$ by $\mathrm{TiO}_{2}$.

On the other hand, selenium (Se), one congener of sulfur, shows a high theoretical volumetric capacity density of $3253 \mathrm{~mA} \mathrm{~h} \mathrm{~cm}^{-3}$, comparable to that of $\mathrm{S}\left(3467 \mathrm{~mA} \mathrm{~h} \mathrm{~cm}^{-3}\right)$ and higher electronic conductivity than S [250]. However, the similar dissolution of lithium selenides results in poor cycle performance of Se. To address the issue, Zeng and co-workers [251] prepared CNFs with micropores, which would accommodate $\mathrm{Se}$ and restrain the dissolution of selenides. As shown in Figs 29a and b, Se was encapsulated in microporous CNFs with uniform diameter of $\sim 250 \mathrm{~nm}$. The encapsulation situation of Se in microporous CNFs was confirmed by Raman spectra in Fig. 29c, remarkably decreased and blue shifted peak of Se in Se@PCNFs. Due to the confined Se nanoparticles in 3D interconnected con- a

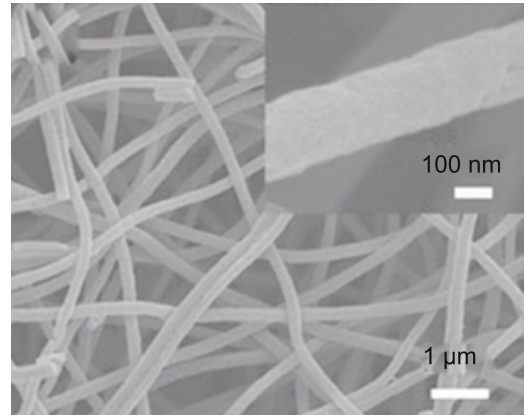

b
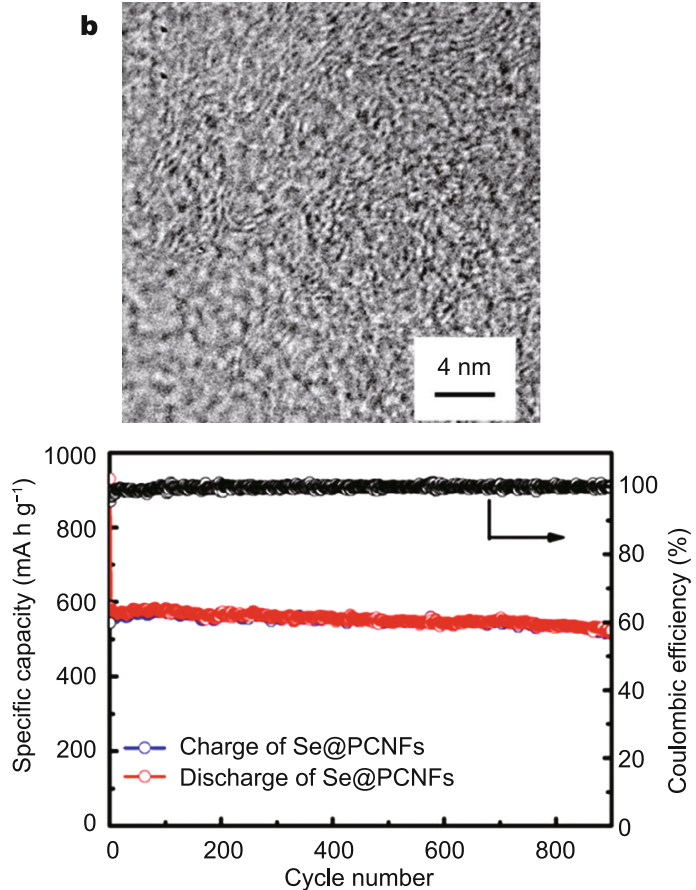

Figure 29 (a) SEM and (b) HRTEM images of Se@PCNFs; (c) Raman spectra of Se@PCNFs and Se; (d) cycle performance of Se@PCNFs at a current density of $500 \mathrm{~mA} \mathrm{~g}^{-1}$. Reproduced with permission from Ref. [251] , Copyright 2015, Wiley. 
ductive microporous CNFs, Se@PCNFs exhibited excellent cycle performance of $516 \mathrm{~mA} \mathrm{~h} \mathrm{~g}^{-1}$ after 900 cycles at a current density of $500 \mathrm{~mA} \mathrm{~g}^{-1}$.

\section{CONCLUSIONS AND PERSPECTIVE}

In this review, we summarized almost all the progress in electrospun electrode nanomaterials for LIBs and NIBs and briefly introduced the recent development in cathode materials for Li-S and Li-Se batteries. Moreover, this review focuses on the evolution in structures and constitution of electrospun electrode materials. By summarizing the development of electrospun electrode materials, the electrospinning strategy shows various distinctive advantages in preparation of electrode materials: a) controllability of electrospinning process. These related parameters of electrospinning strategy are facile to be tuned to match the needs for different electrode materials; b) diversity of post-treatments. It is convenient to produce materials with hybrid structures via proper post-treatment strategie; c) 3D interconnected nanofibers structures. The obtained electrospun electrode materials tend to form 3D interconnected networks, which would enhance electrochemical activity of electrode materials via facilitating electronic/ionic transfer.

Currently, the development of the electrospinning technique focuses on structure evolution of electrospun nanofibers in the aspect of science and large-scale production of electrospun nanofibers in the aspect of engineering. Researchers have been designing and fabricating electrospun nanofibers with controlled micro-structures via adjusting parameters of electrospinning. On the other hand, fabrication rate and cost are main concerns for the large-scale production. Industry-grade electrospinning machines have been fabricated via multi-spinnerets and non-needle electrospinning systems. Through increasing production rate and decreasing production time, the cost would be reduced accordingly. Owing to the rapid development in electrospinning, numerous electrospun electrode materials showed excellent electrochemical performance and hold great promise for practical application in commercial LIBs and for substantial progress in NIBs, Li-S batteries and other energy-related fields in the future.

Received 24 March 2016; accepted 22 April 2016;

published online 29 April 2016

1 Winter M, Brodd RJ. What are batteries, fuel cells, and supercapacitors? Chem Rev, 2004, 104: 4245-4270

2 Scrosati B. Battery technology-challenge of portable power. Nature, 1995, 373: 557-558

3 Nelson RF. Power requirements for batteries in hybrid electric vehi- cles. J power Sources, 2000, 91: 2-26

4 Jiang C, Hosono E, Zhou H. Nanomaterials for lithium ion batteries. Nano Today, 2006, 1: 28-33

5 Hong SY, Kim Y, Park Y, et al. Charge carriers in rechargeable batteries: Na ions vs. Li ions. Energy Environ Sci, 2013, 6: 2067-2081

6 Slater MD, Kim D, Lee E, Johnson CS. Sodium-ion batteries. Adv Funct Mater, 2013, 23: 947-958

7 Kim SW, Seo DH, Ma X, et al. Electrode materials for rechargeable sodium-ion batteries: potential alternatives to current lithium-ion batteries. Adv Energy Mater, 2012, 2: 710-721

8 Chevrier VL, Ceder G. Challenges for Na-ion negative electrodes. Electrode Materials for rechargeable sodium-ion batteries: potential alternatives to current lithium-ion batteries. J Electrochem Soc, 2011, 158: A1011-A1014

9 Goodenough JB. Evolution of strategies for modern rechargeable batteries. Acc Chem Res, 2012, 46: 1053-1061

10 Han MH, Gonzalo E, Singh G, Rojo T. A comprehensive review of sodium layered oxides: powerful cathodes for Na-ion batteries. Energy Environ Sci, 2015, 8: 81-102

11 Pan H, Hu YS, Chen L. Room-temperature stationary sodium-ion batteries for large-scale electric energy storage. Energy Environ Sci, 2013, 6: 2338-2360

12 Yabuuchi N, Kubota K, Dahbi M, Komaba S. Research development on sodium-ion batteries. Chem Rev, 2014, 114: 11636-11682

13 Dunn B, Kamath H, Tarascon JM. Electrical energy storage for the grid: a battery of choices. Science, 2011, 334: 928-935

14 Yilmaz M, Krein PT. Review of battery charger topologies, charging power levels, and infrastructure for plug-in electric and hybrid vehicles. IEEE Trans Power Electron, 2013, 28: 2151-2169

15 Malhotra A, Battke B, Beuse M, et al. Use cases for stationary battery technologies: a review of the literature and existing projects. Renew Sust Energy Rev, 2016, 56: 705-721

16 Guo YG, Hu JS, Wan LJ. Nanostructured materials for electrochemical energy conversion and storage devices. Adv Mater, 2008, 20: 2878-2887

17 Zhang Q, Uchaker E, Candelaria SL, Cao G. Nanomaterials for energy conversion and storage. Chem Soc Rev, 2013, 42: 3127-3171

18 Liu D, Cao G. Engineering nanostructured electrodes and fabrication of film electrodes for efficient lithium ion intercalation. Energy Environ Sci, 2010, 3: 1218-1237

19 Scrosati B, Garche J. Lithium batteries: status, prospects and future. J Power Sources, 2010, 195: 2419-2430

20 Chan CK, Peng H, Liu G, et al. High-performance lithium battery anodes using silicon nanowires. Nat Nanotechnol, 2008, 3: 31-35

21 Liu B, Zhang J, Wang X, et al. Hierarchical three-dimensional $\mathrm{ZnCo}_{2} \mathrm{O}_{4}$ nanowire arrays/carbon cloth anodes for a novel class of high-performance flexible lithium-ion batteries. Nano Lett, 2012, 12: $3005-3011$

22 Hosono E, Kudo T, Honma I, et al. Synthesis of single crystalline spinel $\mathrm{LiMn}_{2} \mathrm{O}_{4}$ nanowires for a lithium ion battery with high power density. Nano Lett, 2009, 9: 1045-1051

23 Kim H, Son Y, Park C, et al. Catalyst-free direct growth of a single to a few layers of graphene on a germanium nanowire for the anode material of a lithium battery. Angew Chem, 2013, 125: 6113-6117

24 Cao Y, Xiao L, Sushko ML, et al. Sodium ion insertion in hollow carbon nanowires for battery applications. Nano lett, 2012, 12: 3783-3787

25 Liu J, Song K, van Aken PA, et al. Self-supported $\mathrm{Li}_{4} \mathrm{Ti}_{5} \mathrm{O}_{12}-\mathrm{C}$ nanotube arrays as high-rate and long-life anode materials for flexible Li-ion batteries. Nano lett, 2014, 14: 2597-2603

26 Liu J, Song K, Zhu C, et al. Ge/C nanowires as high-capacity and 
long-life anode materials for Li-ion batteries. ACS Nano, 2014, 8: 7051-7059

27 Cao Y, Xiao L, Wang W, et al. Reversible sodium ion insertion in single crystalline manganese oxide nanowires with long cycle life. Adv Mater, 2011, 23: 3155-3160

28 Liao JY, Higgins D, Lui G, et al. Multifunctional $\mathrm{TiO}_{2}-\mathrm{C} / \mathrm{MnO}_{2}$ coredouble-shell nanowire arrays as high-performance 3D electrodes for lithium ion batteries. Nano lett, 2013, 13: 5467-5473

$29 \mathrm{He} \mathrm{H}$, Jin $\mathrm{G}$, Wang $\mathrm{H}$, et al. Annealed $\mathrm{NaV}_{3} \mathrm{O}_{8}$ nanowires with good cycling stability as a novel cathode for $\mathrm{Na}$-ion batteries. J Mater Chem A, 2014, 2: 3563-3570

30 Ding YL, Wen $\mathrm{Y}$, Wu C, et al. 3D V $\mathrm{V}_{13}$ Nanotextiles assembled from interconnected nanogrooves as cathode materials for high-energy lithium ion batteries. Nano Lett, 2015, 15: 1388-1394

31 Cui LF, Yang Y, Hsu CM, Cui Y. Carbon-silicon core-shell nanowires as high capacity electrode for lithium ion batteries. Nano Lett, 2009 9: 3370-3374

32 Chan CK, Zhang XF, Cui Y. High capacity Li ion battery anodes using Ge nanowires. Nano Lett, 2008, 8: 307-309

33 Seo MH, Park M, Lee KT, et al. High performance Ge nanowire an ode sheathed with carbon for lithium rechargeable batteries. Energy Environ Sci, 2011, 4: 425-428

34 Chockla AM, Klavetter KC, Mullins CB, Korgel BA. Solution-grown germanium nanowire anodes for lithium-ion batteries. ACS App Mater interfaces, 2012, 4: 4658-4664

35 Ni J, Fu S, Wu C, et al. Self-supported nanotube arrays of sulfurdoped $\mathrm{TiO}_{2}$ enabling ultrastable and robust sodium storage. Adv Mater, 2016, 28: 2259-2265

36 Peng M, Li B, Yan $\mathrm{H}$, et al. Ruthenium-oxide-coated sodium vanadium fluorophosphate nanowires as high-power cathode materials for sodium-ion batteries. Angew Chem Inter Ed, 2015, 54 6452-6456

37 Liu Q, Jiang $\mathrm{Y}, \mathrm{Xu}$ J, et al. Hierarchical $\mathrm{Co}_{3} \mathrm{O}_{4}$ porous nanowires as an efficient bifunctional cathode catalyst for long life $\mathrm{Li}-\mathrm{O}_{2}$ batteries. Nano Res, 2015, 8: 576-583

38 Liu Y, Zhang N, Kang $\mathrm{H}$, et al. $\mathrm{WS}_{2}$ nanowires as a high-performance anode for sodium-ion batteries. Chem A Euro J, 2015, 21 $11878-11884$

39 Zhang Y, Fu Q, Xu Q, et al. Improved electrochemical performance of nitrogen doped $\mathrm{TiO}_{2}-\mathrm{B}$ nanowires as anode materials for $\mathrm{Li}$-ion batteries. Nanoscale, 2015, 7: 12215-12224

40 Zhang X, Ji L, Toprakci O, et al. Electrospun nanofiber-based an odes, cathodes, and separators for advanced lithium-ion batteries. Polym Rev, 2011, 51: 239-264

41 Wang HG, Yuan S, Ma DL, et al. Electrospun materials for lithium and sodium rechargeable batteries: from structure evolution to electrochemical performance. Energy Environ Sci, 2015, 8: 1660-1681

42 Dong Z, Kennedy SJ, Wu Y. Electrospinning materials for energy-related applications and devices. J Power Sources, 2011, 196: 4886-4904

43 Cavaliere S, Subianto S, Savych I, et al. Electrospinning: designed architectures for energy conversion and storage devices. Energy Environ Sci, 2011, 4: 4761-4785

44 Li D, Xia Y. Electrospinning of nanofibers: reinventing the wheel? Adv Mater, 2004, 16: 1151-1170

45 Greiner A, Wendorff JH. Electrospinning: a fascinating method for the preparation of ultrathin fibers. Angew Chem Inter Ed, 2007, 46: 5670-5703

46 Teo W, Ramakrishna S. A review on electrospinning design and nanofibre assemblies. Nanotechnology, 2006, 17: R89-R106

47 Yarin AL, Koombhongse S, Reneker DH. Taylor cone and jetting from liquid droplets in electrospinning of nanofibers. J Appl Phys, 2001, 90: 4836-4846

48 Bhardwaj N, Kundu SC. Electrospinning: a fascinating fiber fabrication technique. Biotechnol Adv, 2010, 28: 325-347

49 Spivak A, Dzenis Y, Reneker D. A model of steady state jet in the electrospinning process. Mech Res Commun, 2000, 27: 37-42

50 Spivak A, Dzenis YA. Asymptotic decay of radius of a weakly conductive viscous jet in an external electric field. Appl Phys Lett, 1998, 73: 3067-3069

51 Fridrikh SV, Jian HY, Brenner MP, Rutledge GC. Controlling the fiber diameter during electrospinning. Phys Rev Lett, 2003, 90: 144502

52 Zeleny J. The electrical discharge from liquid points, and a hydrostatic method of measuring the electric intensity at their surfaces. Phys Rev, 1914, 3: 69-91

53 Anton F. Process and apparatus for preparing artificial threads. US Patent, 1934, No. 1975504

54 Baumgarten PK. Electrostatic spinning of acrylic microfibers. J Colloid Interface Sci, 1971, 36: 71-79

55 Larrondo L, St John Manley R. Electrostatic fiber spinning from polymer melts. I. Experimental observations on fiber formation and properties. J Polym Sci Polym Phys Ed, 1981, 19: 909-920

56 Doshi J, Reneker DH. Electrospinning process and applications of electrospun fibers. J Electrostat, 1993, 35: 151-160

57 Reneker DH, Chun I. Nanometre diameter fibres of polymer, produced by electrospinning. Nanotechnology, 1996, 7: 216

58 Koski A, Yim K, Shivkumar S. Effect of molecular weight on fibrous PVA produced by electrospinning. Mater Lett, 2004, 58: 493-497

59 Qin XH, Yang EL, Li N, Wang SY. Effect of different salts on electrospinning of polyacrylonitrile (PAN) polymer solution. J Appl Polym Sci, 2007, 103: 3865-3870

60 Pan H, Li L, Hu L, Cui X. Continuous aligned polymer fibers produced by a modified electrospinning method. Polymer, 2006, 47: 4901-4904

61 Son WK, Youk JH, Lee TS, Park WH. The effects of solution properties and polyelectrolyte on electrospinning of ultrafine poly (ethylene oxide) fibers. Polymer, 2004, 45: 2959-2966

62 Kim C, Jeong YI, Ngoc BTN, et al. Synthesis and characterization of porous carbon nanofibers with hollow cores through the thermal treatment of electrospun copolymeric nanofiber webs. Small, 2007, 3: 91-95

63 Yu X, Xiang H, Long Y, et al. Preparation of porous polyacrylonitrile fibers by electrospinning a ternary system of $\mathrm{PAN} / \mathrm{DMF} / \mathrm{H}_{2} \mathrm{O}$. Mater Lett, 2010, 64: 2407-2409

64 Di J, Chen H, Wang X, et al. Fabrication of zeolite hollow fibers by coaxial electrospinning. Chem Mater, 2008, 20: 3543-3545

65 Zhao Y, Cao X, Jiang L. Bio-mimic multichannel microtubes by a facile method. J Am Chem Soc, 2007, 129: 764-765

66 McCann JT, Marquez M, Xia Y. Highly porous fibers by electrospinning into a cryogenic liquid. J Am Chem Soc, 2006, 128: 1436-1437

67 Xie J, MacEwan MR, Willerth SM, et al. Conductive core-sheath nanofibers and their potential application in neural tissue engineering. Adv Funct Mater, 2009, 19: 2312-2318

68 Larsen G, Velarde-Ortiz R, Minchow K, et al. A method for making inorganic and hybrid (organic/inorganic) fibers and vesicles with diameters in the submicrometer and micrometer range via sol-gel chemistry and electrically forced liquid jets. J Am Chem Soc, 2003 125: 1154-1155

69 Choi SS, Lee SG, Im SS, et al. Silica nanofibers from electrospinning/sol-gel process. J Mater Sci Lett, 2003, 22: 891-893

70 Li D, Xia Y. Fabrication of titania nanofibers by electrospinning. 
Nano Lett, 2003, 3: 555-560

71 Liu Y, Sagi S, Chandrasekar R, et al. Preparation and characterization of electrospun $\mathrm{SiO}_{2}$ nanofibers. J Nanosci Nanotechnol, 2008 8: $1528-1536$

72 Azad AM. Fabrication of yttria-stabilized zirconia nanofibers by electrospinning. Mater Lett, 2006, 60: 67-72

73 Guan $\mathrm{H}$, Shao $\mathrm{C}$, Chen $\mathrm{B}$, et al. A novel method for making $\mathrm{CuO}$ superfine fibres via an electrospinning technique. Inorg Chem Commun, 2003, 6: 1409-1411

74 Viswanathamurthi P, Bhattarai N, Kim H, et al. Preparation and morphology of niobium oxide fibres by electrospinning. Chem Phys Lett, 2003, 374: 79-84

75 Persson K, Sethuraman VA, Hardwick LJ, et al. Lithium diffusion in graphitic carbon. J Phys Chem Lett, 2010, 1: 1176-1180

76 Shu Z, McMillan R, Murray J. Electrochemical intercalation of lithium into graphite. J Electrochem Soc, 1993, 140: 922-927

77 Gu S, Ren J, Vancso G. Process optimization and empirical modeling for electrospun polyacrylonitrile (PAN) nanofiber precursor of carbon nanofibers. Euro Polym J, 2005, 41: 2559-2568

78 Niu H, Zhang J, Xie Z, et al. Preparation, structure and supercapacitance of bonded carbon nanofiber electrode materials. Carbon 2011, 49: 2380-2388

79 Fatema UK, Uddin AJ, Uemura K, Gotoh Y. Fabrication of carbon fibers from electrospun poly(vinyl alcohol) nanofibers. Text Res J 2011, 81: 659-672

80 Xuyen NT, Ra EJ, Geng HZ, et al. Enhancement of conductivity by diameter control of polyimide-based electrospun carbon nanofibers. J Phys Chem B, 2007, 111: 11350-11353

81 Yang Y, Centrone A, Chen L, et al. Highly porous electrospun polyvinylidene fluoride (PVDF)-based carbon fiber. Carbon, 2011 49: 3395-3403

82 Park SH, Kim C, Choi YO, Yang KS. Preparations of pitch-based CF/ACF webs by electrospinning. Carbon, 2003, 41: 2655-2657

83 Inagaki M, Yang Y, Kang F. Carbon nanofibers prepared via electrospinning. Adv Mater, 2012, 24: 2547-2566

84 Liu CK, Lai K, Liu W, et al. Preparation of carbon nanofibres through electrospinning and thermal treatment. Polym Inter, 2009, 58: $1341-1349$

85 Kim C, Yang K. Electrochemical properties of carbon nanofiber web as an electrode for supercapacitor prepared by electrospinning. App Phys Lett, 2003, 83: 1216-1218

86 Wang Y, Serrano S, Santiago-Aviles J. Conductivity measurement of electrospun PAN-based carbon nanofiber. J Mater Sci Lett, 2002, 21 : 1055-1057

87 Kumar B, Asadi M, Pisasale D, et al. Renewable and metal-free carbon nanofibre catalysts for carbon dioxide reduction. Nat Commun, 2013, 4: 2819

88 Kim C, Yang KS, Kojima M, et al. Fabrication of electrospinningderived carbon nanofiber webs for the anode material of lithium-ion secondary batteries. Adv Funct Mater, 2006, 16: 2393-2397

89 Wu Y, Reddy M, Chowdari B, Ramakrishna S. Long-term cycling studies on electrospun carbon nanofibers as anode materia for lithium ion batteries. ACS Appl Mater Interfaces, 2013, 5: 12175-12184

90 Kumar PS, Sahay R, Aravindan V, et al. Free-standing electrospun carbon nanofibres? A high performance anode material for lithium ion batteries. J Phys D Appl Phys, 2012, 45: 265302

91 Nan D, Huang ZH, Lv R, et al. Nitrogen-enriched electrospun porous carbon nanofiber networks as high-performance free-standing electrode materials. J Mater Chem A, 2014, 2: 19678-19684

92 Ji L, Lin Z, Medford AJ, Zhang X. Porous carbon nanofibers from electrospun polyacrylonitrile/ $\mathrm{SiO}_{2}$ composites as an energy storage material. Carbon, 2009, 47: 3346-3354

93 Nan D, Wang JG, Huang ZH, et al. Highly porous carbon nanofibers from electrospun polyimide/ $\mathrm{SiO}_{2}$ hybrids as an improved anode for lithium-ion batteries. Electrochem Commun, 2013, 34: 52-55

94 Ji L, Zhang X. Fabrication of porous carbon nanofibers and their application as anode materials for rechargeable lithium-ion batteries. Nanotechnology, 2009, 20: 155705

95 Li W, Li M, Wang M, et al. Electrospinning with partially carbonization in air: highly porous carbon nanofibers optimized for highperformance flexible lithium-ion batteries. Nano Energy, 2015, 13: 693-701

96 Arshad SN, Naraghi M, Chasiotis I. Strong carbon nanofibers from electrospun polyacrylonitrile. Carbon, 2011, 49: 1710-1719

97 Linchao Z, Fusen P, Weihan L, et al. Free-standing porous carbon nanofibers-sulfur composite for flexible Li-S battery cathode. Nanoscale, 2014, 6: 9579-9587

98 Dong L, Wang G, Li X, et al. PVP-derived carbon nanofibers harvesting enhanced anode performance for lithium ion batteries. RSC Adv, 2016, 6: 4193-4199

99 Chen Y, Lu Z, Zhou L, et al. In situ formation of hollow graphitic carbon nanospheres in electrospun amorphous carbon nanofibers for high-performance Li-based batteries. Nanoscale, 2012, 4: 6800-6805

100 Zhang B, Xu ZL, He YB, et al. Exceptional rate performance of functionalized carbon nanofiber anodes containing nanopores created by (Fe) sacrificial catalyst. Nano Energy, 2014, 4: 88-96

101 Chen Y, Lu Z, Zhou L, et al. Triple-coaxial electrospun amorphous carbon nanotubes with hollow graphitic carbon nanospheres for high-performance Li ion batteries. Energy Environ Sci, 2012, 5: 7898-7902

102 Chen Y, Li X, Park K, et al. Hollow carbon-nanotube/carbon-nanofiber hybrid anodes for Li-ion batteries. J Am Chem Soc, 2013, 135: 16280-16283

103 Chen Y, Li X, Zhou X, et al. Hollow-tunneled graphitic carbon nanofibers through Ni-diffusion-induced graphitization as high-performance anode materials. Energy Environ Sci, 2014, 7: 2689-2696

104 Zhang WJ. A review of the electrochemical performance of alloy anodes for lithium-ion batteries. J Power Sources, 2011, 196: 13-24

105 Lee DJ, Lee H, Ryou MH, et al. Electrospun three-dimensional mesoporous silicon nanofibers as an anode material for high-performance lithium secondary batteries. ACS Appl Mater Interfaces, 2013, 5: 12005-12010

106 Wang L, Ding C, Zhang L, et al. A novel carbon-silicon composite nanofiber prepared via electrospinning as anode material for high energy-density lithium ion batteries. J Power Sources, 2010, 195: 5052-5056

$107 \mathrm{Xu} \mathrm{Y,} \mathrm{Zhu} \mathrm{Y,} \mathrm{Han} \mathrm{F,} \mathrm{et} \mathrm{al.} \mathrm{3D} \mathrm{Si/C} \mathrm{fiber} \mathrm{paper} \mathrm{electrodes} \mathrm{fabricated}$ using a combined electrospray/electrospinning technique for Li-ion batteries. Adv Energy Mater, 2015, 5, doi: 10.1002/aenm.201400753

108 Liu Y, Huang K, Fan Y, et al. Binder-free Si nanoparticles@carbon nanofiber fabric as energy storage material. Electrochim Acta, 2013, 102: $246-251$

109 Ji L, Zhang X. Evaluation of Si/carbon composite nanofiber-based insertion anodes for new-generation rechargeable lithium-ion batteries. Energy Environ Sci, 2010, 3: 124-129

110 Shin J, Park K, Ryu WH, et al. Graphene wrapping as a protective clamping layer anchored to carbon nanofibers encapsulating Si nanoparticles for a Li-ion battery anode. Nanoscale, 2014, 6: 12718-12726

111 Kim YS, Kim KW, Cho D, et al. Silicon-rich carbon hybrid nanofibers from water-based spinning: the synergy between silicon 
and carbon for Li-ion battery anode application. ChemElectroChem, 2014, 1: 220-226

112 Zhou X, Wan LJ, Guo YG. Electrospun silicon nanoparticle/porous carbon hybrid nanofibers for lithium-ion batteries. Small, 2013, 9: 2684-2688

113 Wang J, Yu Y, Gu L, et al. Highly reversible lithium storage in $\mathrm{Si}$ (core)-hollow carbon nanofibers (sheath) nanocomposites. Nanoscale, 2013, 5: 2647-2650

114 Hieu NT, Suk J, Kim DW, et al. Electrospun nanofibers with a coreshell structure of silicon nanoparticles and carbon nanotubes in carbon for use as lithium-ion battery anodes. J Mater Chem A, 2014, 2: 15094-15101

115 Zhang H, Qin X, Wu J, et al. Electrospun core-shell silicon/carbon fibers with an internal honeycomb-like conductive carbon framework as an anode for lithium ion batteries. J Mater Chem A, 2015, 3: $7112-7120$

116 Hwang TH, Lee YM, Kong BS, et al. Electrospun core-shell fibers for robust silicon nanoparticle-based lithium ion battery anodes. Nano Lett, 2012, 12: 802-807

117 Yu Y, Gu L, Wang C, et al. Encapsulation of Sn@carbon nanoparticles in bamboo-like hollow carbon nanofibers as an anode material in lithium-based batteries. Angew Chem Inter Ed, 2009, 48 6485-6489

$118 \mathrm{Yu}$ Y, Gu L, Zhu C, et al. Tin nanoparticles encapsulated in porous multichannel carbon microtubes: preparation by single-nozzle electrospinning and application as anode material for high-performance Li-based batteries. J Am Chem Soc, 2009, 131: 15984-15985

119 Zhang G, Zhu J, Zeng W, et al. Tin quantum dots embedded in nitrogen-doped carbon nanofibers as excellent anode for lithium-ion batteries. Nano Energy, 2014, 9: 61-70

120 Lee YW, Kim DM, Kim SJ, et al. In-situ synthesis and characterization of Ge embedded electrospun carbon nanostructures as high performance anode material for lithium-ion batteries. ACS Appl Mater Interfaces, 2016, 8: 7022-7029

$121 \mathrm{Li} \mathrm{W}$, Yang Z, Cheng J, et al. Germanium nanoparticles encapsulated in flexible carbon nanofibers as self-supported electrodes for high performance lithium-ion batteries. Nanoscale, 2014, 6: 4532-4537

122 Wang W, Xiao Y, Wang X, et al. In situ encapsulation of germanium clusters in carbon nanofibers: high-performance anodes for lithiumion batteries. ChemSusChem, 2014, 7: 2914-2922

123 Wang X, Fan L, Gong D, et al. Core-shell Ge@graphene@ $\mathrm{TiO}_{2}$ nanofibers as a high-capacity and cycle-stable anode for lithium and sodium ion battery. Adv Funct Mater, 2015, 26: 1104-1111

$124 \mathrm{Li} \mathrm{W}$, Li M, Yang Z, et al. Carbon-coated germanium nanowires on carbon nanofibers as self-supported electrodes for flexible lithiumion batteries. Small, 2015, 11: 2762-2767

$125 \mathrm{Li} \mathrm{W}$, Yang Z, Jiang Y, et al. Crystalline red phosphorus incorporated with porous carbon nanofibers as flexible electrode for high performance lithium-ion batteries. Carbon, 2014, 78: 455-462

126 Wang L, Xiao Q, Li Z, et al. Synthesis of $\mathrm{Li}_{4} \mathrm{Ti}_{5} \mathrm{O}_{12}$ fibers as a high rate electrode material for lithium-ion batteries. J Solid State Electrochem, 2012, 16: 3307-3313

127 Park H, Song T, Han H, Paik U. Electrospun $\mathrm{Li}_{4} \mathrm{Ti}_{5} \mathrm{O}_{12}$ nanofibers sheathed with conductive $\mathrm{TiN} / \mathrm{TiO}_{x} \mathrm{~N}_{y}$ layer as an anode material for high power Li-ion batteries. J Power Sources, 2013, 244: 726-730

128 Choi HS, Kim T, Im JH, Park CR. Preparation and electrochemical performance of hyper-networked $\mathrm{Li}_{4} \mathrm{Ti}_{5} \mathrm{O}_{12} /$ carbon hybrid nanofiber sheets for a battery-supercapacitor hybrid system. Nanotechnology, 2011, 22: 405402

129 Zhu N, Liu W, Xue M, et al. Graphene as a conductive additive to enhance the high-rate capabilities of electrospun $\mathrm{Li}_{4} \mathrm{Ti}_{5} \mathrm{O}_{12}$ for lithium-ion batteries. Electrochim Acta, 2010, 55: 5813-5818
$130 \mathrm{Xu} \mathrm{H}, \mathrm{Hu} \mathrm{X}$, Luo W, et al. Electrospun conformal $\mathrm{Li}_{4} \mathrm{Ti}_{5} \mathrm{O}_{12} / \mathrm{C}$ fibers for high-rate lithium-ion batteries. ChemElectroChem, 2014, 1: $611-616$

$131 \mathrm{Xu} \mathrm{H}, \mathrm{Hu} \mathrm{X}$, Sun $\mathrm{Y}$, et al. Highly porous $\mathrm{Li}_{4} \mathrm{Ti}_{5} \mathrm{O}_{12} / \mathrm{C}$ nanofibers for ultrafast electrochemical energy storage. Nano Energy, 2014, 10: $163-171$

132 Kumar PS, Aravindan V, Sundaramurthy J, et al. High performance lithium-ion cells using one dimensional electrospun $\mathrm{TiO}_{2}$ nanofibers with spinel cathode. RSC Adv, 2012, 2: 7983-7987

133 Yuan T, Zhao B, Cai R, et al. Electrospinning based fabrication and performance improvement of film electrodes for lithium-ion batteries composed of $\mathrm{TiO}_{2}$ hollow fibers. J Mater Chem, 2011, 21: 15041-15048

134 Zhang X, Aravindan V, Kumar PS, et al. Synthesis of $\mathrm{TiO}_{2}$ hollow nanofibers by co-axial electrospinning and its superior lithium storage capability in full-cell assembly with olivine phosphate. Nanoscale, 2013, 5: 5973-5980

135 Tang $\mathrm{K}, \mathrm{Yu} \mathrm{Y}, \mathrm{Mu} \mathrm{X}$, et al. Multichannel hollow $\mathrm{TiO}_{2}$ nanofibers fabricated by single-nozzle electrospinning and their application for fast lithium storage. Electrochem Commun, 2013, 28: 54-57

136 Kim JG, Shi D, Kong KJ, et al. Structurally and electronically designed $\mathrm{TiO}_{2} \mathrm{~N}_{x}$ nanofibers for lithium rechargeable batteries. ACS Appl Mater Interfaces, 2013, 5: 691-696

$137 \mathrm{Han} \mathrm{H}$, Song $\mathrm{T}$, Bae JY, et al. Nitridated $\mathrm{TiO}_{2}$ hollow nanofibers as an anode material for high power lithium ion batteries. Energy Environ Sci, 2011, 4: 4532-4536

138 Nam SH, Shim HS, Kim YS, et al. Ag or Au nanoparticle-embedded one-dimensional composite $\mathrm{TiO}_{2}$ nanofibers prepared via electrospinning for use in lithium-ion batteries. ACS Appl Mater Interfaces, 2010, 2: 2046-2052

139 Zhang G, Duan H, Lu B, Xu Z. Electrospinning directly synthesized metal nanoparticles decorated on both sidewalls of $\mathrm{TiO}_{2}$ nanotubes and their applications. Nanoscale, 2013, 5: 5801-5808

140 Zhao B, Jiang S, Su C, et al. A 3D porous architecture composed of $\mathrm{TiO}_{2}$ nanotubes connected with a carbon nanofiber matrix for fast energy storage. J Mater Chem A, 2013, 1: 12310-12320

141 Ryu MH, Jung KN, Shin KH, et al. High performance N-doped mesoporous carbon decorated $\mathrm{TiO}_{2}$ nanofibers as anode materials for lithium-ion batteries. J Phys Chem C, 2013, 117: 8092-8098

142 Yang Z, Du G, Meng Q, et al. Synthesis of uniform $\mathrm{TiO}_{2} @$ carbon composite nanofibers as anode for lithium ion batteries with enhanced electrochemical performance. J Mater Chem, 2012, 22: 5848-5854

143 Li X, Chen Y, Zhou L, et al. Exceptional electrochemical performance of porous $\mathrm{TiO} 2$-carbon nanofibers for lithium ion battery anodes. J Mater Chem A, 2014, 2: 3875-3880

144 Tang K, Mu X, van Aken PA, et al. "Nano-pearl-string" $\mathrm{TiNb}_{2} \mathrm{O}_{7}$ as anodes for rechargeable lithium batteries. Adv Energy Mater, 2013, 3: $49-53$

145 Aravindan V, Sundaramurthy J, Jain A, et al. Unveiling $\mathrm{TiNb}_{2} \mathrm{O}_{7}$ as an insertion anode for lithium ion capacitors with high energy and power density. ChemSusChem, 2014, 7: 1858-1863

146 Palacin MR. Recent advances in rechargeable battery materials: a chemist's perspective. Chem Soc Rev, 2009, 38: 2565-2575

147 Ji L, Toprakci O, Alcoutlabi M, et al. $\alpha-\mathrm{Fe}_{2} \mathrm{O}_{3}$ nanoparticle-loaded carbon nanofibers as stable and high-capacity anodes for rechargeable lithium-ion batteries. ACS Appl Mater Interfaces, 2012, 4: $2672-2679$

148 Zhang X, Liu H, Petnikota S, et al. Electrospun $\mathrm{Fe}_{2} \mathrm{O}_{3}$-carbon composite nanofibers as durable anode materials for lithium ion batteries. J Mater Chem A, 2014, 2: 10835-10841

149 Wang $\mathrm{L}$, Yu Y, Chen $\mathrm{P}$, et al. Electrospinning synthesis of $\mathrm{C} / \mathrm{Fe}_{3} \mathrm{O}_{4}$ 
composite nanofibers and their application for high performance lithium-ion batteries. J Power Sources, 2008, 183: 717-723

$150 \mathrm{Gu}$ S, Liu Y, Zhang G, et al. $\mathrm{Fe}_{3} \mathrm{O}_{4} /$ carbon composites obtained by electrospinning as an anode material with high rate capability for lithium ion batteries. RSC Adv, 2014, 4: 41179-41184

151 Chaudhari S, Srinivasan M. 1D hollow $a-\mathrm{Fe}_{2} \mathrm{O}_{3}$ electrospun nanofibers as high performance anode material for lithium ion batteries. J Mater Chem, 2012, 22: 23049-23056

152 Wang HG, Zhou Y, Shen Y, et al. Fabrication, formation mechanism and the application in lithium-ion battery of porous $\mathrm{Fe}_{2} \mathrm{O}_{3}$ nanotubes via single-spinneret electrospinning. Electrochim Acta 2015, 158: 105-112

153 Luo H, Huang K, Sun B, Zhong J. Strategy to synthesize $\mathrm{Fe}_{3} \mathrm{O}_{4} / \mathrm{C}$ nanotubes as anode material for advanced lithium-ion batteries. Electrochim Acta, 2014, 149: 11-17

154 Cho JS, Hong YJ, Kang YC. Design and synthesis of bubble-nanorodstructured $\mathrm{Fe}_{2} \mathrm{O}_{3}$-carbon nanofibers as advanced anode material for Li-ion batteries. ACS Nano, 2015, 9: 4026-4035

155 Abouali S, Garakani MA, Zhang B, et al. $\mathrm{Co}_{3} \mathrm{O}_{4}$ /porous electrospun carbon nanofibers as anodes for high performance Li-ion batteries. J Mater Chem A, 2014, 2: 16939-16944

156 Zhang M, Uchaker E, Hu S, et al. CoO-carbon nanofiber networks prepared by electrospinning as binder-free anode materials for lithium-ion batteries with enhanced properties. Nanoscale, 2013, 5 12342-12349

157 Barakat NA, Khil MS, Sheikh FA, Kim HY. Synthesis and optical properties of two cobalt oxides $\left(\mathrm{CoO}\right.$ and $\left.\mathrm{Co}_{3} \mathrm{O}_{4}\right)$ nanofibers produced by electrospinning process. J Phys Chem C, 2008, 112 : 12225-12233

158 Liu B, Hu X, Xu H, et al. Encapsulation of MnO nanocrystals in electrospun carbon nanofibers as high-performance anode materials for lithium-ion batteries. Sci Rep, 2014, 4, doi: 10.1038/srep04229

159 Zhao X, Du Y, Jin L, et al. Membranes of MnO beading in carbon nanofibers as flexible anodes for high-performance lithium-ion batteries. Sci Rep, 2015, 5, doi: 10.1038/srep14146

160 Aravindan V, Kumar PS, Sundaramurthy J, et al. Electrospun NiO nanofibers as high performance anode material for Li-ion batteries. J Power Sources, 2013, 227: 284-290

161 Wang B, Cheng J, Wu Y, et al. Porous $\mathrm{NiO}$ fibers prepared by electrospinning as high performance anode materials for lithium ion batteries. Electrochem Commun, 2012, 23: 5-8

$162 \mathrm{Xu} \mathrm{W}$, Zhao K, Niu C, et al. Heterogeneous branched core-shell $\mathrm{SnO}_{2}$-PANI nanorod arrays with mechanical integrity and three dimentional electron transport for lithium batteries. Nano Energy, 2014, 8: 196-204

163 Lin J, Peng Z, Xiang C, et al. Graphene nanoribbon and nanostructured $\mathrm{SnO}_{2}$ composite anodes for lithium ion batteries. ACS Nano 2013, 7: 6001-6006

164 Guo X, Fang X, Sun Y, et al. Lithium storage in carbon-coated $\mathrm{SnO}_{2}$ by conversion reaction. J Power Sources, 2013, 226: 75-81

165 Liu X, Cheng J, Li W, et al. Superior lithium storage in a 3D macroporous graphene framework/ $\mathrm{SnO}_{2}$ nanocomposite. Nanoscale, 2014 6: 7817-7822

166 Hwang SM, Lim YG, Kim JG, et al. A case study on fibrous porous $\mathrm{SnO}_{2}$ anode for robust, high-capacity lithium-ion batteries. Nano energy, 2014, 10: 53-62

167 Yang T, Lu B. Highly porous structure strategy to improve the $\mathrm{SnO}_{2}$ electrode performance for lithium-ion batteries. Phys Chem Chem Phy, 2014, 16: 4115-4121

168 Zhao Y, Li X, Dong L, et al. Electrospun $\mathrm{SnO}_{2}-\mathrm{ZnO}$ nanofibers with improved electrochemical performance as anode materials for lithium-ion batteries. Inter J Hydrogen Energy, 2015, 40
$14338-14344$

169 Jiang S, Zhao B, Ran R, et al. A freestanding composite film electrode stacked from hierarchical electrospun $\mathrm{SnO}_{2}$ nanorods and graphene sheets for reversible lithium storage. RSC Adv, 2014, 4: 9367-9371

170 Zhu J, Zhang G, Yu X, et al. Graphene double protection strategy to improve the $\mathrm{SnO} 2$ electrode performance anodes for lithium-ion batteries. Nano Energy, 2014, 3: 80-87

171 Ji L, Lin Z, Guo B, et al. Assembly of carbon-SnO 2 core-sheath composite nanofibers for superior lithium storage. Chem A Euro J, 2010, 16: $11543-11548$

172 Dirican M, Yanilmaz M, Fu K, et al. Carbon-enhanced electrodeposited $\mathrm{SnO}_{2}$ /carbon nanofiber composites as anode for lithium-ion batteries. J Power Sources, 2014, 264: 240-247

173 Kong J, Liu Z, Yang Z, et al. Carbon/ $/ \mathrm{SnO}_{2} /$ carbon core/shell/shell hybrid nanofibers: tailored nanostructure for the anode of lithium ion batteries with high reversibility and rate capacity. Nanoscale, 2012, 4: 525-530

174 Zhang B, Yu Y, Huang Z, et al. Exceptional electrochemical performance of freestanding electrospun carbon nanofiber anodes containing ultrafine $\mathrm{SnO}_{x}$ particles. Energy Environ Sci, 2012, 5: 9895-9902

175 Kim D, Lee D, Kim J, Moon J. Electrospun Ni-added $\mathrm{SnO}_{2}$-carbon nanofiber composite anode for high-performance lithium-ion batteries. ACS Appl Mater Interfaces, 2012, 4: 5408-5415

176 Zhou X, Dai Z, Liu S, et al. Ultra-uniform $\mathrm{SnO}_{x} /$ carbon nanohybrids toward advanced lithium-ion battery anodes. Adv Mater, 2014, 26 3943-3949

177 Fei L, Williams BP, Yoo SH, et al. A general approach to fabricate free-standing metal sulfide@ carbon nanofiber networks as lithium ion battery anodes. Chem Commun, 2016, 52: 1501-1504

178 Zhao C, Kong J, Yao X, et al. Thin $\mathrm{MoS}_{2}$ nanoflakes encapsulated in carbon nanofibers as high-performance anodes for lithium-ion batteries. ACS Appl Mater Interfaces, 2014, 6: 6392-6398

179 Yu S, Jung JW, Kim ID. Single layers of $\mathrm{WS}_{2}$ nanoplates embedded in nitrogen-doped carbon nanofibers as anode materials for lithiumion batteries. Nanoscale, 2015, 7: 11945-11950

180 Kong D, He H, Song Q, et al. A novel SnS ${ }_{2} @$ graphene nanocable network for high-performance lithium storage. RSC Adv, 2014, 4: 23372-23376

181 Kong D, He H, Song Q, et al. Rational design of $\mathrm{MoS}_{2} @ g r a p h e n e$ nanocables: towards high performance electrode materials for lithium ion batteries. Energy Environ Sci, 2014, 7: 3320-3325

182 Miao YE, Huang Y, Zhang L, et al. Electrospun porous carbon nanofiber@ $\mathrm{MoS}_{2}$ core/sheath fiber membranes as highly flexible and binder-free anodes for lithium-ion batteries. Nanoscale, 2015 , 7: 11093-11101

183 Zhang L, Huang Y, Zhang Y, et al. Flexible electrospun carbon nanofiber@NiS core/sheath hybrid membranes as binder-free anodes for highly reversible lithium storage. Adv Mater Interfaces, 2015, 3, doi: 10.1002/admi.201500467

$184 \mathrm{Gu}$ Y, Chen D, Jiao X. Synthesis and electrochemical properties of nanostructured $\mathrm{LiCoO}_{2}$ fibers as cathode materials for lithium-ion batteries. J Phys Chem B, 2005, 109: 17901-17906

185 Mizuno Y, Hosono E, Saito T, et al. Electrospinning synthesis of wire-structured $\mathrm{LiCoO}_{2}$ for electrode materials of high-power $\mathrm{Li}$-ion batteries. J Phys Chem C, 2012, 116: 10774-10780

186 Lu HW, Yu L, Zeng W. Fabrication and electrochemical properties of three-dimensional structure of $\mathrm{LiCoO}_{2}$ fibers. Electrochem SolidState Lett, 2008, 11: A140-A144

$187 \mathrm{Gu}$ Y, Chen D, Jiao X, Liu F. LiCoO $2-\mathrm{MgO}_{2}$ coaxial fibers: co-electrospun fabrication, characterization and electrochemical properties. J Mater Chem, 2007, 17: 1769-1776 
188 Chen Q, Qiao X, Peng C, et al. Electrochemical performance of electrospun $\mathrm{LiFePO}_{4} / \mathrm{C}$ submicrofibers composite cathode material for lithium ion batteries. Electrochim Acta, 2012, 78: 40-48

189 Dimesso L, Spanheimer C, Jaegermann W, et al. $\mathrm{LiFePO}_{4}-3 \mathrm{D}$ carbon nanofiber composites as cathode materials for Li-ions batteries. J Appl Phys, 2012, 111: 064307

190 Toprakci O, Ji L, Lin Z, et al. Fabrication and electrochemical characteristics of electrospun $\mathrm{LiFePO}_{4} /$ carbon composite fibers for lithium-ion batteries. J Power Sources, 2011, 196: 7692-7699

191 Toprakci O, Toprakci HA, Ji L. Carbon nanotube-loaded electrospun $\mathrm{LiFePO}_{4} /$ carbon composite nanofibers as stable and binder-free cathodes for rechargeable lithium-ion batteries. ACS Appl Mater Interfaces, 2012, 4: 1273-1280

192 Hosono E, Wang Y, Kida N. Synthesis of triaxial $\mathrm{LiFePO}_{4}$ nanowire with a VGCF core column and a carbon shell through the electrospinning method. ACS Appl Mater Interfaces, 2009, 2: 212-218

193 Zhu C, Yu Y, Gu L. Electrospinning of highly electroactive carboncoated single-crystalline $\mathrm{LiFePO}_{4}$ nanowires. Angew Chem Inter Ed, 2011, 50: 6278-6282

194 Zhou H, Ding X, Yin Z. Fabrication and electrochemical characteristics of electrospun $\mathrm{LiMn}_{2} \mathrm{O}_{4}$ nanofiber cathode for $\mathrm{Li}$-ion batteries Mater Lett, 2014, 117: 175-178

195 Jayaraman S, Aravindan V, Kumar PS. Synthesis of porous $\mathrm{LiMn}_{2} \mathrm{O}_{4}$ hollow nanofibers by electrospinning with extraordinary lithium storage properties. Chem Commun, 2013, 49: 6677-6679

196 Chen L, Yan B, Xu J. Bicontinuous structure of $\mathrm{Li}_{3} \mathrm{~V}_{2}\left(\mathrm{PO}_{4}\right)_{3}$ clustered via carbon nanofiber as high-performance cathode material of Li-ion batteries. ACS Appl Mater Interfaces, 2015, 7: 13934-13943

197 Chen Q, Zhang T, Qiao X. $\mathrm{Li}_{3} \mathrm{~V}_{2}\left(\mathrm{PO}_{4}\right)_{3} / \mathrm{C}$ nanofibers composite as a high performance cathode material for lithium-ion battery. J Power Sources, 2013, 234: 197-200

198 Kim C, Kim B, Son J. Synthesis mechanism of new morphology $\mathrm{LiMnPO}_{4}$ nanofibers using electrospinning process. J Electroceram, 2014, 33: 7-11

199 Ban C, Chernova NA, Whittingham MS. Electrospun nano-vanadium pentoxide cathode. Electrochem Commun, 2009, 11: 522-525

200 Mai L, Xu L, Han C, et al. Electrospun ultralong hierarchical vanadium oxide nanowires with high performance for lithium ion batteries. Nano Lett, 2010, 10: 4750-4755

201 Wang HG, Ma DL, Huang Y, Zhang XB. Electrospun $\mathrm{V}_{2} \mathrm{O}_{5}$ nanostructures with controllable morphology as high-performance cathode materials for lithium-ion batteries. Chem A Euro J, 2012, 18 8987-8993

202 Cheah YL, Aravindan V, Madhavi S. Improved elevated temperature performance of Al-intercalated $\mathrm{V}_{2} \mathrm{O}_{5}$ electrospun nanofiber for lithium-ion batteries. ACS Appl Mater Interfaces, 2012, 4 3270-3277

203 Pham-Cong D, Ahn K, Hong S, et al. Cathodic performance of $\mathrm{V}_{2} \mathrm{O}_{5}$ nanowires and reduced graphene oxide composites for lithium ion batteries. Curr Appl Phys, 2014, 14: 215-221

204 Yan B, Li X, Bai Z, et al. Superior lithium storage performance of hierarchical porous vanadium pentoxide nanofibers for lithium ion battery cathodes. J Alloys Compd, 2015, 634: 50-57

205 Liu J, Wen Y, Wang Y, et al. Carbon-encapsulated pyrite as stable and earth-abundant high energy cathode material for rechargeable lithium batteries. Adv Mater, 2014, 26: 6025-6030

206 Zhu C, Wen Y, van Aken PA, et al. High lithium storage performance of FeS nanodots in porous graphitic carbon nanowires. Adv Funct Mater, 2015, 25: 2335-2342

207 Zhu Y, Fan X, Suo L, et al. Electrospun FeS $@ @$ carbon fiber electrode as a high energy density cathode for rechargeable lithium batteries. ACS Nano, 2015, 10: 1529-1538
208 Chen T, Liu Y, Pan L, et al. Electrospun carbon nanofibers as anode materials for sodium ion batteries with excellent cycle performance. J Mater Chem A, 2014, 2: 4117-4121

209 Jin J, Shi ZQ, Wang CY. Electrochemical performance of electrospun carbon nanofibers as free-standing and binder-free anodes for sodium-ion and lithium-ion batteries. Electrochim Acta, 2014, 141: 302-310

210 Zeng L, Li W, Cheng J, et al. N-doped porous hollow carbon nanofibers fabricated using electrospun polymer templates and their sodium storage properties. RSC Adv, 2014, 4: 16920-16927

211 Zhu J, Chen C, Lu Y, et al. Nitrogen-doped carbon nanofibers derived from polyacrylonitrile for use as anode material in sodium-ion batteries. Carbon, 2015, 94: 189-195

212 Jin J, Yu BJ, Shi ZQ, et al. Lignin-based electrospun carbon nanofibrous webs as free-standing and binder-free electrodes for sodium ion batteries. J Power Sources, 2014, 272: 800-807

213 Li W, Zeng L, Yang Z, et al. Free-standing and binder-free sodiumion electrodes with ultralong cycle life and high rate performance based on porous carbon nanofibers. Nanoscale, 2014, 6: 693-698

$214 \mathrm{Xu} \mathrm{Y,} \mathrm{Swaans} \mathrm{E,} \mathrm{Basak} \mathrm{S,} \mathrm{et} \mathrm{al.} \mathrm{Reversible} \mathrm{Na-ion} \mathrm{up-}$ take in Si nanoparticles. Adv Energy Mater, 2016, 6, doi: 10.1002/aenm.201501436

215 Kohandehghan A, Cui K, Kupsta M, et al. Activation with Li enables facile sodium storage in germanium. Nano lett, 2014, 14: 5873-5882

216 Liu J, Wen Y, van Aken PA, et al. Facile synthesis of highly porous $\mathrm{Ni}-\mathrm{Sn}$ intermetallic microcages with excellent electrochemical performance for lithium and sodium storage. Nano Lett, 2014, 14: 6387-6392

217 Yang C, Li W, Yang Z, et al. Nanoconfined antimony in sulfur and nitrogen co-doped three-dimensionally (3D) interconnected macroporous carbon for high-performance sodium-ion batteries. Nano Energy, 2015, 18: 12-19

218 Zhu Y, Han X, Xu Y, et al. Electrospun Sb/C fibers for a stable and fast sodium-ion battery anode. ACS Nano, 2013, 7: 6378-6386

219 Wu L, Hu X, Qian J, et al. Sb-C nanofibers with long cycle life as an anode material for high-performance sodium-ion batteries. Energy Environ Sci, 2014, 7: 323-328

$220 \mathrm{Xu} \mathrm{Y,} \mathrm{Zhu} \mathrm{Y,} \mathrm{Liu} \mathrm{Y,} \mathrm{Wang} \mathrm{C.} \mathrm{Electrochemical} \mathrm{performance} \mathrm{of} \mathrm{porous}$ carbon/tin composite anodes for sodium-ion and lithium-ion batteries. Adv Energy Mater, 2013, 3: 128-133

221 Shiva K, Rajendra HB, Bhattacharyya AJ. Electrospun SnSb crystalline nanoparticles inside porous carbon fibers as a high stability and rate capability anode for rechargeable batteries. ChemPlusChem, 2015, 80: 516-521

222 Ji L, Gu M, Shao Y, et al. Controlling SEI formation on SnSb-porous carbon nanofibers for improved $\mathrm{Na}$ ion storage. Adv Mater, 2014, 26: $2901-2908$

223 Liu J, Tang K, Song K, et al. Tiny $\mathrm{Li}_{4} \mathrm{Ti}_{5} \mathrm{O}_{12}$ nanoparticles embedded in carbon nanofibers as high-capacity and long-life anode materials for both Li-ion and Na-ion batteries. Phys Chem Chem Phy, 2013, 15: 20813-20818

224 Wang J, Li W, Yang Z, et al. Free-standing and binder-free sodium-ion electrodes based on carbon-nanotube decorated $\mathrm{Li}_{4} \mathrm{Ti}_{5} \mathrm{O}_{12}$ nanoparticles embedded in carbon nanofibers. RSC Adv, 2014, 4: 25220-25226

225 Ge Y, Zhu J, Lu Y, et al. The study on structure and electrochemical sodiation of one-dimensional nanocrystalline $\mathrm{TiO}_{2} @ \mathrm{C}$ nanofiber composites. Electrochim Acta, 2015, 176: 989-996

226 Dirican M, Lu Y, Ge Y, et al. Carbon-confined $\mathrm{SnO}_{2}$-electrodeposited porous carbon nanofiber composite as high-capacity sodium-ion battery anode material. ACS Appl Mater Interfaces, 2015, 7: 18387-18396 
227 Qu B, Ma C, Ji G, et al. Layered SnS 2 -reduced graphene oxide composite-a high-capacity, high-rate, and long-cycle life sodium-ion battery anode material. Adv Mater, 2014, 26: 3854-3859

228 Zhu C, Kopold P, Li W, et al. A general strategy to fabricate carboncoated $3 \mathrm{D}$ porous interconnected metal sulfides: case study of $\mathrm{SnS} / \mathrm{C}$ nanocomposite for high-performance lithium and sodium ion batteries. Adv Sci, 2015, 2, doi: 10.1002/advs.201500200

229 Zhao Y, Manthiram A. Amorphous $\mathrm{Sb}_{2} \mathrm{~S}_{3}$ embedded in graphite: a high-rate, long-life anode material for sodium-ion batteries. Chem Commun, 2015, 51: 13205-13208

230 David L, Bhandavat R, Singh G. $\mathrm{MoS}_{2} /$ graphene composite paper for sodium-ion battery electrodes. ACS Nano, 2014, 8: 1759-1770

231 Zhu C, Mu X, van Aken PA. Single-layered ultrasmall nanoplates of $\mathrm{MoS}_{2}$ embedded in carbon nanofibers with excellent electrochemical performance for lithium and sodium storage. Angew Chem Inter Ed, 2014, 53: 2152-2156

232 Ryu WH, Jung JW, Park K. Vine-like $\mathrm{MoS}_{2}$ anode materials self-assembled from 1-D nanofibers for high capacity sodium rechargeable batteries. Nanoscale, 2014, 6: 10975-10981

233 Liu J, Tang K, Song K. Electrospun $\mathrm{Na}_{3} \mathrm{~V}_{2}\left(\mathrm{PO}_{4}\right)_{3} / \mathrm{C}$ nanofibers as stable cathode materials for sodium-ion batteries. Nanoscale, 2014, 6: 5081-5086

$234 \mathrm{Li} \mathrm{H}$, Bai Y, Wu F, et al. Budding willow branches shaped $\mathrm{Na}_{3} \mathrm{~V}_{2}\left(\mathrm{PO}_{4}\right)_{3} / \mathrm{C}$ nanofibers synthesized via an electrospinning technique and used as cathode material for sodium ion batteries. J Power Sources, 2015, 273: 784-792

235 Kajiyama S, Kikkawa J, Hoshino J. Assembly of $\mathrm{Na}_{3} \mathrm{~V}_{2}\left(\mathrm{PO}_{4}\right)_{3}$ nanoparticles confined in a one-dimensional carbon sheath for enhanced sodium-ion cathode properties. Chem A Euro J, 2014 20: $12636-12640$

236 Kalluri S, Pang WK, Seng KH. One-dimensional nanostructured de sign of $\mathrm{Li}_{1+x}\left(\mathrm{Mn}_{1 / 3} \mathrm{Ni}_{1 / 3} \mathrm{Fe}_{1 / 3}\right) \mathrm{O}_{2}$ as a dual cathode for lithium-ion and sodium-ion batteries. J Mater Chem A, 2015, 3: 250-257

237 Kalluri S, Seng KH, Pang WK. Electrospun P2-type $\mathrm{Na}_{2 / 3}\left(\mathrm{Fe}_{1 / 2} \mathrm{Mn}_{1 / 2}\right) \mathrm{O}_{2}$ hierarchical nanofibers as cathode materia for sodium-ion batteries. ACS Appl Mater Interfaces, 2014, 6: 8953-8958

238 Niu C, Meng J, Wang X. General synthesis of complex nanotubes by gradient electrospinning and controlled pyrolysis. Nat Commun, 2015, 6: 7402

239 Manthiram A, Fu Y, Chung SH. Rechargeable lithium-sulfur batteries. Chem Rev, 2014, 114: 11751-11787

240 Wu F, Shi L, Mu D. A hierarchical carbon fiber/sulfur composite as cathode material for Li-S batteries. Carbon, 2015, 86: 146-155
241 Zeng L, Pan F, Li W. Free-standing porous carbon nanofibers-sulfur composite for flexible Li-S battery cathode. Nanoscale, 2014, 6: 9579-9587

242 Wang H, Zhang C, Chen Z. Large-scale synthesis of ordered mesoporous carbon fiber and its application as cathode material for lithium-sulfur batteries. Carbon, 2015, 81: 782-787

243 Ji L, Rao M, Aloni S. Porous carbon nanofiber-sulfur composite electrodes for lithium/sulfur cells. Energy Environ Sci, 2011, 4: 5053-5059

244 Wu Y, Gao M, Li X. Preparation of mesohollow and microporous carbon nanofiber and its application in cathode material for lithiumsulfur batteries. J Alloys Compd, 2014, 608: 220-228

245 Chen Y, Li X, Park KS. Sulfur encapsulated in porous hollow CNTs@ CNFs for high-performance lithium-sulfur batteries. J Mater Chem A, 2014, 2: 10126-10130

246 Li Z, Zhang JT, Chen YM. Pie-like electrode design for high-energy density lithium-sulfur batteries. Nat commun, 2015, 6: 8850

247 Yao H, Zheng G, Hsu PC. Improving lithium-sulphur batteries through spatial control of sulphur species deposition on a hybrid electrode surface. Nat Commun, 2014, 5: 3943

248 Zeng L, Jiang Y, Xu J. Flexible copper-stabilized sulfur-carbon nanofibers with excellent electrochemical performance for $\mathrm{Li}-\mathrm{S}$ batteries. Nanoscale, 2015, 7: 10940-10949

$249 \mathrm{Ma} \mathrm{XZ}$, Jin B, Wang HY. S-TiO 2 composite cathode materials for lithium/sulfur batteries. J Electroanal Chem, 2015, 736: 127-131

250 Yang CP, Xin S, Yin YX. An advanced selenium-carbon cathode for rechargeable lithium-selenium batteries. Angew Chem Intern Ed, 2013, 52: 8363-8367

251 Zeng L, Zeng W, Jiang Y, et al. A flexible porous carbon nanofibers-selenium cathode with superior electrochemical performance for both Li-Se and Na-Se batteries. Adv Energy Mater, 2015, 5, doi: 10.1002/aenm.201401377

Acknowledgments This work was supported by the National Natural Science Foundation of China (21373195), the "Recruitment Program of Global Experts", the program for New Century Excellent Talents in University (NCET-12-0515), the Fundamental Research Funds for the Central Universities (WK3430000004), and the Collaborative Innovation Center of Suzhou Nano Science and Technology.

Author contributions $\mathrm{Yu}$ Y designed the outlines; Li W, Zeng L and $\mathrm{Wu}$ Y searched the reference papers. Li W and Yu Y wrote the paper.

Conflict of interest The authors declare that they have no conflict of interest. 


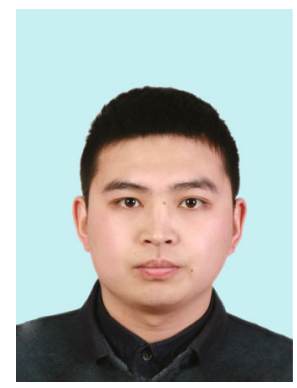

Weihan Li is currently a PhD candidate at the Key Laboratory of Materials for Energy Conversion, Chinese Academy of Sciences, Department of Materials Science and Engineering, University of Science and Technology of China. His research interests mainly include synthesis and application of nanomaterials for lithium-ion battery and sodium-ion battery.

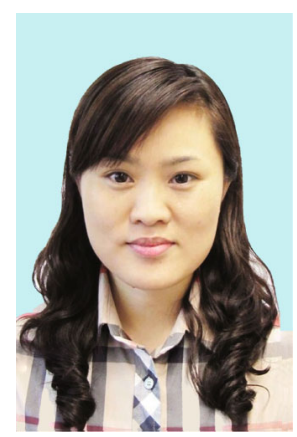

Yan Yu completed her PhD in materials science at the University of Science and Technology of China, Hefei in 2007, where she is currently working as a professor. Her current research interests mainly include design of novel nanomaterials for clean energy, specially for batteries (lithium battery, sodium battery and Li-S battery) and the fundamental science of energy storage system.

\section{静电纺丝方法在锂(钠)离子电池纳米电极材料制备中的应用}

李维汉 ${ }^{1}$, 曾林超 ${ }^{1}$, 吴影 ${ }^{1}$, 余彦 $1,2,3^{*}$

摘要 静电纺丝方法由于具有简便和灵活的特点, 使其在一维锂(钠)离子电池纳米电极材料制备方面受到了广泛的关注. 本综述不仅全面 总结了静电纺丝方法制备锂(钠)离子电池纳米电极材料方面的进展, 并且简要介绍了静电纺丝方法在其他电极材料中的应用. 在总结电化 学活性材料的基础上, 本文将关注的重点放在了电极材料结构以及成分的演变上,详细介绍了众多静电纺丝方法制备的锂(钠)离子电池纳 米电极材料, 并且针对每个部分进行了合理的讨论. 在结尾部分, 简要总结了现有的发展进程, 并且指出了未来的发展方向. 在不远的将来, 静电纺丝方法将会在锂离子电池电极材料的应用上展现其优异的特性, 并且促进钠离子电池电极材料的发展. 本综述希望通过总结以上 内容对未来先进能源材料的设计与制备有所帮助. 